\title{
Identification and characterisation of stress-regulated genes in the central nervous system : in vitro and in vitro studies on rodents
}

Citation for published version (APA):

Föcking, M. (2009). Identification and characterisation of stress-regulated genes in the central nervous system : in vitro and in vitro studies on rodents. [Doctoral Thesis, Maastricht University]. Maastricht University. https://doi.org/10.26481/dis.20090703mf

Document status and date:

Published: 01/01/2009

DOI:

10.26481/dis.20090703mf

Document Version:

Publisher's PDF, also known as Version of record

Please check the document version of this publication:

- A submitted manuscript is the version of the article upon submission and before peer-review. There can be important differences between the submitted version and the official published version of record.

People interested in the research are advised to contact the author for the final version of the publication, or visit the DOI to the publisher's website.

- The final author version and the galley proof are versions of the publication after peer review.

- The final published version features the final layout of the paper including the volume, issue and page numbers.

Link to publication

\footnotetext{
General rights rights.

- You may freely distribute the URL identifying the publication in the public portal. please follow below link for the End User Agreement:

www.umlib.nl/taverne-license

Take down policy

If you believe that this document breaches copyright please contact us at:

repository@maastrichtuniversity.nl

providing details and we will investigate your claim.
}

Copyright and moral rights for the publications made accessible in the public portal are retained by the authors and/or other copyright owners and it is a condition of accessing publications that users recognise and abide by the legal requirements associated with these

- Users may download and print one copy of any publication from the public portal for the purpose of private study or research.

- You may not further distribute the material or use it for any profit-making activity or commercial gain

If the publication is distributed under the terms of Article $25 \mathrm{fa}$ of the Dutch Copyright Act, indicated by the "Taverne" license above, 


\section{Identification and Characterisation of Stress-regulated Genes in the Central Nervous System - in vivo and in vitro studies on rodents -}

Melanie Föcking 


\section{Identification and Characterisation of Stress-regulated Proteins in the Central Nervous System \\ - in vivo and in vitro studies on rodents -}

\section{PROEFSCHRIFT}

ter verkrijging van de graad van doctor aan de Universiteit Maastricht

op gezag van de Rector Magnificus, Prof. mr. G.P.M.F. Mols

volgens het besluit van het College van Decanen

in het openbaar te verdedigen

op vrijdag 03. Juli 2009 om 16:00 uur

door

Melanie Föcking

Geboren op 6 juni 1969 te Bocholt (Duitsland) 
Promotor

Prof. Dr. H.W.M. Steinbusch

Co-promotor

Prof. Dr. D.R. Cotter (Royal College of Surgeons in Ireland, Dublin)

Dr. T. Trapp (Heinrich Heine University Düsseldorf, Germany

Beoordelingscommissie

Prof. Dr. M. de Baets (voorzitter)

Prof. Dr. M.J. Dunn (University College Dublin, Ireland)

Prof. Dr. F.W. van Leeuwen

Prof. Dr. F. Ramaekers

Prof. Dr. H. Schröder (University of Cologne, Germany) 


\section{Contents}

$\begin{array}{ll}\text { Abbreviations } & 5\end{array}$

$\begin{array}{lll}\text { Chapter } 1 \text { General Introduction } & 6\end{array}$

Chapter 2 2-D DIGE as a quantitative tool for investigating the HUPO Brain Proteome Project mouse series

Chapter 3 A proteomic investigation of similarities between conventional and herbal antidepressant treatments

Chapter 4 Chronic glucocorticoid receptor activation impairs CREB transcriptional activity in clonal neurons

Chapter 5 Proteomics of experimental stroke in mice

Chapter 6 Statins potentiate caspase-3 activity in immortalized neurons

Chapter 7 General discussion

Summary

Samenvatting

Publications

Curriculum Vitae 


\section{Abbreviations}

\begin{tabular}{|c|c|c|c|}
\hline 2D-GE & $\begin{array}{l}\text { Two-dimensional gel } \\
\text { electrophoresis }\end{array}$ & $\begin{array}{l}\mathrm{kDa} \\
\text { LB-Medium }\end{array}$ & $\begin{array}{l}\text { Kilo Dalton } \\
\text { Luria-Bertani-Medium }\end{array}$ \\
\hline AMP & Adenosinmonophosphate & LDF & Laser doppler flow \\
\hline atm & Atmosphere & LUC & Luciferase \\
\hline ATP & Adenosin-5'-triphosphate & $\operatorname{MCA}(0)$ & Middle cerebral artery \\
\hline BSA & Bovine serum albumin & & (occlusion) \\
\hline CAM & $\begin{array}{l}\text { Complementary }+ \text { alternative } \\
\text { medicine }\end{array}$ & $\begin{array}{l}\text { MMTV } \\
\text { MOPS }\end{array}$ & $\begin{array}{l}\text { Mouse mammary tumor virus } \\
\text { (3-[Morpholino] }\end{array}$ \\
\hline CBB & Coomassie brilliant blue & & propanesulfonic acid \\
\hline $\mathrm{CBZ}$ & Carbamazepine & mRNA & Messenger-RNA \\
\hline CHAPS & $\begin{array}{l}\text { 3-[(3-Cholamido- } \\
\text { propyl)dimethylammonio]-1- } \\
\text { propanesulfate }\end{array}$ & $\begin{array}{l}\text { MRI } \\
\text { MS } \\
\text { MTT }\end{array}$ & $\begin{array}{l}\text { Magnetic Resonance Imaging } \\
\text { Mass spectrometry } \\
\text { 3-(4,5 Dimethylthiazol-2- }\end{array}$ \\
\hline CNS & Central nervous system & & yl)2,5diphenyltetrazolium- \\
\hline CPS & Cerebral protein synthesis & & bromide \\
\hline CREB & $\begin{array}{l}\text { cAMP responsive element- } \\
\text { binding protein }\end{array}$ & $\begin{array}{l}\text { OD } \\
\text { PBS }\end{array}$ & $\begin{array}{l}\text { Optical density } \\
\text { Phosphate-buffered saline }\end{array}$ \\
\hline Cy3 & Indocarbocyanine & PBS-T & PBS plus Tween \\
\hline DEPC & Diethylpyrocarbonate & PCR & Polymerase-chain-reaction \\
\hline DMEM & $\begin{array}{l}\text { Dulbecco's modified Eagle's } \\
\text { medium }\end{array}$ & $\begin{array}{l}\text { RNA } \\
\text { RT }\end{array}$ & $\begin{array}{l}\text { Ribonucleic acid } \\
\text { Room temperature }\end{array}$ \\
\hline DMSO & Dimethylsulfoxide & SDS & Dodecyl sulfate sodium salt \\
\hline DEVD & Asp-Glu-Val-Asp & SDS-PAGE & SDS-Polyacrylamid \\
\hline DIGE & $\begin{array}{l}\text { Difference in gel } \\
\text { electrophoresis }\end{array}$ & SJW & $\begin{array}{l}\text { gelelectrophoresis } \\
\text { St. John's Wort }\end{array}$ \\
\hline DNA & Desoxyribonucleic acid & TBS & Tris-buffered saline \\
\hline DTT & Dithiothreitol & TEMED & $\mathbf{N}, \mathbf{N}, \mathbf{N}^{\prime}, \mathbf{N}^{\prime}-$ \\
\hline ECL & Enhanced & & Tetramethylendiamine \\
\hline EDTA & $\begin{array}{l}\text { chemiluminescence } \\
\text { Ethylendiamintetraacetic acid }\end{array}$ & Tris & $\begin{array}{l}\text { Tris- (hydroxymethyl)-amino } \\
\text { methane }\end{array}$ \\
\hline FCS & Foetal calf serum & Triton X-100 & PEG- $(9,6)-p-t-$ \\
\hline GO & Gene ontology & & octylphenylether \\
\hline GR & Glucocorticoid receptor & TUNEL & Teminal-deoxynucleotidyl \\
\hline GRE & $\begin{array}{l}\text { Glucocorticoid response } \\
\text { element }\end{array}$ & & $\begin{array}{l}\text { transferase-mediated dUTP- } \\
\text { biotin nick end labeling }\end{array}$ \\
\hline HEPES & $\begin{array}{l}\text { 4-(2-hydroxyethyl)-1- } \\
\text { piperazineethanesulfonic acid }\end{array}$ & Tween 20 & $\begin{array}{l}\text { Poly-oxyethylensorbit- } \\
\text { monolaureate }\end{array}$ \\
\hline HMG CoA & $\begin{array}{l}\text { Hydroxymethylgutaryl } \\
\text { coenzyme A }\end{array}$ & $\begin{array}{l}v / v \\
w / v\end{array}$ & $\begin{array}{l}\text { Volume per volume } \\
\text { Weight per volume }\end{array}$ \\
\hline HUPO & $\begin{array}{l}\text { Human Proteome } \\
\text { Organisation }\end{array}$ & XYS & Jia-Wei-Xiao-Yao-San \\
\hline IEF & Iso-electric focussing & & \\
\hline Ip & Intraperitoneal & & \\
\hline IPG & Immobilised $\mathrm{pH}$ gradient & & \\
\hline
\end{tabular}




\section{General Introduction}

\section{Stress- making an attempt of a definition}

Stress is a normal part of life that can help us learn and grow. Conversely, stress can cause significant problems.

A stressor is defined as a stimulus or event that provokes a stress response in an organism. Stressors can be categorised as acute or chronic, and as external or internal to the organism.

Stress releases powerful neurochemicals and hormones that prepare us for action (to fight or flee). If we don't take action, the stress response can lead to health problems. Prolonged, uninterrupted, unexpected, and unmanageable stresses are the most damaging types of stress.

The term "stress" in general describes a physical or psychic burden of an organism. Triggering physical factors can be injuries, temperature changes, oxygen deprivation, exertion, virus infections, inflammation or metabolites. The metabolic stress reaction of humans is mediated through complex interactions between the nerve-, hormone- and immune system and releases for instance stress hormones, catecholamines, glucocorticoids and cytokines [44].

The reaction of the organism as a whole has its analogy in cellular changes. Stress is not a specific phenomenon of humans. In reactions of cells of higher organisms to changes in the environment mechanisms become obvious that refer back to evolutionary conserved strategies of stress processing. The cellular stress response represents basic defence mechanisms in all cells and shows essential similarities at the molecular level, irresponsible of the causing factor. Because a high amount of damaging influences cause similar changes in gene expression [3], the reactions of the cells are increasingly referred to as stress response and the proteins with increased expression under these conditions are named stress proteins [45]. Trigger of a cellular stress response, next to cell damaging factors as for instance amino acid analogues, heavy metals, toxic substances and heat shock, can also be pathophysiological changes of an organism, for instance ischemia [24]. The inhibition of global protein synthesis is another common characteristic of the cellular stress response [46]. Therefore, an important common reaction of all cells to stress situation lies in the inhibition of global protein synthesis and activation of the expression of stress-related genes.

\section{Cerebral Ischemia}

The medical term "ischemia" describes an absolute or relative shortage of the blood supply, resulting in a pathological change of the metabolism of the affected cells. A short interruption of the blood circulation in the brain causes severe metabolic disturbances in the cell within minutes because neurons only have a small own energy supply and are 
dependent on a continuous supply of glucose and oxygen. If this supply is interrupted a fast dearth of energy-rich phosphates occurs and the energy balance of the neurons will be disturbed if not collapsed and then are no longer able to keep the membrane potential. The resulting depolarisation leads to an influx of sodium- and calcium-ions from the extracellular space and results in the disturbance of the post-ischemic extracellular ion homeostasis [14]. The enhanced cytoplasmic calcium concentration causes lipolytic and proteolytic processes that can lead to a loss in cell structure. In addition the oxygen deprivation due to anaerobic glycolysis during ischemia can lead to a local acidosis [1]. Moreover due to the disturbed blood flow the removal of harmful metabolites is impaired and this can also further affect the tissue.

The acute deficiency of oxygen and glucose within the neurons is indeed the crucial factor but cannot solely explain the -to some extent delayed- neuronal damage after ischemia. Shortly after a transient ischemia a global recovery of the energy metabolism occurs, the protein synthesis in contrast only recovers in resistant neurons [13, 34, 35]. The ischemic brain damage has a multi-factorial pathophysiology, several mechanisms are discussed: excitatory effects of the neurotransmitter glutamate [6, 25-27], increase of the cellular calcium concentration $[19,39]$, formation of nitric oxide or oxygen radicals $[2,7,9,15]$, disturbance of calcium homeostasis [28]. Alongside this the expression of numerous genes that are able to contribute to the ischemia activated processes can be changed [38].

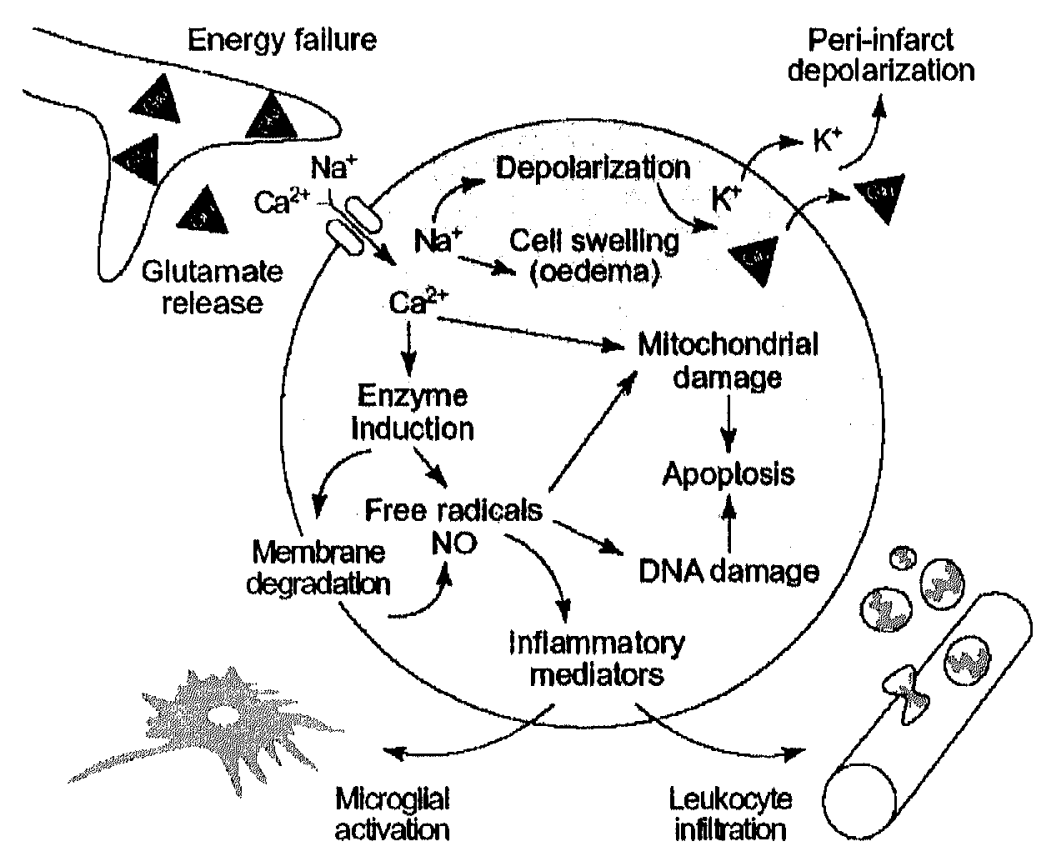

Fig. 1. Simplified overview of pathophysiological mechanisms in the focally ischemic brain.

Energy failure leads to the depolarization of neurones. Activation of specific glutamate receptors dramatically increases intracellular $\mathrm{Ca}^{2+}, \mathrm{Na}^{+}$, and $\mathrm{Cl}^{-}$levels while $\mathrm{K}^{+}$is released into the extracellular space. Diffusion of glutamate (Glu) and $\mathrm{K}^{+}$in the extracellular space can propagate a series of spreading waves of depolarization (peri-infarct depolarisations). Water shifts to the intracellular space via osmotic gradients and cells swell (oedema). The universal intracellular messenger $\mathrm{Ca}^{2+}$ over-activates numerous enzyme systems (proteases, lipases, endonucleases, etc.). Free radicals are generated, which damage membranes (lipolysis), mitochondria and DNA, in turn triggering caspase-mediated cell death (apoptosis). Free radicals also induce the formation of inflammatory mediators, which activate microglia and lead to the invasion of blood-borne inflammatory cells (leukocyte infiltration) via up-regulation of endothelial adhesion molecules. 


\section{Modelling Ischemia}

Cerebral ischemia can generally be induced by cerebrovascular or through extra cerebral factors only. Extra cerebral causes, for instance cardiac arrest, heart failure or shock lead to an impaired blood circulation of the whole organism and is called global ischemia. With cerebrovascular ischemia a distinct blood vessel in the brain, for instance due to atherosclerosis, arterial embolism or tumour is closed. The impaired blood circulation affects the tissue that was supplied by this vessel and this is called focal ischemia.

Global ischemia is normally only of short duration, the cell damage is normally restricted to neurons and occurs with delay $[18,33]$. On the other hand a permanent focal ischemia leads to necrosis of all affected cell types $[10,30]$.

Ischemic pathomechanisms are often investigated in animal models. For the induction of a global ischemia the occlusion of multiple cranial arteries is utilised. Often the model of two- or four- vessel-occlusion is used $[17,32,37]$. For the reproduction of pathophysiological procedures as they for instance occur after stroke, models of focal ischemia are used. In this connexion mostly the middle cerebral artery is permanently or transiently closed (MCAO, middle cerebral artery occlusion [40]). This artery serves in large part the cortex and striatum of the respective hemisphere.

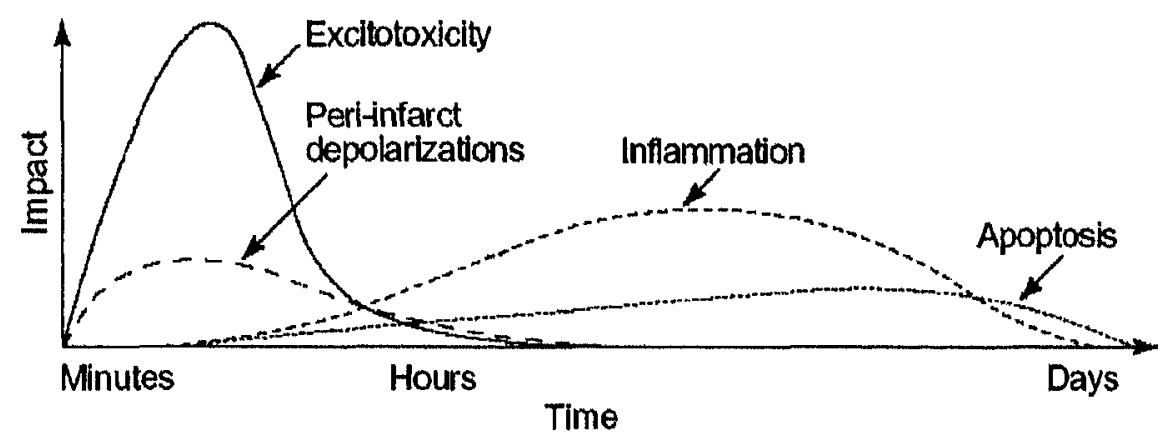

Fig. 2. Putative cascade of damaging events in focal cerebral ischemia. Very early after the onset of the focal perfusion deficit, excitotoxic mechanisms can damage neurones and glia lethally. In addition, excitotoxicity triggers a number of events that can further contribute to the demise of the tissue. Such events include periinfarct depolarisations and the more-delayed mechanisms of inflammation and programmed cell death. The $\mathrm{x}$-axis reflects the evolution of the cascade over time, while the $y$-axis aims to illustrate the impact of each element of the cascade on final outcome.

\section{Long-term stress}

The brain creates biological stress in response to real or imagined stimuli. The many physiological responses associated with stress help to protect the brain from the dangers that triggers the stress in the first place. But stress in chronic doses can also have malignant noxious effects. Therefore, stress is defined as a state of threatened homeostasis and represents both the subjective experience induced by a stressor, as well as the adaptive neurochemical and behavioural response to it, in order to preserve homeostasis [5].

The body reacts to stress first by releasing the catecholamine hormones, epinephrine and norepinephrine, and the glucocorticoid hormones, cortisol and cortisone.

The hypothalamic-pituitary-adrenal (HPA) axis is a major part of the neuroendocrine system, involving the interactions of the hypothalamus, the pituitary gland and the adrenal 
glands. The HPA axis is believed to play a primary role in the body's reactions to stress, by balancing hormone releases from the adrenaline-producing adrenal medulla and from the corticosteroid-producing adrenal cortex.

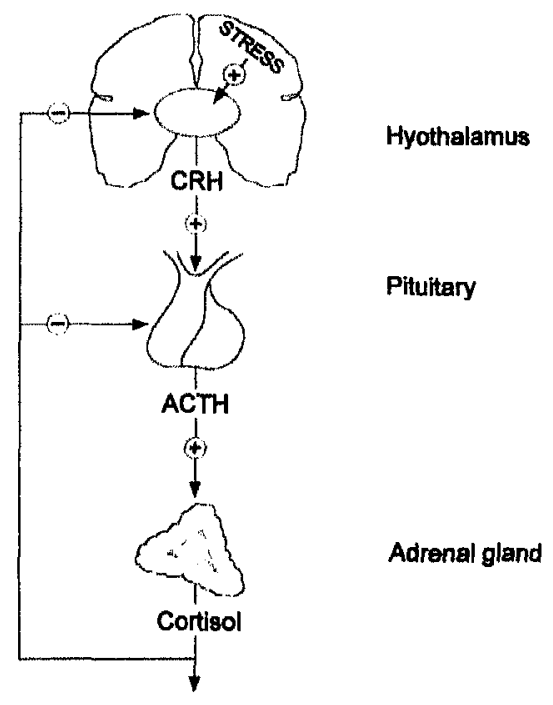

Figure 3.: Stressful environmental stimuli trigger the release of corticotrophin releasing factor (CRF) from nerve cells in the hypothalamus into a blood system that travels to the anterior pituitary. In response to $\mathrm{CRF}$, the anterior pituitary releases adrenocorticotrophic hormone (ACTH) into the blood system. ACTH is transported to the remotely located adrenal gland and stimulates the production of cortisol in the adrenal cortex.

Cortisol is released into the blood stream. Cortisol affects the body's reaction to stress. The pituitaryadrenal-axis is a complex feedback mechanism. Cortisol feeds back to the hypothalamus to control release of CRF. High levels of cortisol in the blood tend to inhibit the release of CRF by the hypothalamus. Therefore less ACTH is released by the anterior pituitary. Consequently the amount of cortisol circulating in the blood stream is reduced. This is called a negative feedback system.

The HPA axis is regulated by several negative feedback loops, at various levels, in order to prevent an excessive reaction to stress, for example by the regulation of glucocorticoid receptors. The glucocorticoid receptor (GR) is important in terms of negative feedback at circulating glucocorticoid concentrations seen in response to stress [42]. The production and release of both corticotrophin releasing factor and adrenocorticotrophic hormone is inhibited by glucocorticoids at the levels of the hypothalamus and the pituitary. In addition, GR-mediated negative feedback is also thought to be present at the level of the hippocampus, which is strongly linked to HPA axis functioning [16].

When the nature, magnitude, or duration of a stressor is beyond the adaptive capabilities of an individual, this may lead to HPA axis hyperactivity through an impaired negative feedback regulation. This impaired negative feedback is either due to glucocorticoidinduced damage to the hippocampus [22], or a reduced function of the GR at the level of the paraventricular nucleus, pituitary or hippocampus [31]. An overactive or dysregulated HPA axis may eventually contribute to the development of stress-related pathology.

\section{Proteomics}

A proteome is defined as the protein complement of a genome present in cells and/or tissue [47]. Processes including alternative splice variation and post translational-modifications, the proteome is several times more complex than the genome. While gene expression analysis (e.g. microarrays) allows the determination of the transcript level for thousands of genes, this does not necessarily equate for the production of functional protein and provides no information about post-translational events that may often change in disease.

Proteomic methods allow us to examine the protein profile of a particular tissue. Consequently, by looking at the differential expression of proteins between disease and control states we gain insights into protein pathways involved in the disease. The 
application of proteomics to brain diseases is relatively new and thus has the potential to provide important insights into our understanding of psychiatric, neurodegenerative and neurological diseases. By characterising disease-associated protein profiles in sera they may be able to identify and quantify proteins that serve as diagnostic or prognostic markers. Furthermore, proteomic investigation of the effects of pharmaceutical agents in vitro may help to identify new therapeutic pathways. The main methods encompassed within this term can be broadly described as those using two-dimensional gel electrophoresis (2-DE) and those using non-gel based methods to separate out and identify proteins in a complex mixture such as a whole cell or tissue lysate.

\section{D-DIGE}

Traditionally, the most frequent method used to investigate differential protein abundance in large scale proteomic experiments is by two-dimensional gel electrophoresis (2D-GE). 2D-GE enables the separation of complex mixtures of proteins on a polyacrylamide gel, according to charge or isoelectric point in the first dimension and molecular weight in the second dimension. The gel is subsequently stained for visualization of protein spots, delivering a map of intact proteins characteristic for that particular cell or tissue type. Moreover, this protein profile which reflects changes in protein expression level, as well as isoforms and post-translational modifications, can be compared between groups of samples enabling large scale comparative studies [29]. A recently introduced and novel approach to 2D gel-based proteomics is to fluorescently label protein extracts prior to electrophoresis (Cy2, Cy3, Cy5), enabling the separation of up to three samples on the same gel [43]. This multiplexing approach was enhanced by the introduction of an internal standard, usually labeled with $\mathrm{Cy} 2$, which is run on each gel in the experiment, alongside the Cy3 and Cy5 labeled biological samples. Typically the internal standard is made up of equal aliquots of all biological samples in the experiment. Including an internal standard on each gel allows for normalization of data between gels, thereby minimizing experimental variation and increasing confidence in matching between different gels [21].

\section{Western Blot Array Analysis}

2-DE coupled to MALDI-TOF mass spectrometry yields valuable insights into the molecular composition of cells and tissues. However technical difficulties (as briefly described above) make it difficult or even prevent the display of certain proteins and the limited dynamic range results in a bias towards abundant proteins $[8,11,36]$. The limitations have deployed efforts to find alternatives. One possibility is to make use of antibodies for protein profiling, e.g. Multi-western blot formats or protein microarrays [4, 23, 41].

PowerBlot $^{\mathrm{TM}}$ is a commercial Western blot format of BD Bioscience, a high-throughput, proteomic screen designed to identify differentially expressed proteins. It is possible to study relative changes in the expression levels of hundreds of proteins simultaneously. With an approach that complements the current nucleic acid methods for monitoring gene expression, this method analyses cellular changes on the protein level and provides a powerful tool for proteomic studies determining the effect of a certain treatment, drug, product, or disease state on cellular protein expression[20]. Western Array Screening entails polyacrylamide gel electrophoresis, western blotting, and protein visualization via chemiluminescence. A simultaneous screening of samples with more than 700 monoclonal antibodies is possible. Those antibodies are combined into unique cocktails to probe for several hundred cellular signalling proteins at one time. The antibodies detect nanogram quantities of protein and can distinguish closely related members of many signalling 
families. Because each antibody identifies a unique target among the array of thousands of proteins displayed on the western blot, this approach eliminates the need for further processing such as is necessary with 2-D gel electrophoresis and mass spectrometry.

\section{Aim and outline of the thesis}

The treatment of brain injury in several neurological and neurodegenerative diseases remains a major therapeutic target in modern medicine. Similarly there are no current treatments to prevent cell loss after brain injury. Cell death and survival pathways in the brain are highly complex, coordinated events, and we still know little about which proteins are the most important, how best to intervene in their function and what impact this has for the brain during recovery.

We hypothesise that protein expression patterns detected by high throughput techniques can lead to uncovering surrogate end point biomarkers and novel mechanisms.

The objective of our project is to improve our understanding of the molecular process of cell death following stroke and long-term stress, and to learn how best to target this to protect the brain.

The focus of this thesis is to use the recently developed proteomics technology to identify differentially expressed proteins in an in vivo model of focal cerebral ischemia and an in vitro stress model and to get new insights into drug related findings.

First, (Chapter 2) we assessed whether currently used proteomics techniques are sufficiently robust and reproducible to obtain reliable results. As part of the HUPO brain proteome project we investigated proteomic changes in developing mouse brain from the embryonic to the early adult stage.

The use of complementary and alternative medicines in the treatment of depression is increasing. In Chapter 3 we describe a study in which we used the proteomics technique to have a closer look at conventional and herbal antidepressants and their influence on the protein pattern as well as similarities between those treatments.

The hypothesis that CREB may be involved in glucocorticoid stress-modulated signal transduction is explored in Chapter 4.

In order to get more insights into stroke-initiated pathways we screened for proteins that regulate survival and death decisions in damaged neurons applying a multi western blot proteomic technique to a murine stroke model (Chapter 5).

It was shown in clinical studies [12] that statins known to reduce cholesterol and lowdensity lipoprotein levels represent a promising class of agents for treating patients with (risk of) stroke. We followed the hypothesis that neuroprotective effects of statins may involve the inhibition of the small GTPase RhoB (Chapter 6).

Finally, in Chapter 7 the results of the experiments are critically reviewed.

\section{References}

[1] T. Back, M. Hoehn-Berlage, K. Kohno, K.A. Hossmann, Diffusion nuclear magnetic resonance imaging in experimental stroke. Correlation with cerebral metabolites, Stroke 25 (1994) 494-500.

[2] E. Barrett-Connor, J.C. Chang, S.L. Edelstein, Coffee-associated osteoporosis offset by daily milk consumption. The Rancho Bernardo Study, Jama 271 (1994) 280-283. 
[3] I.J. Benjamin, D.R. McMillan, Stress (heat shock) proteins: molecular chaperones in cardiovascular biology and disease, Circ Res 83 (1998) 117-132.

[4] M. Castedo, K.F. Ferri, J. Blanco, T. Roumier, N. Larochette, J. Barretina, A. Amendola, R. Nardacci, D. Metivier, J.A. Este, M. Piacentini, G. Kroemer, Human immunodeficiency virus 1 envelope glycoprotein complex-induced apoptosis involves mammalian target of rapamycin/FKBP12-rapamycin-associated protein-mediated p53 phosphorylation, The Journal of experimental medicine 194 (2001) 1097-1110.

[5] E. Charmandari, C. Tsigos, G. Chrousos, Endocrinology of the stress response, Annu Rev Physiol 67 (2005) 259-284.

[6] D.W. Choi, Glutamate neurotoxicity and diseases of the nervous system, Neuron 1 (1988) 623-634.

[7] D.W. Choi, Nitric oxide: foe or friend to the injured brain?, Proc Natl Acad Sci U S A 90 (1993) 9741-9743.

[8] G.L. Corthals, V.C. Wasinger, D.F. Hochstrasser, J.C. Sanchez, The dynamic range of protein expression: a challenge for proteomic research, Electrophoresis 21 (2000) 11041115.

[9] T. Dalkara, T. Yoshida, K. Irikura, M.A. Moskowitz, Dual role of nitric oxide in focal cerebral ischemia, Neuropharmacology 33 (1994) 1447-1452.

[10] J.H. Garcia, Experimental ischemic stroke: a review, Stroke 15 (1984) 5-14.

[11] S.P. Gygi, G.L. Corthals, Y. Zhang, Y. Rochon, R. Aebersold, Evaluation of twodimensional gel electrophoresis-based proteome analysis technology, Proc Natl Acad Sci U S A 97 (2000) 9390-9395.

[12] D.C. Hess, A.M. Demchuk, L.M. Brass, F.M. Yatsu, HMG-CoA reductase inhibitors (statins): a promising approach to stroke prevention. [see comments.], Neurology 54 (2000) 790-796.

[13] K.A. Hossmann, P. Kleihues, Reversibility of ischemic brain damage, Arch Neurol 29 (1973) 375-384.

[14] K.A. Hossmann, B.G. Ophoff, L. Csiba, W. Paschen, Regional pH and electrolyte homeostasis of cat brain after prolonged ischemia, Neurochem Pathol 9 (1988) 127-137.

[15] C. Iadecola, Bright and dark sides of nitric oxide in ischemic brain injury, Trends Neurosci 20 (1997) 132-139.

[16] L. Jacobson, R. Sapolsky, The role of the hippocampus in feedback regulation of the hypothalamic-pituitary-adrenocortical axis, Endocr Rev 12 (1991) 118-134.

[17] T. Kirino, Delayed neuronal death in the gerbil hippocampus following ischemia, Brain Res 239 (1982) 57-69.

[18] T. Kirino, A. Tamura, K. Sano, Delayed neuronal death in the rat hippocampus following transient forebrain ischemia, Acta Neuropathol (Berl) 64 (1984) 139-147.

[19] T. Kristian, B.K. Siesjo, Calcium in ischemic cell death, Stroke 29 (1998) 705-718.

[20] P. Lorenz, P. Ruschpler, D. Koczan, P. Stiehl, H.J. Thiesen, From transcriptome to proteome: differentially expressed proteins identified in synovial tissue of patients suffering from rheumatoid arthritis and osteoarthritis by an initial screen with a panel of 791 antibodies, Proteomics 3 (2003) 991-1002.

[21] R. Marouga, S. David, E. Hawkins, The development of the DIGE system: 2D fluorescence difference gel analysis technology, Analytical and bioanalytical chemistry 382 (2005) 669-678.

[22] B.S. McEwen, Stress and hippocampal plasticity, Annu Rev Neurosci 22 (1999) 105-122.

[23] M. Melnick, H. Chen, Y. Min Zhou, T. Jaskoll, The functional genomic response of developing embryonic submandibular glands to NF-kappa B inhibition, BMC developmental biology 1 (2001) 15.

[24] R.I. Morimoto, K.D. Sarge, K. Abravaya, Transcriptional regulation of heat shock genes. A paradigm for inducible genomic responses, J Biol Chem 267 (1992) 21987-21990.

[25] J.W. Olney, Brain lesions, obesity, and other disturbances in mice treated with monosodium glutamate, Science 164 (1969) 719-721.

[26] J.W. Olney, O.L. Ho, V. Rhee, Cytotoxic effects of acidic and sulphur containing amino acids on the infant mouse central nervous system, Exp Brain Res 14 (1971) 61-76. 
[27] J.W. Olney, L.G. Sharpe, Brain lesions in an infant rhesus monkey treated with monsodium glutamate, Science 166 (1969) 386-388.

[28] W. Paschen, Disturbances of calcium homeostasis within the endoplasmic reticulum may contribute to the development of ischemic-cell damage, Med Hypotheses 47 (1996) 283288.

[29] K. Pennington, D. Cotter, M.J. Dunn, The role of proteomics in investigating psychiatric disorders, Br J Psychiatry 187 (2005) 4-6.

[30] C.K. Petito, W.A. Pulsinelli, G. Jacobson, F. Plum, Edema and vascular permeability in cerebral ischemia: comparison between ischemic neuronal damage and infarction, J Neuropathol Exp Neurol 41 (1982) 423-436.

[31] J. Prickaerts, T. Steckler, Effects of glucocorticoids on emotion and cognitive processes in animals., Vol. 15, Elsevier, Amsterdam, 2005, 359-386 pp.

[32] W.A. Pulsinelli, J.B. Brierley, A new model of bilateral hemispheric ischemia in the unanesthetized rat, Stroke 10 (1979) 267-272.

[33] W.A. Pulsinelli, J.B. Brierley, F. Plum, Temporal profile of neuronal damage in a model of transient forebrain ischemia, Ann Neurol 11 (1982) 491-498.

[34] W.A. Pulsinelli, T.E. Duffy, Regional energy balance in rat brain after transient forebrain ischemia, J Neurochem 40 (1983) 1500-1503.

[35] W.A. Pulsinelli, D.E. Levy, T.E. Duffy, Regional cerebral blood flow and glucose metabolism following transient forebrain ischemia, Ann Neurol 11 (1982) 499-502.

[36] T. Rabilloud, Two-dimensional gel electrophoresis in proteomics: old, old fashioned, but it still climbs up the mountains, Proteomics 2 (2002) 3-10.

[37] R. Schmidt-Kastner, J. Szymas, K.A. Hossmann, Immunohistochemical study of glial reaction and serum-protein extravasation in relation to neuronal damage in rat hippocampus after ischemia, Neuroscience 38 (1990) 527-540.

[38] F.R. Sharp, A. Lu, Y. Tang, D.E. Millhorn, Multiple molecular penumbras after focal cerebral ischemia, J Cereb Blood Flow Metab 20 (2000) 1011-1032.

[39] B.K. Siesjo, Cell damage in the brain: a speculative synthesis, J Cereb Blood Flow Metab 1 (1981) 155-185.

[40] A. Tamura, D.I. Graham, J. McCulloch, G.M. Teasdale, Focal cerebral ischaemia in the rat: 1. Description of technique and early neuropathological consequences following middle cerebral artery occlusion, J Cereb Blood Flow Metab 1 (1981) 53-60.

[41] M.F. Templin, D. Stoll, M. Schrenk, P.C. Traub, C.F. Vohringer, T.O. Joos, Protein microarray technology, Trends in biotechnology 20 (2002) 160-166.

[42] T. Trapp, R. Rupprecht, M. Castren, J.M. Reul, F. Holsboer, Heterodimerization between mineralocorticoid and glucocorticoid receptor: a new principle of glucocorticoid action in the CNS, Neuron 13 (1994) 1457-1462.

[43] M. Unlu, M.E. Morgan, J.S. Minden, Difference gel electrophoresis: a single gel method for detecting changes in protein extracts, Electrophoresis 18 (1997) 2071-2077.

[44] C. Weissman, The metabolic response to stress: an overview and update, Anesthesiology 73 (1990) 308-327.

[45] W.J. Welch, Mammalian stress response: cell physiology, structure/function of stress proteins, and implications for medicine and disease, Physiol Rev 72 (1992) 1063-1081.

[46] W.J. Welch, J.P. Suhan, Cellular and biochemical events in mammalian cells during and after recovery from physiological stress, J Cell Biol 103 (1986) 2035-2052.

[47] M.R. Wilkins, C. Pasquali, R.D. Appel, K. Ou, O. Golaz, J.C. Sanchez, J.X. Yan, A.A. Gooley, G. Hughes, I. Humphery-Smith, K.L. Williams, D.F. Hochstrasser, From proteins to proteomes: large scale protein identification by two-dimensional electrophoresis and amino acid analysis, Bio/technology (Nature Publishing Company) 14 (1996) 61-65. 


\title{
2D-DIGE as a semi quantitative tool for investigating the HUPO Brain Proteome project mouse series
}

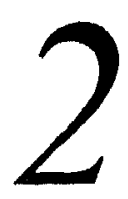

\author{
Melanie Föcking ${ }^{1 *}$, Paul J. Boersema ${ }^{2 *}$, Niaobh O'Donoghue ${ }^{2}$, Gert Lubec $^{3}$, \\ Stephen R.Pennington ${ }^{2}$, David R. Cotter ${ }^{1}$ and Michael J. Dunn ${ }^{2}$
}

${ }^{1}$ Department of Psychiatry, Education and Research Centre, Royal College of Surgeons in Ireland, Beaumont Hospital, Dublin, Ireland. 2Proteome Research Centre, UCD Conway Institute of Biomolecular and Biomedical Research, University College Dublin, Ireland. ${ }^{3}$ Department of Pediatrics, Division Neuroproteomics, Medical University of Vienna, Vienna, Austria

PROTEOMICS 6(18):4914-31 (2006)

\begin{abstract}
Brain development and aging is a complex process involving proliferation, differentiation and apoptosis. Elucidating proteome changes in these processes can help to understand the mechanisms of brain development and maintenance as well as neurodegenerative diseases. The research reported here is a contribution to the HUPO Brain Proteome Project mouse pilot project. Whole, frozen C57/BL6 mouse brain comprising three different developmental stages (embryonic day 16, postnatal day 7, and postnatal day 54-56) were processed by using 2D-DIGE. A total of 1999 spots were matched between all gels. Of these 206 spots were differentially expressed between the different stages. 122 spots were highest in intensity in embryonic stage E16, 26 highest in the adolescent group P7 and 58 spots highest in P56, the adult stage. The results show a pattern of temporal expression. Based on the expression patterns we tentatively suggest that proteins involved in the establishment of primary structures in the brain are expressed highest in the embryonic mouse. Proteins involved in the development of the brain are expressed highest in the juvenile phase and proteins that make utilization of the brain possible by delivering energy are expressed highest in the adult mice.
\end{abstract}

\section{Introduction}

The Human Proteome Organisation (HUPO) was founded as an international organisation to consolidate national and regional proteomics organisations and encourage the spread of proteomics techniques, especially applied to the human and model organisms (www.hupo.org). To assess whether currently used proteomic techniques are sufficiently robust and reproducible to obtain reliable results and to perform inter-laboratory comparisons, the HUPO Brain Proteomics Project (HBPP; www.hbpp.org) has organised two pilot studies using human and mouse brain tissue samples. The aims of the pilot study are given in the overview paper by Hamacher et al. [15] in this Special Issue. 
Samples were prepared in one location and then shipped to different laboratories for analysis with different techniques. Data were gathered in a central place and compared in order to establish standard protocols and start creating 2-D protein maps.

The research presented in this report is a contribution to the HBPP mouse pilot project investigating proteome changes in developing mouse brain from the embryonic to the early adult stage. Whole brains of female animals at embryonic day 16 (E16), postnatal day 7 (P7) and postnatal day 54-56 (P56) were analysed and compared. A 2D-DIGE minimal labelling approach was chosen to deliver qualitative as well as accurate semiquantitative information on protein expression. Brain tissue samples were lysed and labelled with one of the two fluorescent dyes Cy3 and Cy5. An internal standard comprising equal amounts of the mouse samples was labelled with Cy2. Preparative 2-D gels loaded with pooled samples of E16, P7, P56, were run in parallel and stained with a modified silver stain protocol to allow subsequent MS analysis. Based on the DeCyder Biological Variance Analysis (BVA) proteins were selected that have a significant differential expression between the different stages. The representative spots were excised from the silver stained gels and the proteins identified by MS/MS.

\section{Materials and methods}

Animals. C57BL/6J mice, originally obtained from Charles River Germany some months prior to the project, were bred and kept in a barrier unit under SPF conditions according to the FELASA recommendations using Makrolon type IIL cages with soft wood bedding. Mice had free access to an autoclaved standard rodent diet (Altromin 1314, Altromin Gesellschaft für Tierernährung $\mathrm{GmbH}$, Deutschland) and water from automatic valves. Rooms were ventilated with a 15-fold air exchange rate. Room temperature was $22 \pm 1{ }^{\circ} \mathrm{C}$ and relative humidity $50 \pm 10 \%$. The light/dark rhythm was $14 / 10$ [23].

Mice were mated permanent monogamously and offspring used with 7 or 54-58 days of age. For production of the 16-day-old foetuses, females were mated overnight and vaginal plug was controlled in the morning. When plug positive, this was considered day 0 of gestation. Dissection of the females and collection of foetuses was done on day 16. All mice were sacrificed by neck dislocation, foetuses were killed by cutting off the head with scissors. The brain was removed from skull, weighed, immediately frozen on dry ice and stored at $-80^{\circ} \mathrm{C}$. There were no gross abnormalities of the brain at autopsy. The colony from which the cohorts were taken was tested in behavioural (open field, elevated plus maze), neurological (observational neurological battery, rota rod) and cognitive terms (Morris Water Maze and Multiple-T-Maze) as shown previously [24] and did not reveal any abnormalities. Animals were handled according to Austrian Law and Guidelines.

Sample preparation. Whole mouse brain tissue separately for each animal was lysed in $600 \mu \mathrm{L}(\mathrm{E} 16, \mathrm{n}=10)$ or $1 \mathrm{~mL}(\mathrm{P} 7, \mathrm{P} 56, \mathrm{n}=10)$ of lysis buffer $(9.5 \mathrm{M}$ urea, $2 \%$ CHAPS, 20 $\mathrm{mM}$ Tris ( $\mathrm{pH}$ 8.0), Amberlite MB-1 was used for ion exchange) using short bursts of a sonicator while on ice. After spinning down the samples for $5 \mathrm{~min}$ at $14000 \mathrm{rpm}$, the clear solution between a small fatty upper layer and a pellet was used for further protein separation. Protein concentration was measured using a modified Bradford Assay [26].

DIGE labelling. An internal standard for the mouse study was prepared with equal fractions of all mouse samples and bulk labelled with 400 pmol Cy2 per $50 \mu \mathrm{g}$ of protein. A $50 \mu \mathrm{g}$ aliquot of each of the ten sample was labelled with $400 \mathrm{pmol}$ of either Cy3 or Cy5 according to the manufacturer's protocol, performing a so-called dye swap, to make sure 
each developmental stage had an equal number of Cy3 and Cy5 labelled samples. After labelling $\mathrm{Cy} 2, \mathrm{Cy} 3$ and $\mathrm{Cy} 5$, labelled proteins were combined and diluted 1:1 with dilution buffer (9.5 M urea, 2\% Chaps, 2\% DTT, 1.6\% Pharmalyte $\mathrm{pH} 3-10$ ) and subsequently used for IEF.

2-D PAGE. 2-D PAGE was performed according standard protocols established in our laboratory as described by Weekes et al. [34] and Heinke et al. [17]. IEF was performed using 240-mm linear gradient IPG strips of pH 4-7 (GE Healthcare, UK) using an in-gel rehydration method, as described by Rabilloud et al. [25] and Sanchez et al. [28]. Samples were diluted in rehydration solution (8 M urea, 0.5\% (w/v) CHAPS, $0.2 \%(\mathrm{w} / \mathrm{v}) \mathrm{DTT}$, and $0.2 \%(\mathrm{w} / \mathrm{v})$ Pharmalyte, $\mathrm{pH} 3-10)$ and rehydrated overnight in a reswelling tray (Amersham Biosciences, GE Healthcare, UK). Strips were focused at $0.05 \mathrm{~mA} / \mathrm{IPG}$ strip

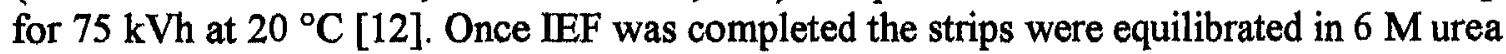
containing 30\% (v/v) glycerol, $2 \%(\mathrm{w} / \mathrm{v})$ SDS, and $0.01 \%(\mathrm{w} / \mathrm{v})$ Bromophenol blue, with the addition of $1 \%(\mathrm{w} / \mathrm{v})$ DTT for $15 \mathrm{~min}$, followed by the same buffer without DTT, but with the addition of $2.5 \%(\mathrm{w} / \mathrm{v})$ iodoacetamide for $15 \mathrm{~min}$ [13].

A piece of Whatman paper soaked with $10 \mu \mathrm{L}$ of protein molecular weight markers (Sigma, Taufkirchen, Germany), labelled with 200 pmol of Cy5, was applied on selected gels. SDS-PAGE was performed using $12 \%$ separating polyacrylamide gels without a stacking gel using the Ettan DALT12 system (Amersham Biosciences, GE Healthcare, UK). The second dimension was carried out overnight at $1 \mathrm{~W} / \mathrm{gel}$ at $15^{\circ} \mathrm{C}$ and was terminated when the Bromophenol dye front had migrated off the lower end of the gels.

Image Analysis. After electrophoresis, scanning of the gels with CyDye-labelled proteins was performed on a Typhoon ${ }^{\mathrm{TM}} 9410$ Image scanner (Amersham Biosciences/GE Healthcare UK). Pre-scans were performed to adjust the photomultiplier tube (PMT) voltage to obtain images with a maximum intensity of 40,000 to $60,000 \mathrm{U}$. Images were cropped with ImageQuant ${ }^{\mathrm{TM}}$ software (Amersham Biosciences/GE Healthcare UK) and further analysed using the software package DeCyder v6.5 (Amersham Biosciences/GE Healthcare UK). Intra-gel spot detection and quantification was performed using the Differential In-Gel Analysis (DIA) mode whereas images from different gels were matched using the Biological Variance Analysis (BVA) mode. Protein spots with an expression level greater than 1.5 fold change between at least two developmental stages and at least $p<0.05$ were defined as being differentially expressed.

Silver stained Gels. Preparative 2-D gels (400 $\mu$ g protein loading) were run as described above and fixed for a minimum of $1 \mathrm{~h}$ in a methanol:acetic acid:water solution (4:1:5 $\mathrm{v} / \mathrm{v} / \mathrm{v}$ ). The resulting 2-D protein profiles were visualised using the PlusOne silver staining kit (Amersham Biosciences) with slight modifications to ensure compatibility with subsequent MS analysis [38].

Spot picking and processing. Based on DeCyder v6.5 analysis and manual comparison of DIGE-gels with silver stained gels, spots were picked using a manual spot picker. Spot plugs were destained and proteins were digested with trypsin as previously described [11].

LCMMS. All samples were run on a Finnigan LTQ mass spectrometer connected to a Surveyor chromatography system incorporating an auto-sampler. Tryptic peptides were resuspended in $0.1 \%$ formic acid and were separated by means of a modular CapaLC system (Finnigan) connected directly to the source of the LTQ. Each sample was loaded onto a Biobasic C18 Picofrit ${ }^{\mathrm{TM}}$ column $(100 \mathrm{~mm}$ length, $75 \mu \mathrm{m} \mathrm{ID})$ at a flow rate of 30 
$\mathrm{nL} / \mathrm{min}$. The samples were then eluted from the $\mathrm{C} 18$ Picofrit $^{\mathrm{TM}}$ column by an increasing ACN gradient. The mass spectrometer was operated in positive ion mode with a capillary temperature of $200^{\circ} \mathrm{C}$, a capillary voltage of $46 \mathrm{~V}$, a tube lens voltage of $140 \mathrm{~V}$ and with a potential of $1800 \mathrm{~V}$ applied to the frit. All data was acquired with the mass spectrometer operating in automatic data-dependent switching mode. A zoom scan was performed on the 5 most intense ions to determine charge state prior to MS/MS analysis. All MS/MS spectra were sequence database searched using TurboSEQUEST. The MS/MS spectra were searched against the non-redundant mouse International Protein Index database (v.3.14). The following search parameters were used: precursor-ion mass tolerance of 1.5, fragment ion tolerance of 1.0 with methionine oxidation and cysteine carboxyamidomethylation specified as differential modifications and a maximum of 2 missed cleavage sites allowed.

\section{Results and Discussion}

Mouse brain samples $(50 \mu \mathrm{g})$ of the different developmental stages E16 (embryonic day 16), postnatal day 7 (P7) and postnatal days 54-58 (P56) were labelled with 400 pmol of CyDye. A so-called dye-swap (half of the samples were labeled with Cy3 the other half with Cy5) was performed to control for preferential labelling by one of the dyes for the different fluorescent characteristics of the gel at the different wavelengths [20]. Representative images of the three different developmental stages are displayed in Fig. 1.
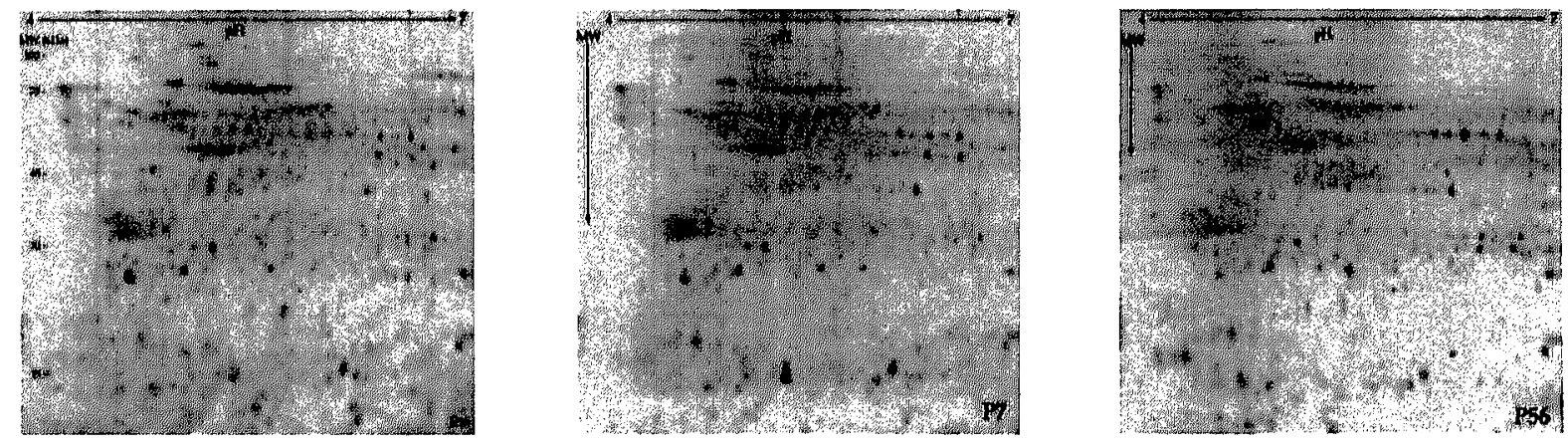

Figure 1. Representative images of 2-D gel separations of proteins from whole mouse brains in developmental stage E16, P7 and P56. Protein (50 mg) was labelled with 400 pmol of CyDye. Proteins were in-gel rehydrated on 24-cm pH 4-7 IPG strips and the second dimension was $12 \%$ SDS-PAGE.

Images were subsequently analysed with the DeCyder v6.5 software packages the differential in-gel analysis (DIA) and biological variance analysis (BVA) for spot detection, gel-matching and differential analysis including statistical testing. Image analysis was performed on 8 images from the E16 group, 10 images from the P7 group and 7 images from the P56 group. In the images derived from the gels an average of 4700 spots were found; 1999 spots were found to match between all of the gels. This is due to DeCyder where a maximum number of spots are detected, with many of them being artefacts and low abundance spots. We checked the matching very carefully. Once a spot was detected to be significant the spot was carefully checked for correct matching between all gels. If this was not the case then the spot was rematched and the statistics recalculated. Of these 1999, 206 spots showed a significant $(p \leq 0.05)$ difference in intensity between at least one of the developmental stages: 122 spots were highest in intensity in the embryonic stage E16, 26 highest in the juvenile P7 group and 58 up-regulated in the early adult P56 
group. Eighty-two spots with a significant difference in intensity were excised from a preparative gel loaded with $400 \mathrm{mg}$ of proteins and stained using a modified PlusOne silver stain protocol. LTQ MS/MS analysis was performed on the digested proteins to reveal their identity. Of the differentially expressed spots, 54 were identified by LTQ (Fig. 2, Table 1, Table 2).

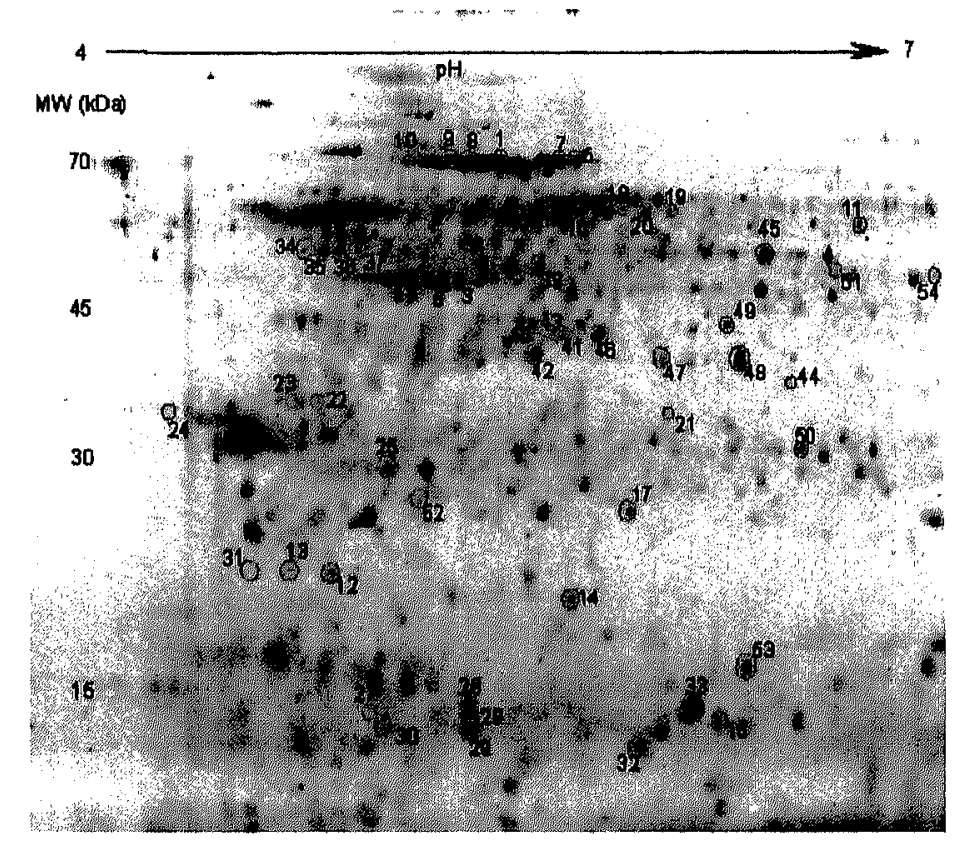

Figure 2. Image of a pH 4-7 2-D gel separation of $50 \mu \mathrm{g}$ proteins from the pool used as internal standard labelled with $400 \mathrm{pmol}$ of CyDye. Spots that were identified and described in the text are annotated. The numbering system is that used in Table 1.

By visual inspection of the overall quite similar 2-D gel protein maps of the developmental stages E16, P7 and P56 (Fig. 1), it is clear that the images from E16 samples show a greater number and more distinct spots than the other two developmental stages. This is also represented by the fact that more spots were highest in intensity in the E16 group in the gels. One possible explanation could be the fact that more processes are going on in the embryonic brain. Not only are basic structures of the brain being established, but development and utilisation of these structures is also occurring.

Another explanation could lie in the rigidity of the brains in the more developed stages with stronger structures and more fatty layers, making lysis and solubilisation of these brains more difficult.

Table 1 lists the differentially expressed proteins that were successfully identified and data of their differential expression are given in Table 2 together with the gene ontology (GO) analysis (molecular function, biological process, and cellular component) for the set of identified differentially expressed proteins. We identified 12 proteins associated with the actin cytoskeleton, 6 of which were up-regulated in the embryonic stage E16. Actin is very abundant in neuronal cells and its abundance makes it easier to identify spots that represent this molecule. That is a reason why we found five spots to represent actin. Its network regulates the shape of the neuron by creating the cytoskeleton 
[22]. Actin exists in two forms within the cell. F-actin is the filamentous, polymeric form of actin and makes up the cytoskeleton. G-actin is the building block of F-actin and is present in the monomeric form. A relative higher expression of $\mathrm{G}$-actin in the embryonic phase could indicate that the brain is in a phase of construction with a high demand for $\mathrm{G}$ actin as building blocks for F-actin organisation. A similar pattern of expression of tubulin was found and could have the same cause. Tubulin, a structural component of microtubules, is part of the cytoskeleton. This is particularly significant as individual neuronal tubulin isoforms have a regulated pattern of expression during the active phase of axonal elongation in development [6]. Additional proteins that direct the morphology of brain cells were identified and found to be highly expressed in the embryonic stages, for example fascin, an actin filament binding protein, and gamma-tropomyosin 3 reported to interact with the F-actin helix [5].

Fatty acid binding proteins (FABP) are proteins that regulate the intracellular transport of fatty acids and their acyl CoA esters and are important in brain development. Brain- FABP (FABP-B) is reported to be important for the establishment of the radial glial fibre system [19]. Epidermal-FABP (FABP-E) has been found at high levels in central neurons during neuronal migration and development [21]. We identified three spots related to brain FABP that slightly differed in molecular weight and $\mathrm{pH}$ and one epidermal FABP to be up-regulated in the samples of postnatal day 7 . The expression pattern of FABP found in this study resembles those found in other studies, using different techniques [ 2 , $19,21]$.

Other proteins that we found to be differentially expressed are known to play a role in the maintenance of the cells. For example, superoxide dismutase and peroxiredoxin are antioxidants that destroy free radicals [7, 27]. Ubiquitin carboxyl- terminal hydrolase isozyme is involved in the processing of ubiquinated proteins and thus degradation of proteins that are not needed anymore [29]. Finally, serum albumin, acts to control the colloidal osmotic pressure of blood, but in the developing brain it is also involved in neuronal differentiation by triggering some reactions [31]. Two serum albumin precursor proteins and peroxiredoxin-2 were found to be increased in E16, a different spot was related to peroxiredoxin-2 in P7, whereas we were able to identify an upregulated spot representing superoxide dismutase in P56.

Four proteins were found to represent dihydropyrimidinase-related protein-3 whose expression were highly upregulated in the brains of the postnatal day 7 (P7) samples when compared to postnatal day 56 (P56) but did not show a significant expression in comparison to the brains from embryonic day 16 (E16). Dihydropyrimidinase-related proteins (DRP) are expressed mainly in foetal and neonatal brain and are involved in axonal outgrowth and pathfinding. Pathfinding of growing axons to reach their target during brain development is a subtle process needed to build up contacts between neurons. It was shown recently [35] that DRP-3 among other DRP was decreased in human Down Syndrome foetal brains by using a proteomic approach a finding that clearly emphasizes the importance of DRP in normal brain development.

The 14-3-3 proteins, members of the family of phosphoserine/ threonine-binding proteins, are highly abundant in brain and have been shown to interact with various protein kinases, receptor proteins, enzymes, structural and cytoskeletal proteins as well as having a function in apoptosis [36]. The function of 14-3-3 proteins in these cellular processes has not been unequivocally established [4]. The epsilon form has been shown to be important for neuronal migration [32]. An in vitro study on cultured astrocytes suggests a possible role of 14-3-3 in growth and differentiation of neurons and astrocytes, indicating an intricate mechanism governing coordinated and well-controlled developmental events in the brain to ensure normal neural functions [8]. We found the level of this protein to be 
changed significantly between P7 and P56 but not between E16 and P7 again suggesting that the above described mechanisms take place early in development.

We found three spots to represent gamma-enolase, a dimeric enzyme in the glycolytic pathway, in the early adult phase P56. Gamma-enolase has been described in vitro to have neurotrophic and neuroprotective effects on rather a broad spectrum of neurons in the CNS [16]. The expression for the gamma subunit of enolase was first detected in postmitotic neurons and it increased progressively until the adult stage. It was suggested that gamma enolase participates in energy production in neurons of the mature brain and that marked changes in the subunit composition of enolase occur according to both neuron type and maturation [33].

Another group of proteins that were identified are involved in cellular metabolism. Five of the identified proteins were found to be related to processes of glucose degradation for the derivation of energy and building blocks for DNA, RNA and proteins. The pentose phosphate pathway not only provides NAD for reduction, but can also deliver the five carbon sugar ribose that is part of the main structure of DNA and RNA [18]. In a phase during which the brain is developing a lot of DNA and RNA needs to be translated and copied, enzymes that are involved in the pentose phosphate pathway, such as 6phosphogluconolactonate are indispensable. Phosphoglycerate mutase and pyruvate kinase are both involved in the processing of glucose to pyruvate [40]. Malate dehydrogenase is involved in the subsequent citric acid cycle. These processes generate energy that is stored as ATP in the cell. The utilization of the brain costs a lot of energy, thus it is not surprising that these enzymes are expressed highest in the phase where the entire brain is used most: P56.

In summary it appears that the proteins that are highest in expression in the embryonic phase are proteins that are involved in the establishment of basic structures. Proteins that are involved in the development of the brain are highest in expression in the juvenile brain and finally, proteins that are necessary for the utilization of the brain are highest in expression in the adult brain. 


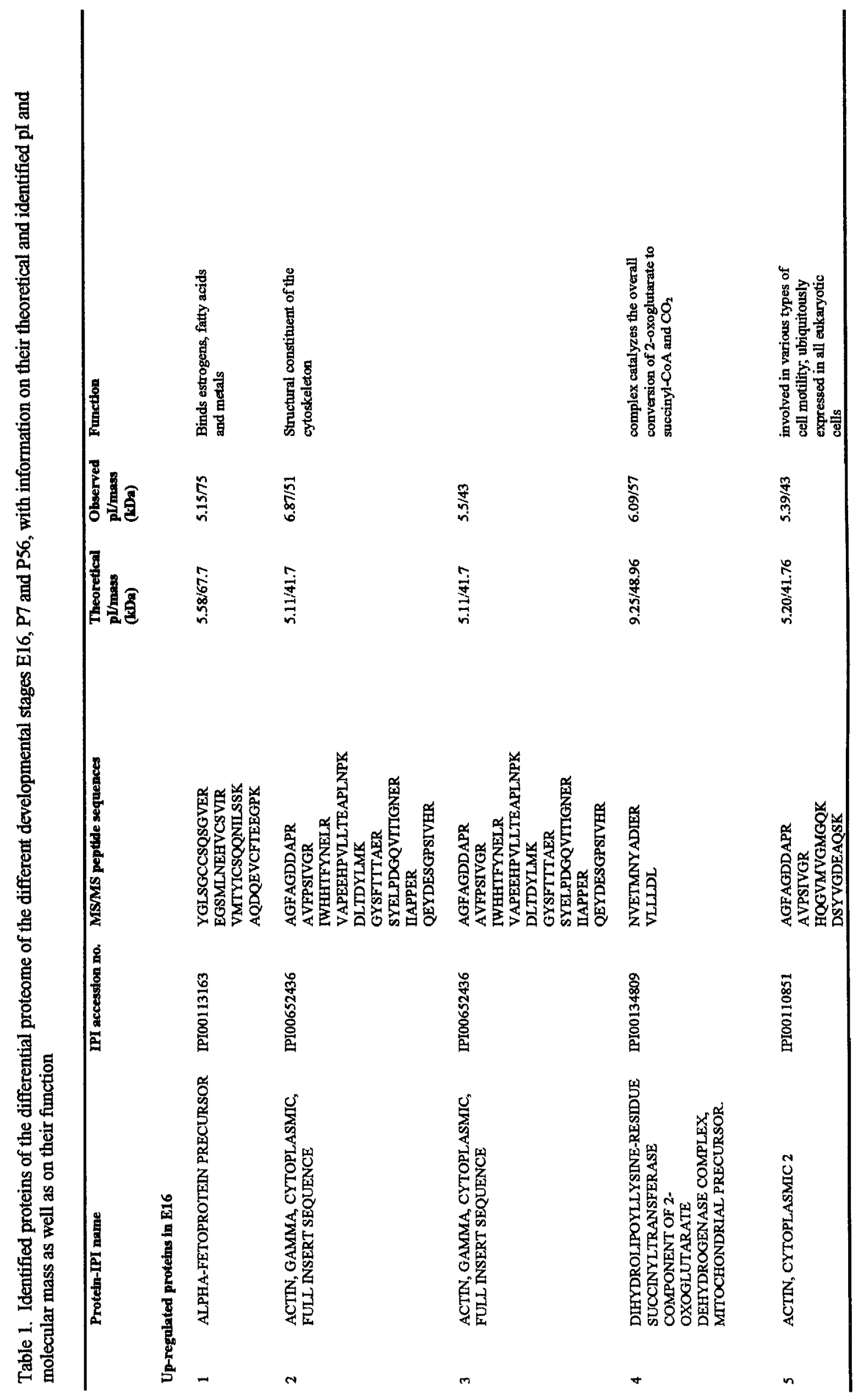




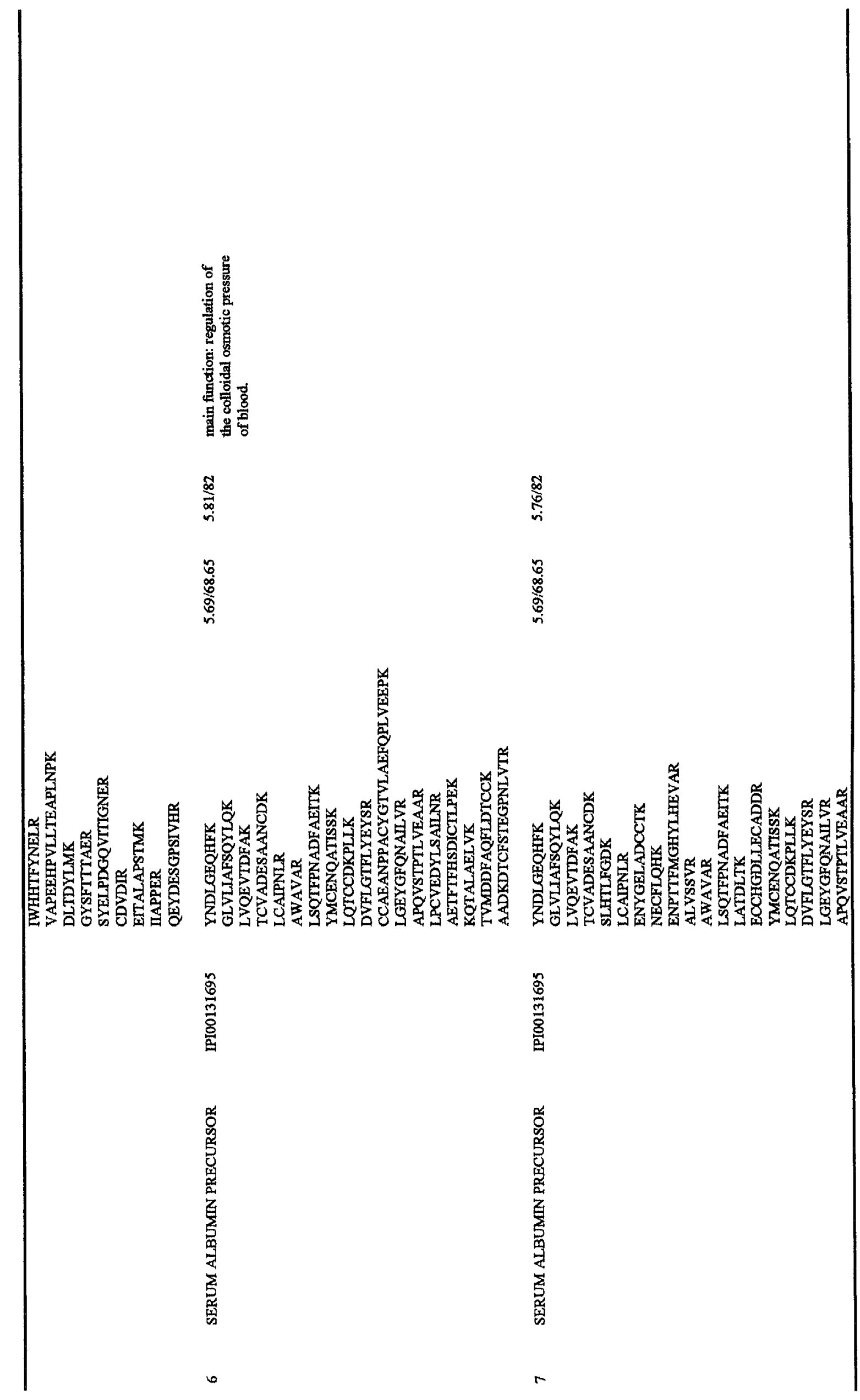




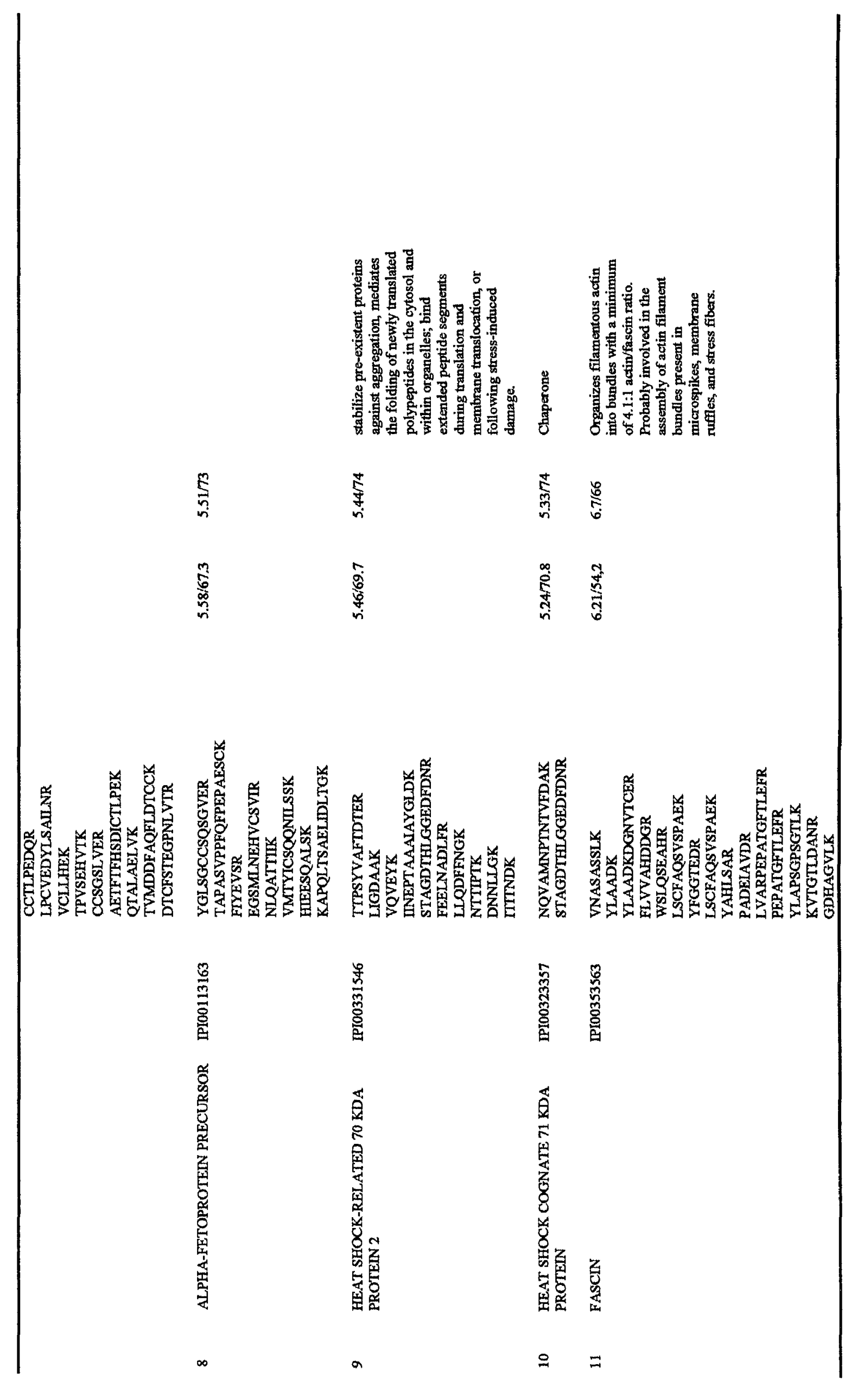

ה 

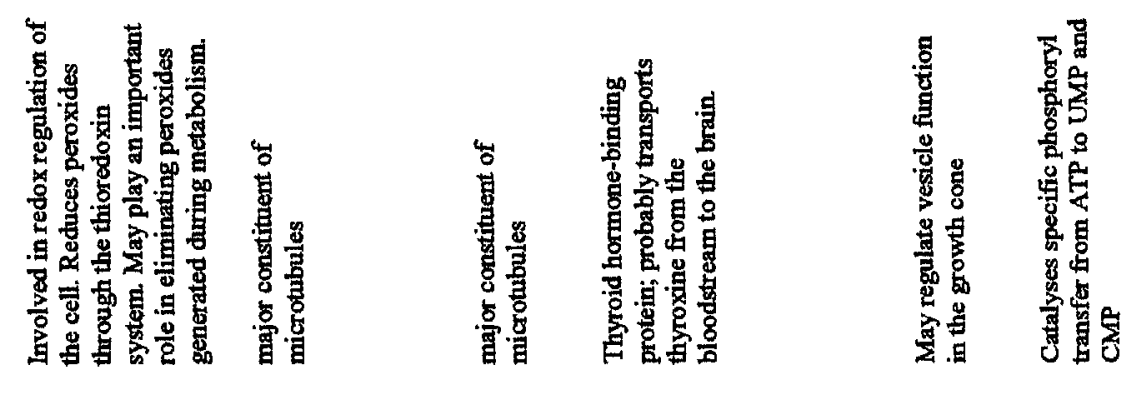

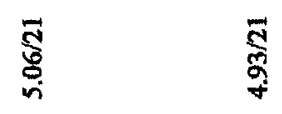
喜

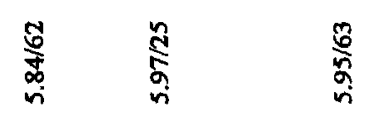
产
$\sum_{\infty}^{\infty}$ in
कृ
क्षे

管善

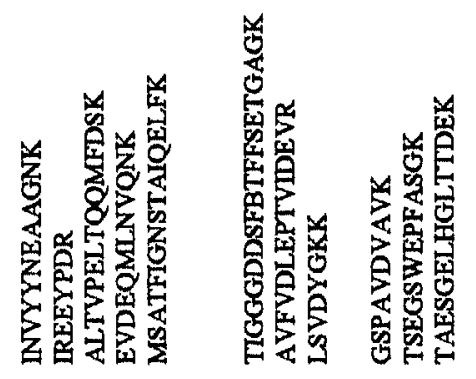

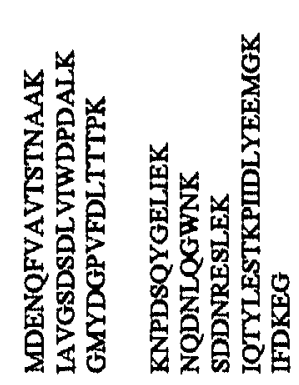

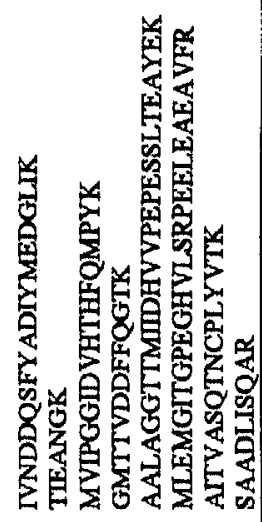

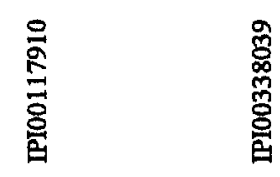

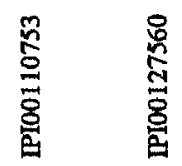

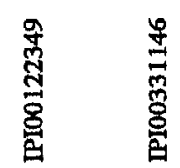

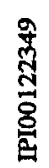

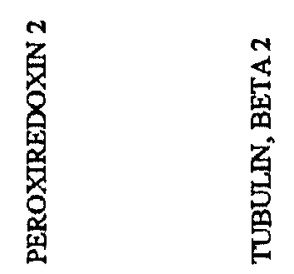

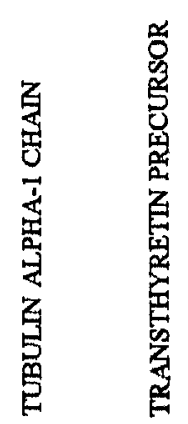

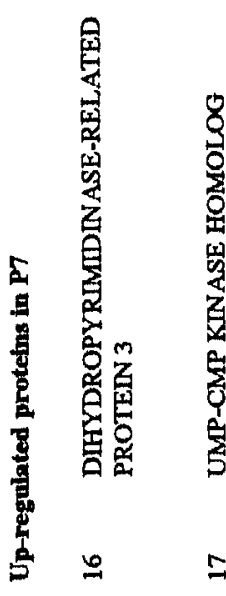

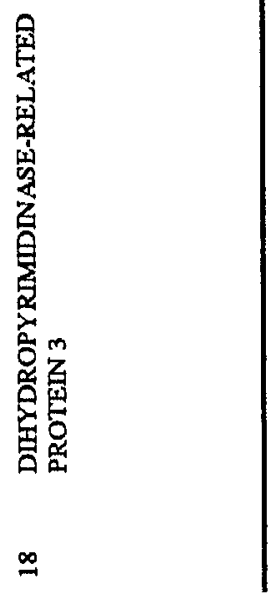




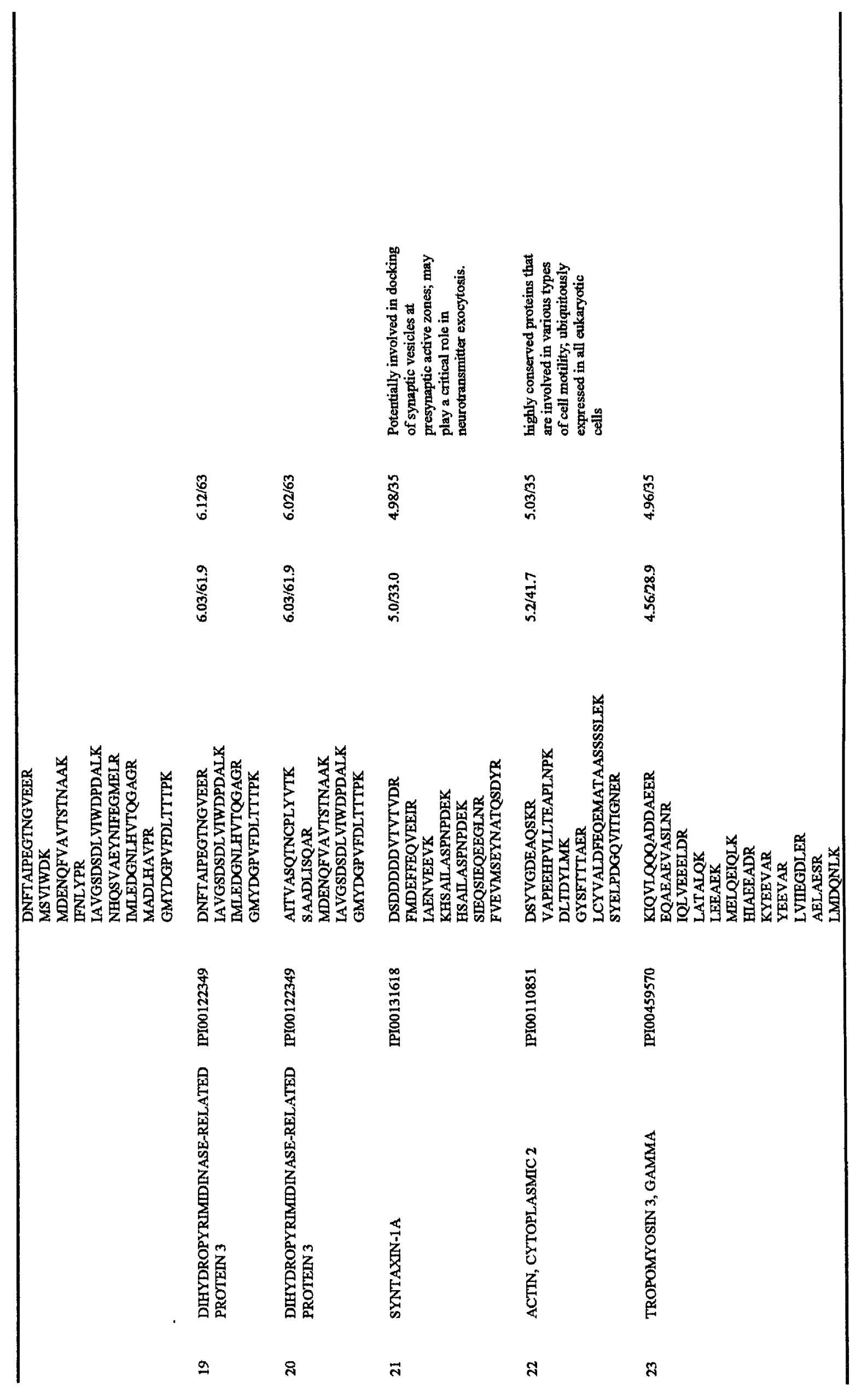



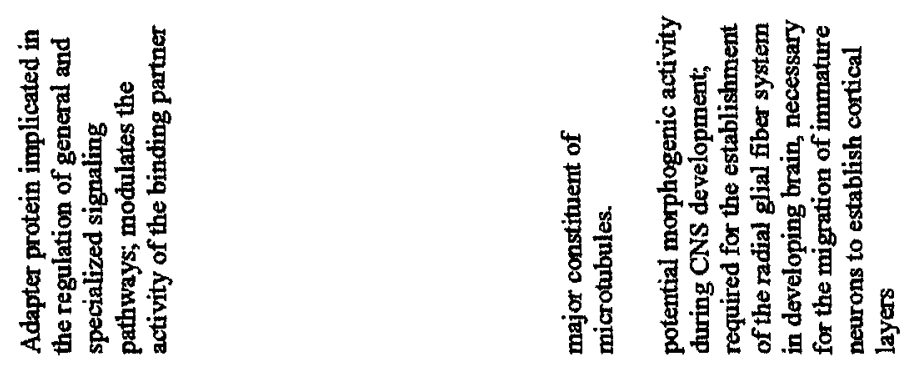

旁

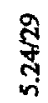

衰高

喜 喜

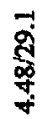

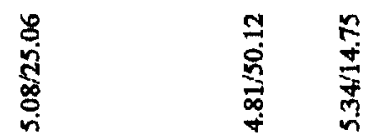

$\begin{array}{ll}n & n \\ \dot{m} & \frac{n}{5}\end{array}$

(1)
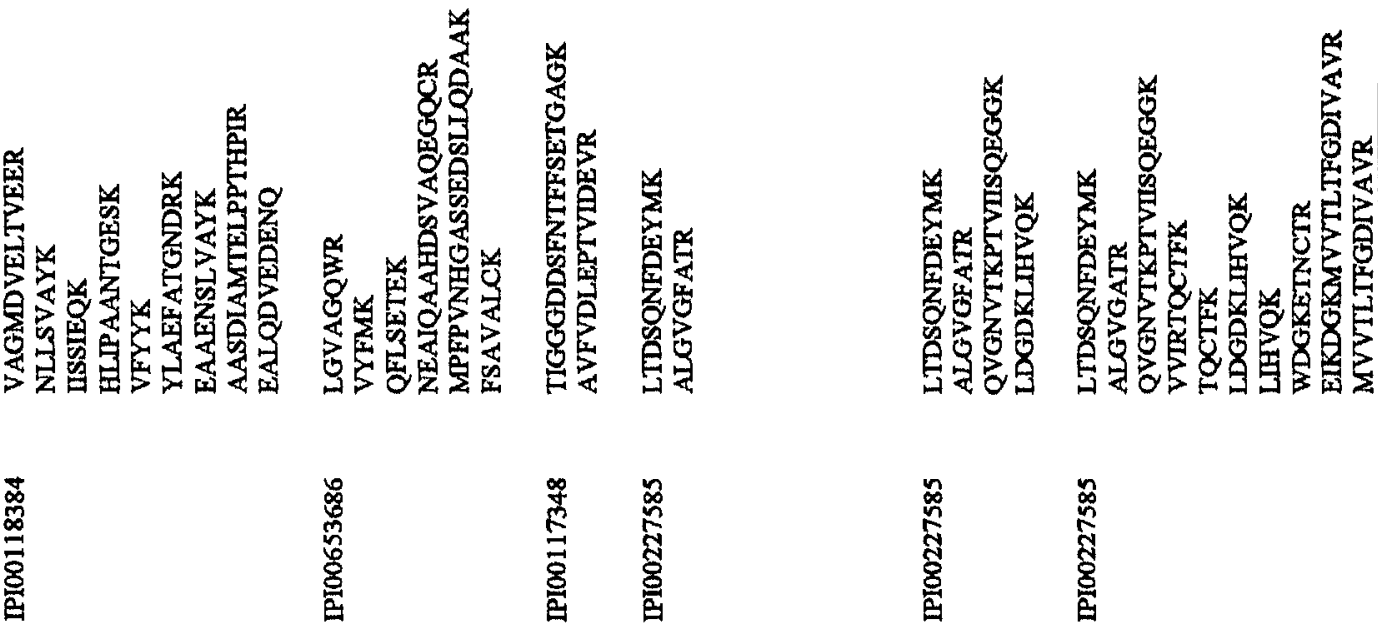

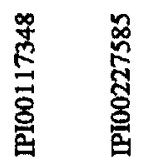

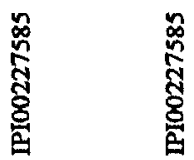

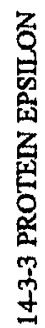
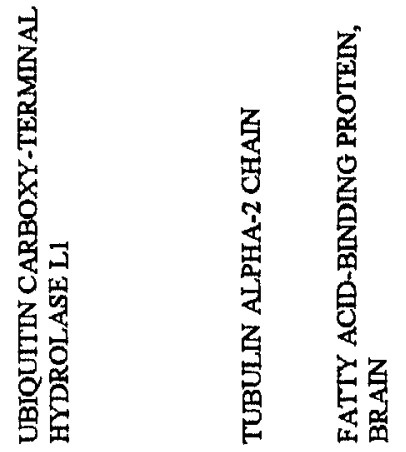

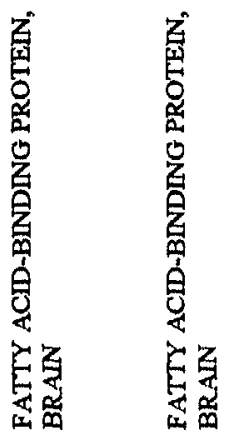

A

2

กั

$\stackrel{\infty}{\wedge}$

ำ 


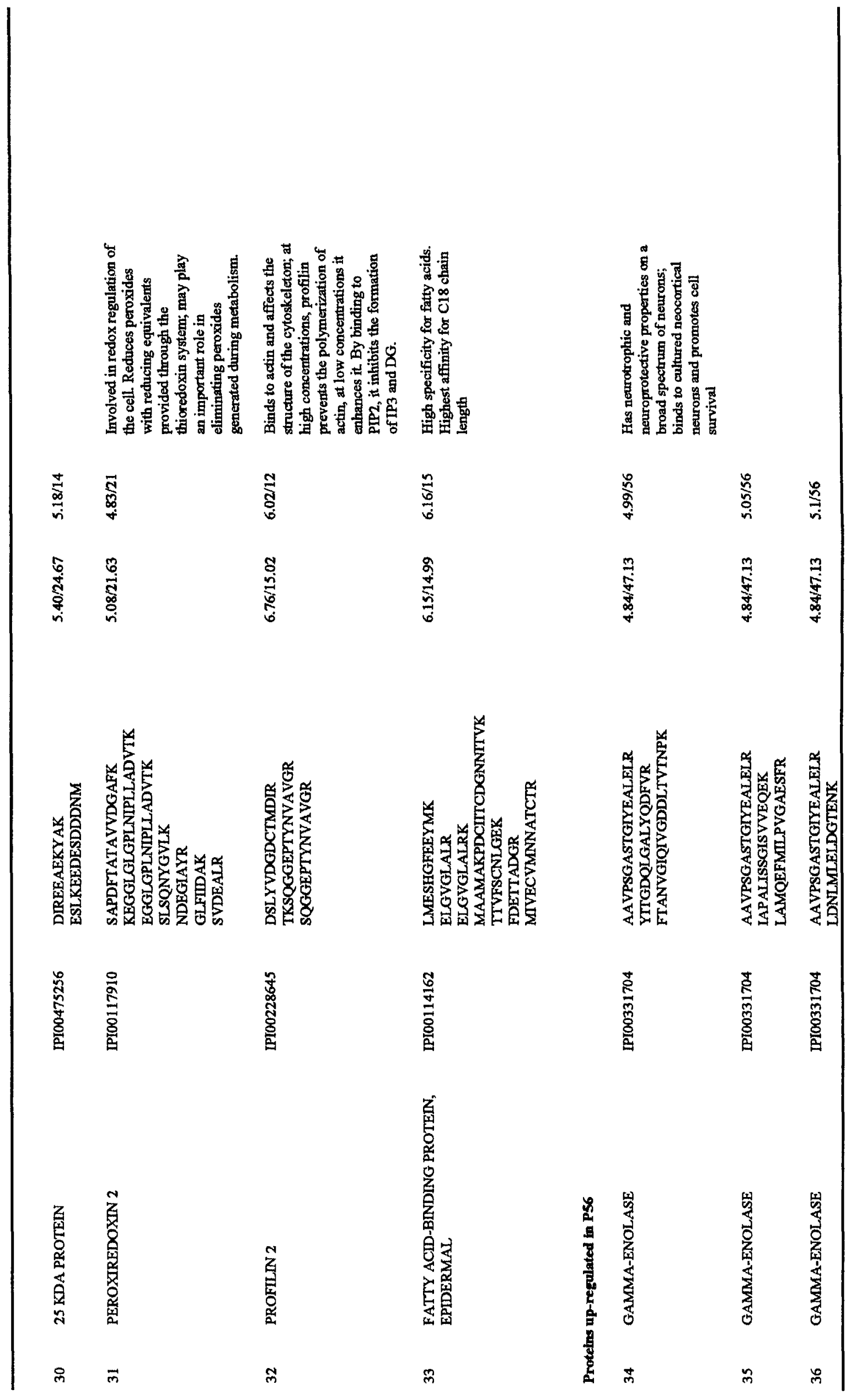



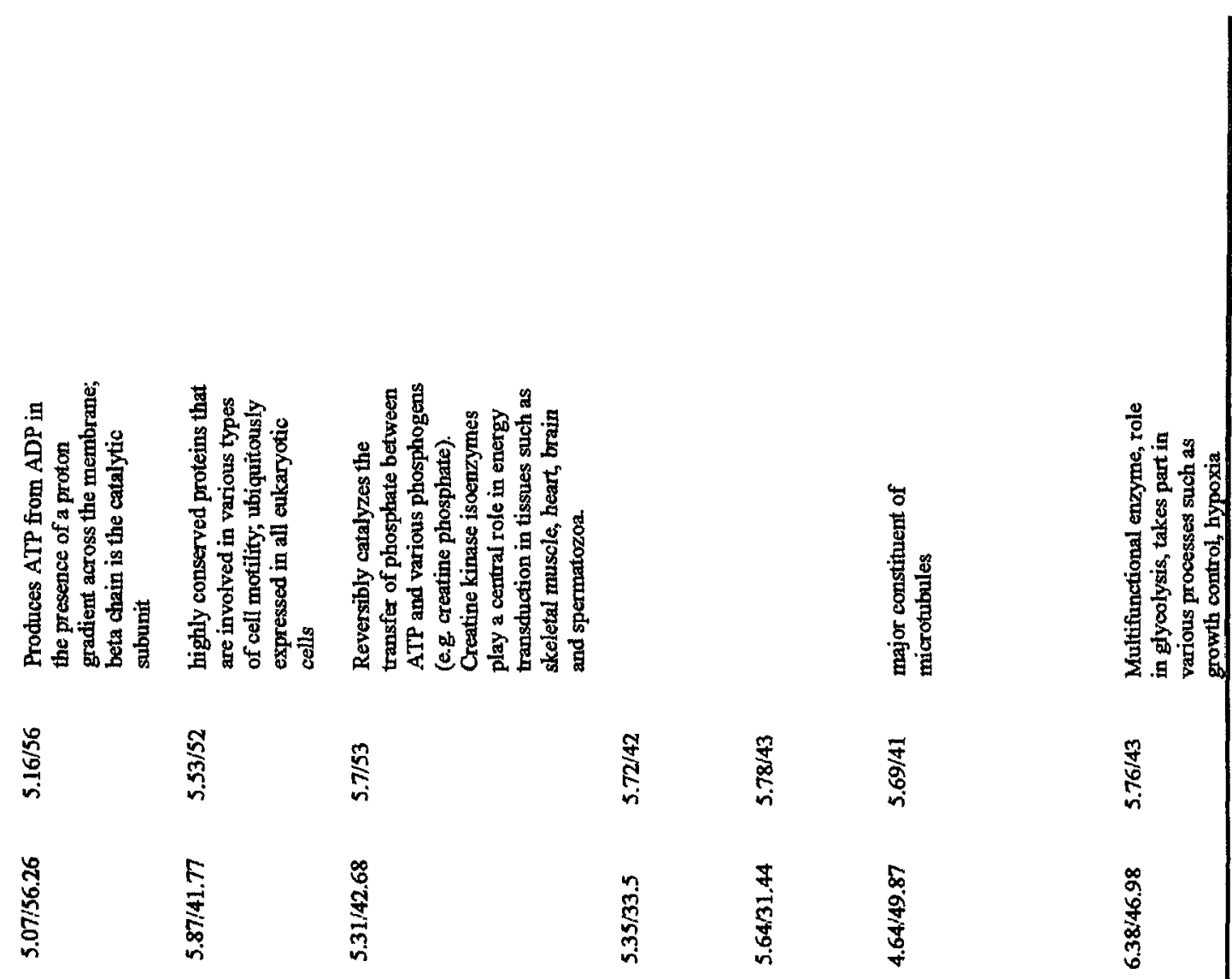

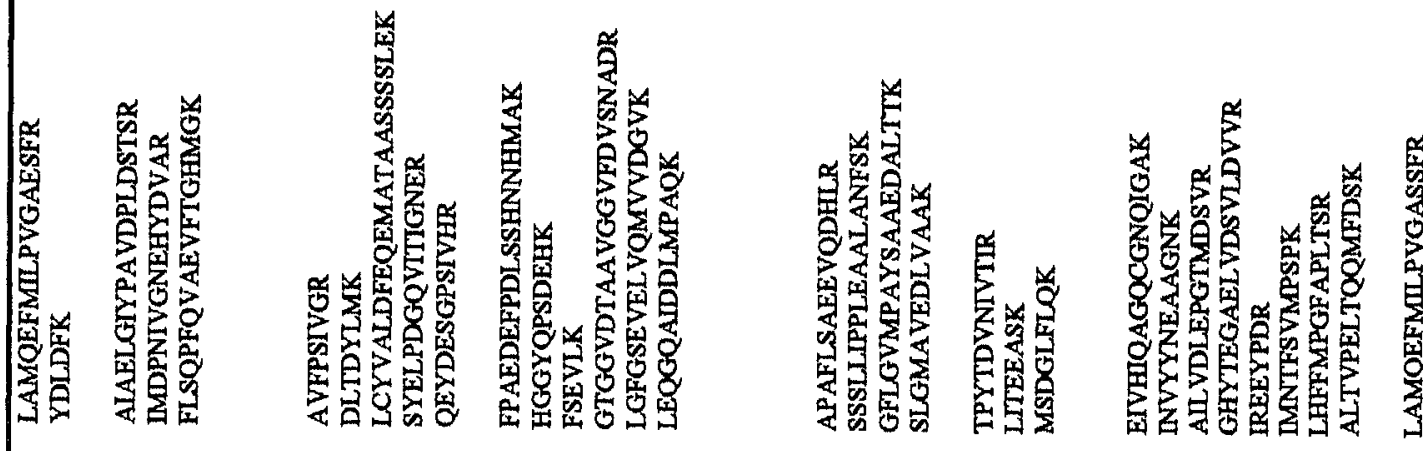
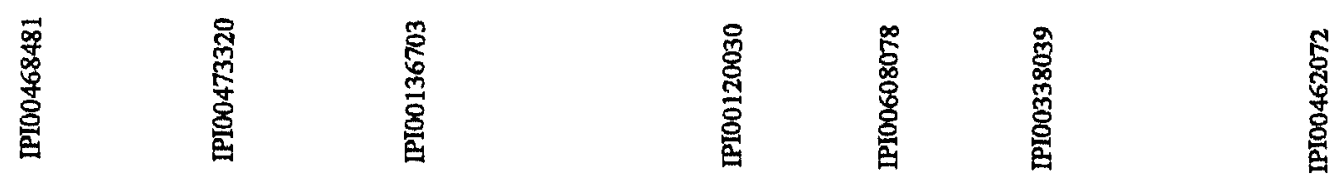

要总

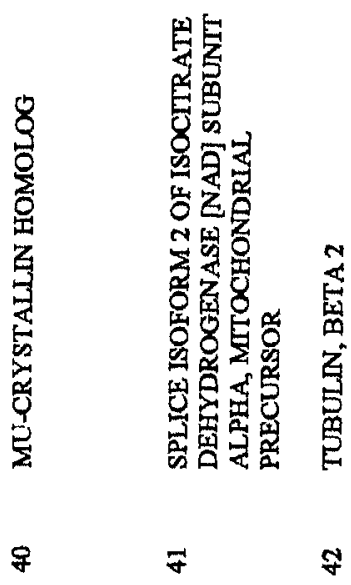

幽 

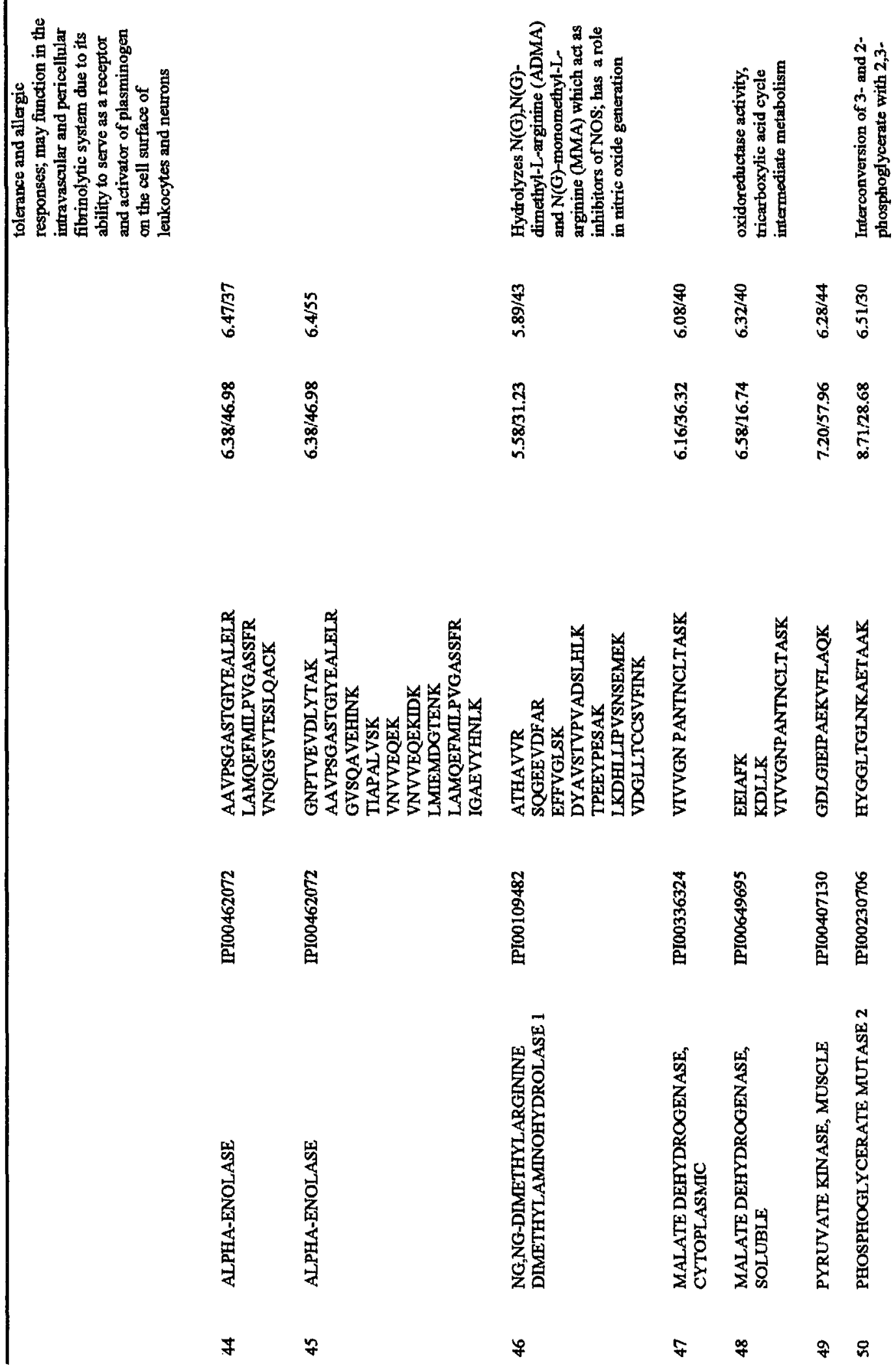

高

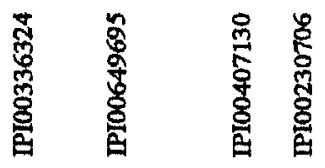




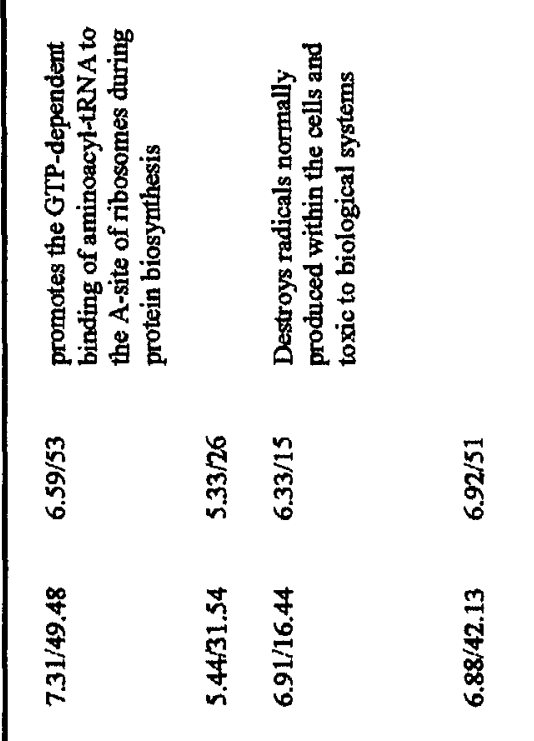

|

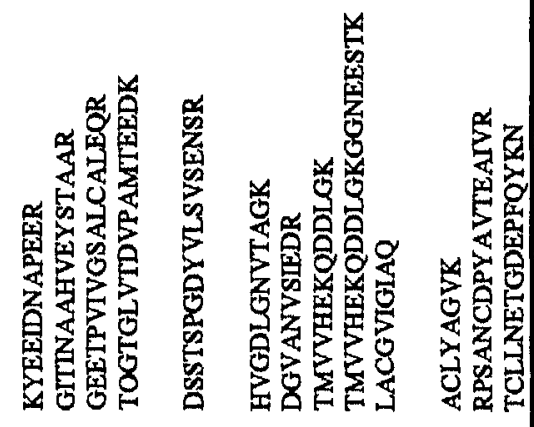

尊

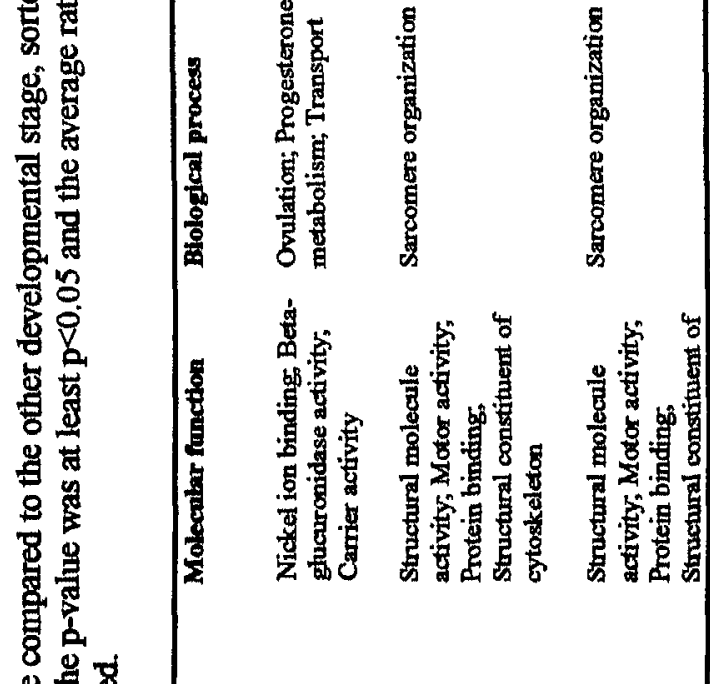

尊尊

을

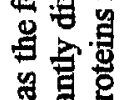

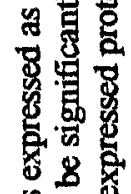

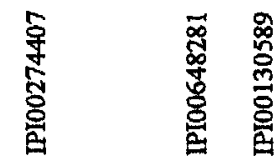

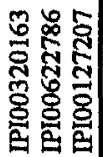

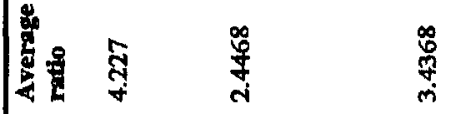

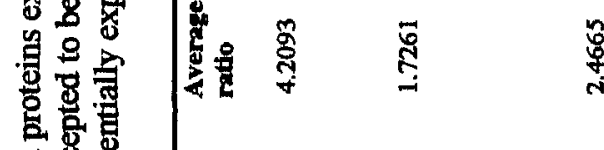

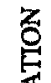

总焉

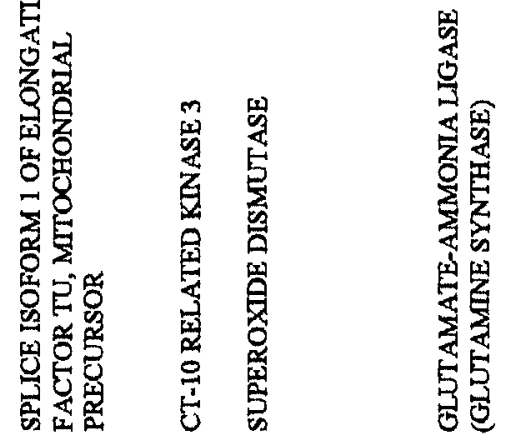

$\approx \pi$ ก

茫

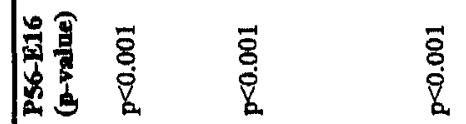

id

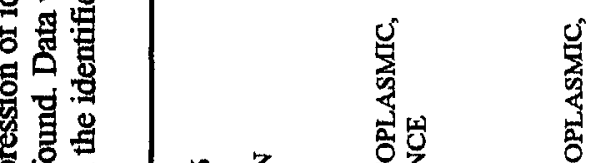

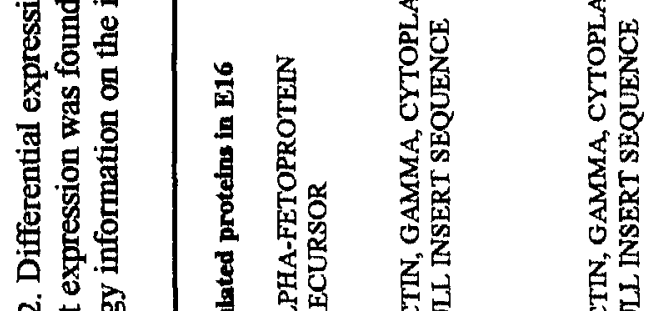

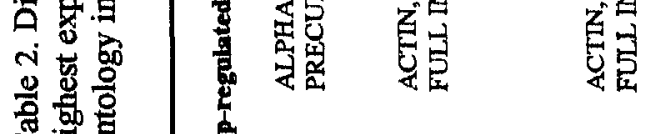




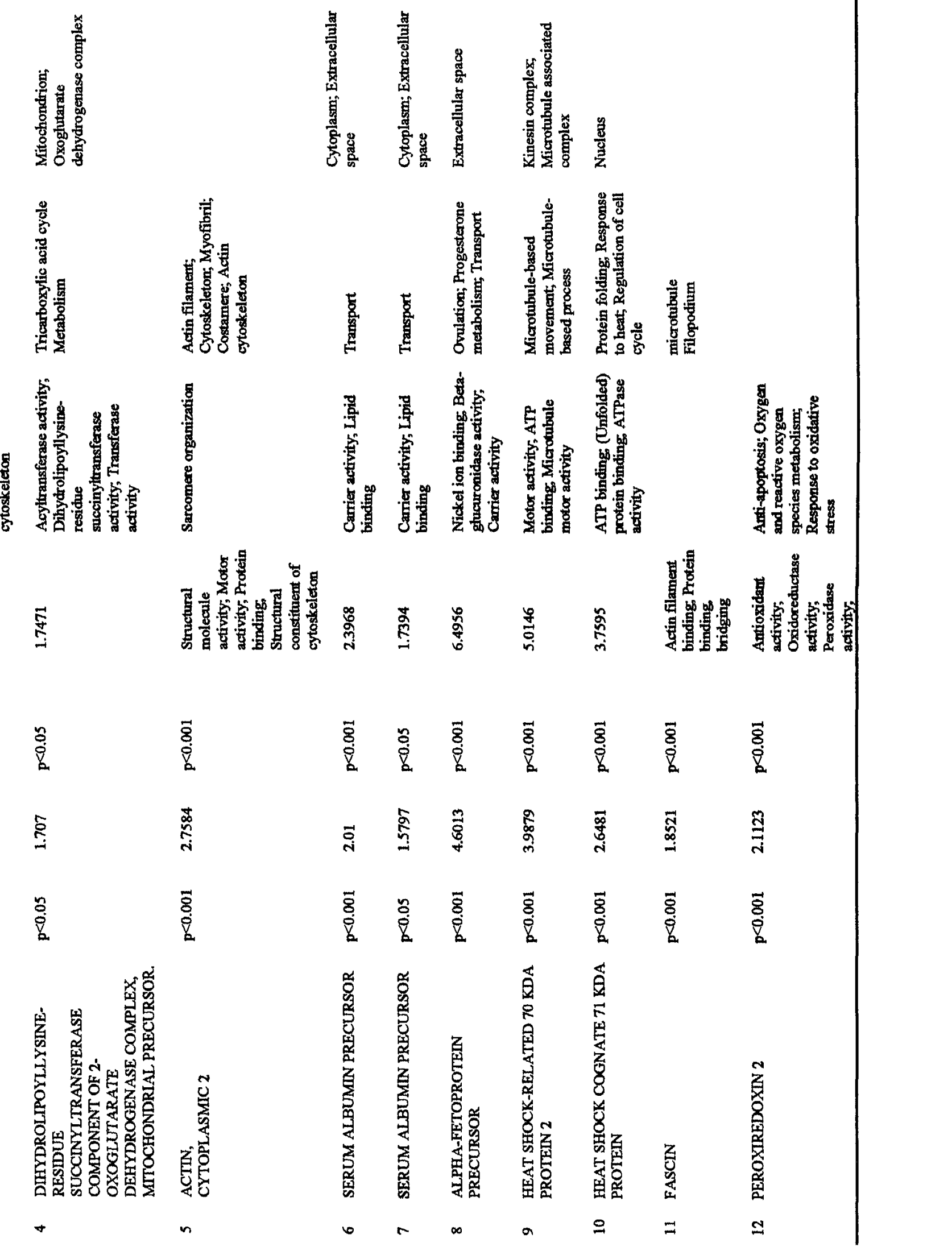




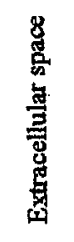

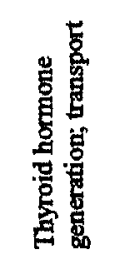

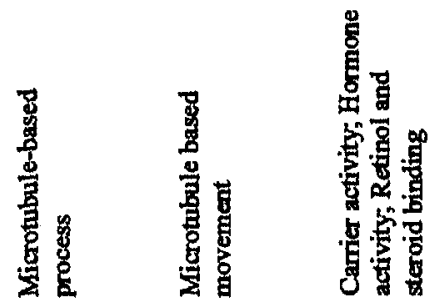

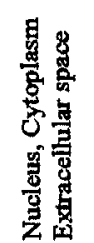

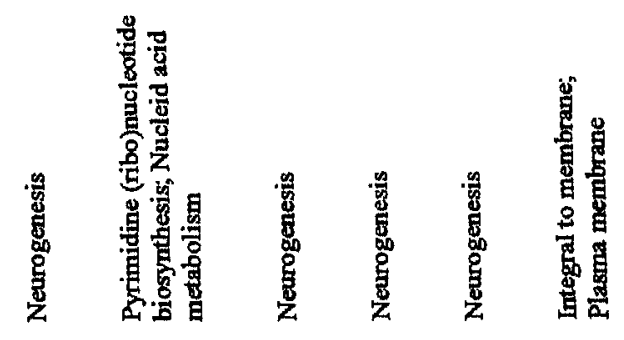

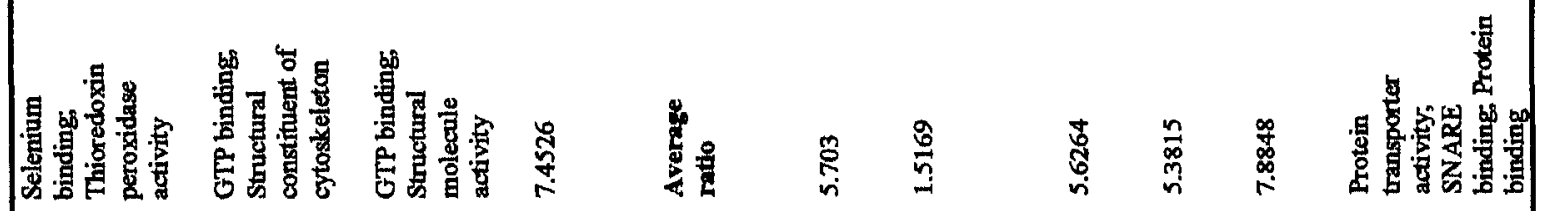

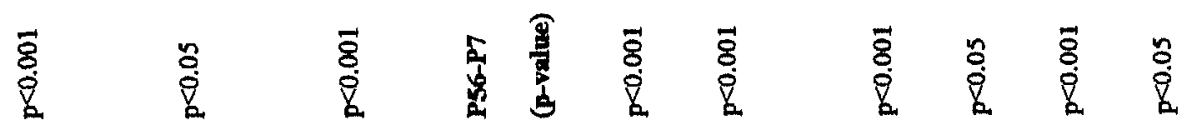

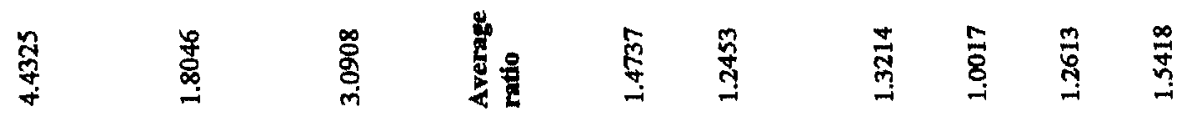

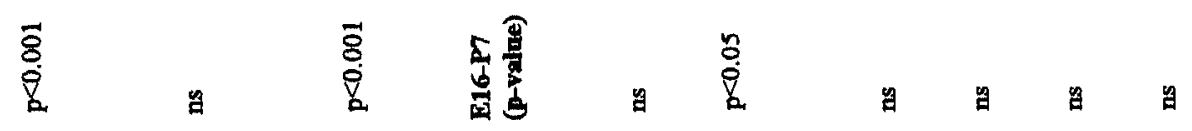

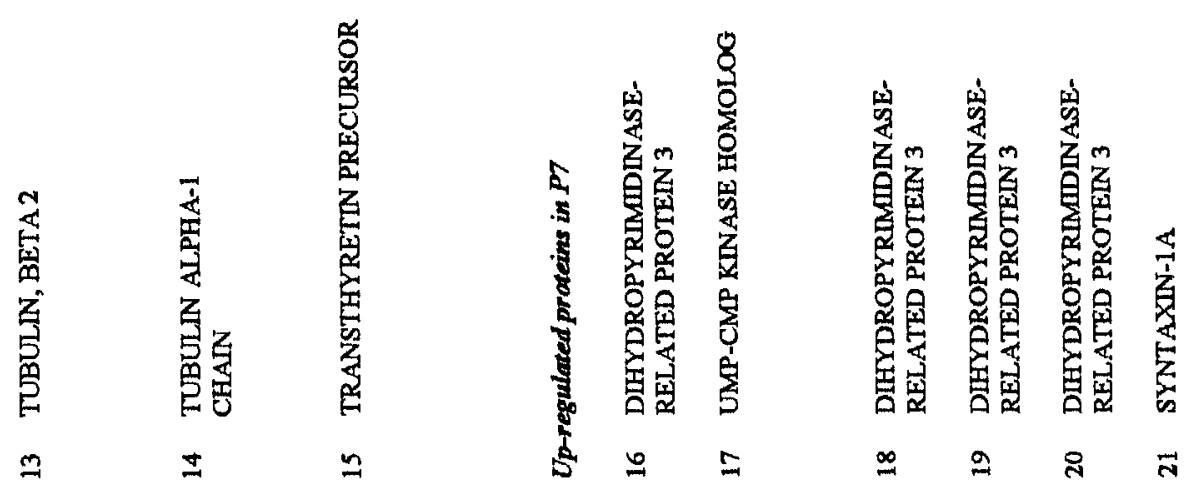




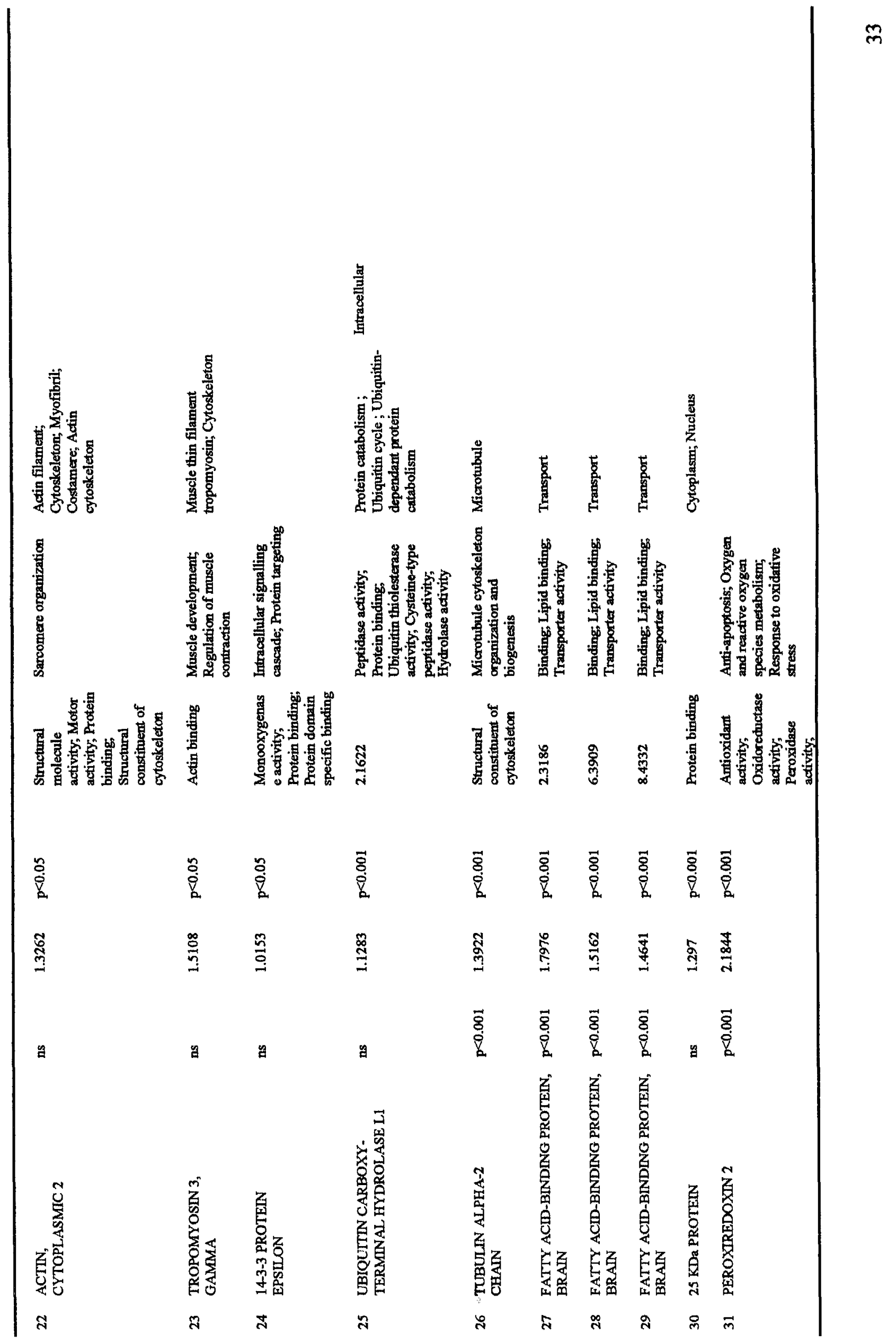




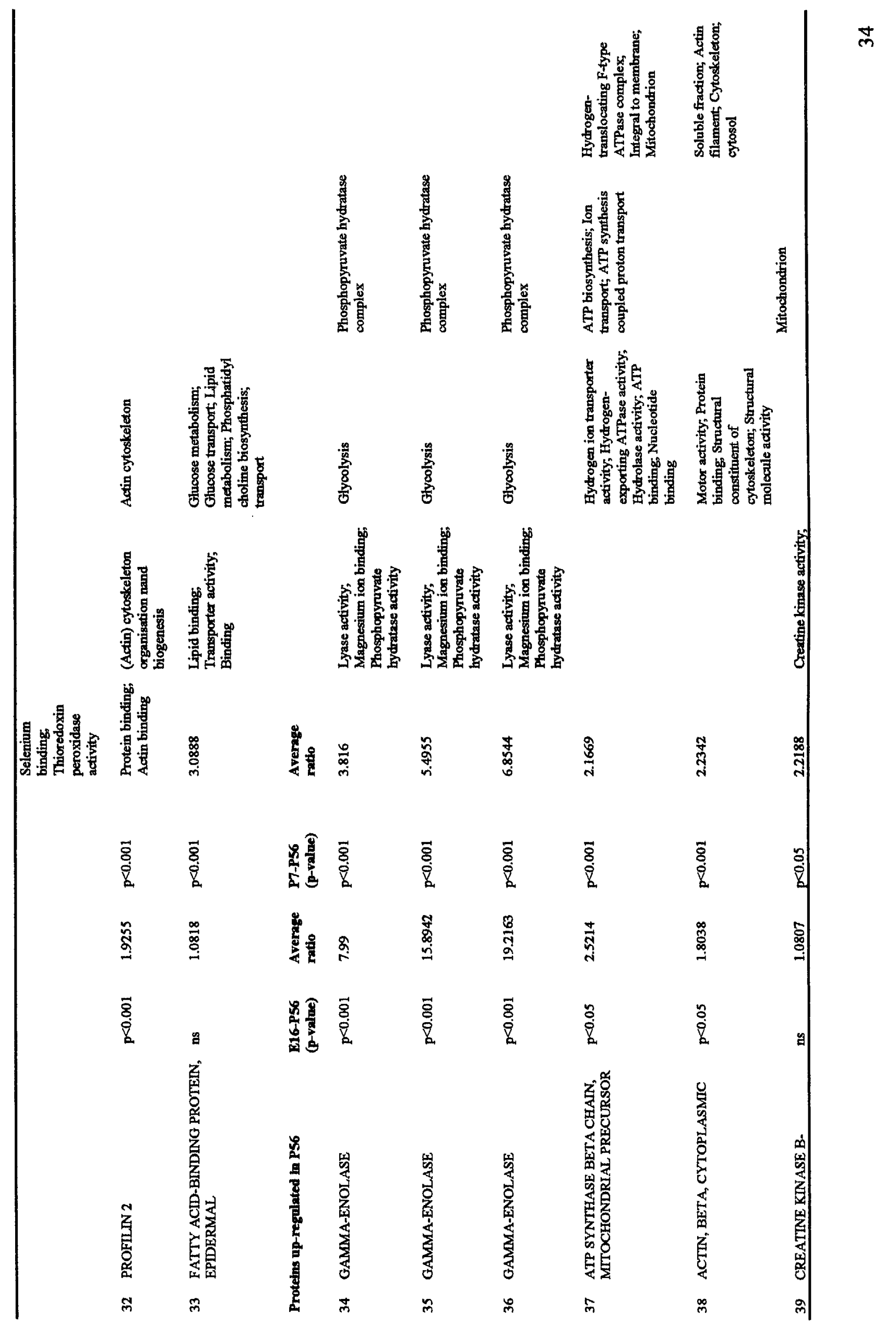




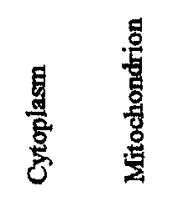

1

$\sqrt{1}+\frac{1}{1}$

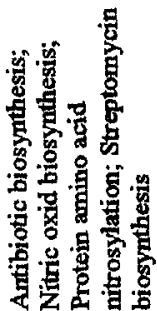

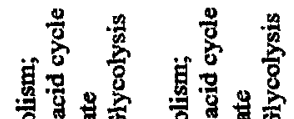

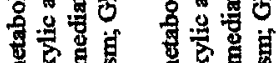

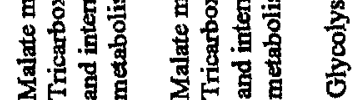

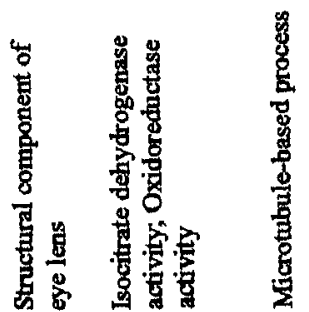

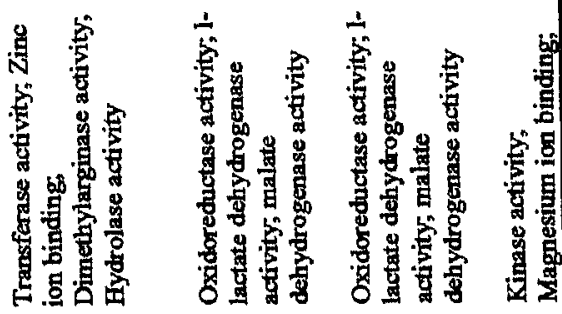

管窎

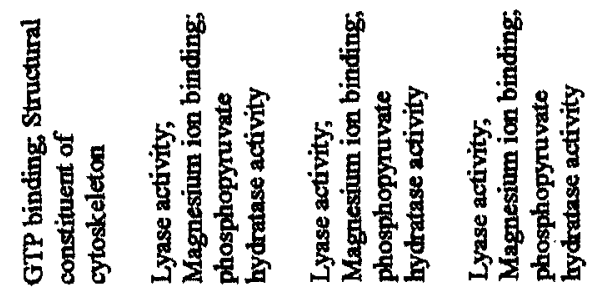

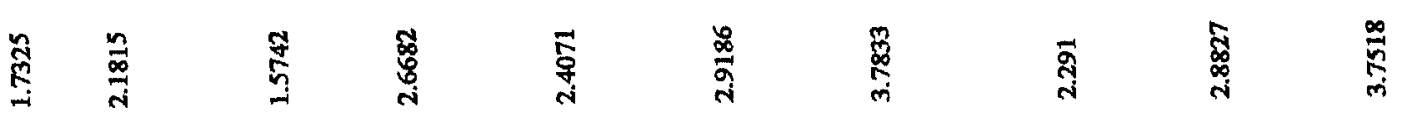

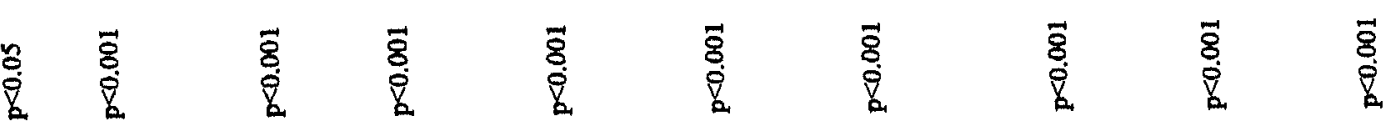

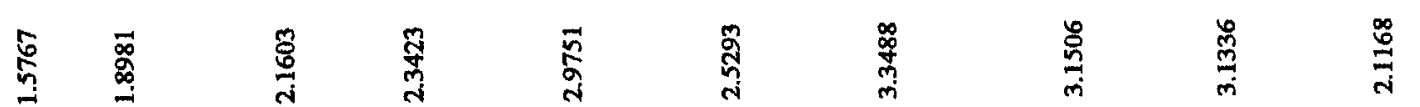

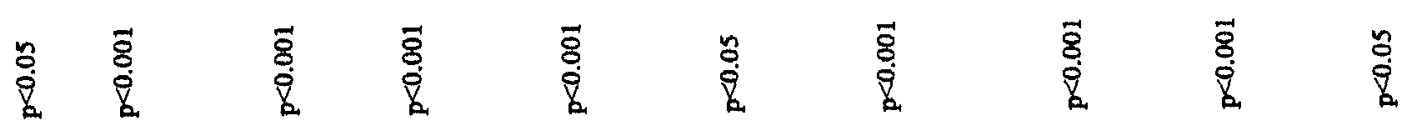

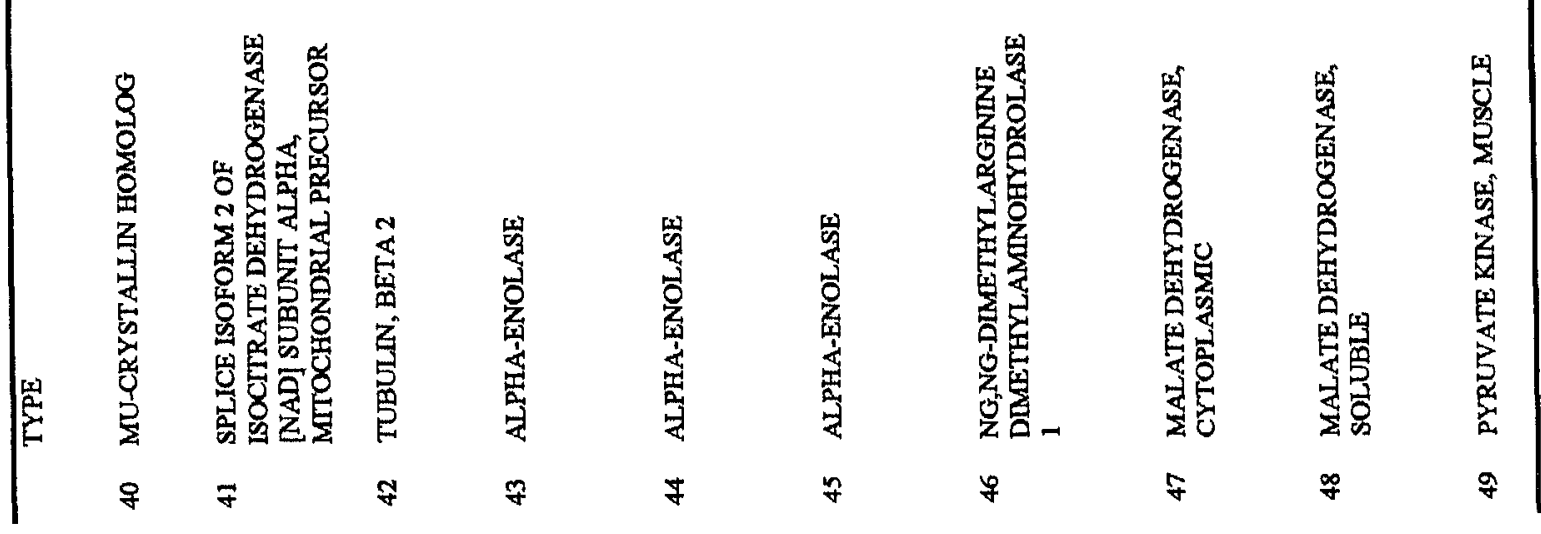




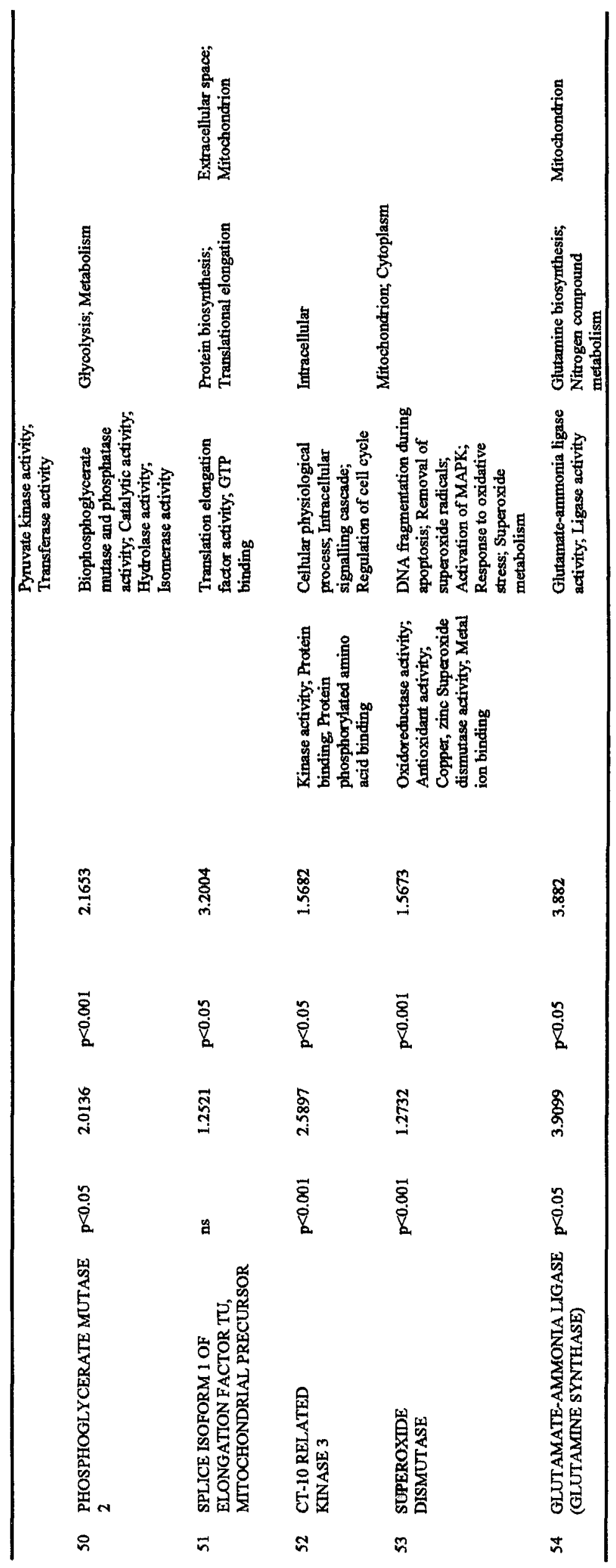




\section{Concluding remarks}

Investigations of the foetal and aged brain increase our knowledge of neuronal life in health and disease. Some studies on normal and diseased foetal and aged brains have been undertaken already $[3,9,10]$. In this study, we identified a number of differentially expressed proteins belonging to different functional groups (Table 2) and most of them have been described in the literature to be changed in different stages during brain development. However, to date we have not been able to identify all the proteins that we found to be differentially expressed in the different developmental stages. Moreover, a 2-D gel-based proteomic approach is not able to provide full coverage of the brain proteome. Our study has been limited to the use of $\mathrm{pH}$ 4-7 IPG IEF in the first dimension. While proteomic coverage could be extended using IPG strips covering other $\mathrm{pH}$ ranges, including narrow range "zoom" IPG, there will still be proteins whose $\mathrm{p} /$ values are extremely basic or extremely acidic so that they will fall outside of the $\mathrm{pH}$ range of the strips. Secondly, current labelling and staining methods are not sensitive enough for the detection of less abundant protein spots and more abundant spots can mask protein spots with a lower abundance [14]. In addition, proteins might be lost during sample preparation [39].

These problems apply to all 2-DE-based proteomic approaches, whether they employ $\mathrm{CBB}$, silver staining or CyDye-labelling for protein detection. The major point that makes a 2D DIGE approach superior to other 2-D gel-based techniques is the use of a "pooled" internal standard sample labelled with $\mathrm{Cy} 2$ for normalisation between gels. This makes gel-to-gel comparison and spot quantitation much more rigorous $[1,7,24,30,37]$, and we have clearly demonstrated that advantage in the present study.

Several aspects of the current study demonstrate that the 2-D DIGE approach is a potentially fruitful approach for analyzing brain development. First, the DIGE labelling is a sensitive technique with a large dynamic range, which makes the detection of proteins of both low and high abundance possible and quantitation robust. Secondly, the high significance levels that are reached reflect the reliability of the quantitative analysis and the normalization power when using an internal standard. Thirdly, the proteins that we identified showed expression patterns that are similar to expression patters revealed in previous studies by using other techniques.

Based on the 2-D DIGE and subsequent MS analysis of mouse brain from embryonic, juvenile and adult animals, we can tentatively suggest that proteins involved in the establishment of basic structures of the brain are expressed highest in the embryonic mouse. Proteins involved in the development of the brain are expressed highest in the juvenile phase and proteins that make utilization of the brain possible by delivering energy are expressed highest in the adult mice.

These results make us confident that further proteomic analysis using 2-D DIGE will reveal new insights in brain development, possibly discovering new proteins or new functions for known proteins. A more spatio-temporal detailed approach will be useful for a better understanding of the biological processes involved in brain development.

\section{Acknowledgements}

This material is based upon works supported by the Science Foundation Ireland under Grant No. 04/RP1/B499 to MJD.

\section{References}


[1] A. Alban, S.O. David, L. Bjorkesten, C. Andersson, E. Sloge, S. Lewis, I. Currie, A novel experimental design for comparative two-dimensional gel analysis: twodimensional difference gel electrophoresis incorporating a pooled internal standard, Proteomics 3 (2003) 36-44.

[2] G.W. Allen, J. Liu, M.A. Kirby, M. De Leon, Induction and axonal localization of epithelial/epidermal fatty acid-binding protein in retinal ganglion cells are associated with axon development and regeneration, J Neurosci Res 66 (2001) 396-405.

[3] M. Bajo, J. Fruehauf, S.H. Kim, M. Fountoulakis, G. Lubec, Proteomic evaluation of intermediary metabolism enzyme proteins in fetal Down's syndrome cerebral cortex, Proteomics 2 (2002) 1539-1546.

[4] D. Berg, C. Holzmann, O. Riess, 14-3-3 proteins in the nervous system, Nat Rev Neurosci 4 (2003) 752-762.

[5] J.H. Brown, Z. Zhou, L. Reshetnikova, H. Robinson, R.D. Yammani, L.S. Tobacman, C. Cohen, Structure of the mid-region of tropomyosin: bending and binding sites for actin, Proc Natl Acad Sci U S A 102 (2005) 18878-18883.

[6] R. Butler, P.N. Leigh, J.M. Gallo, Androgen-induced up-regulation of tubulin isoforms in neuroblastoma cells, J Neurochem 78 (2001) 854-861.

[7] W. Chen, J. Ji, X. Xu, S. He, B. Ru, Proteomic comparison between human young and old brains by two-dimensional gel electrophoresis and identification of proteins, Int $\mathrm{J}$ Dev Neurosci 21 (2003) 209-216.

[8] X.Q. Chen, S. Liu, L.Y. Qin, C.R. Wang, Y.W. Fung, A.C. Yu, Selective regulation of 14-3-3eta in primary culture of cerebral cortical neurons and astrocytes during development, J Neurosci Res 79 (2005) 114-118.

[9] A. De Iuliis, J. Grigoletto, A. Recchia, P. Giusti, P. Arslan, A proteomic approach in the study of an animal model of Parkinson's disease, Clin Chim Acta 357 (2005) 202209.

[10] M. Fountoulakis, J.F. Juranville, M. Dierssen, G. Lubec, Proteomic analysis of the fetal brain, Proteomics 2 (2002) 1547-1576.

[11] F. Gharahdaghi, C.R. Weinberg, D.A. Meagher, B.S. Imai, S.M. Mische, Mass spectrometric identification of proteins from silver-stained polyacrylamide gel: a method for the removal of silver ions to enhance sensitivity, Electrophoresis 20 (1999) 601-605.

[12] A. Gorg, G. Boguth, C. Obermaier, A. Posch, W. Weiss, Two-dimensional polyacrylamide gel electrophoresis with immobilized $\mathrm{pH}$ gradients in the first dimension (IPG-Dalt): the state of the art and the controversy of vertical versus horizontal systems, Electrophoresis 16 (1995) 1079-1086.

[13] A. Gorg, W. Postel, J. Weser, S. Gunther, J.R. Strahler, S.M. Hanash, L. Somerlot, Elimination of point streaking on silver stained two-dimensional gels by addition of iodoacetamide to the equilibration buffer, Electrophoresis 8 (1987) 122-124.

[14] A. Gorg, W. Weiss, M.J. Dunn, Current two-dimensional electrophoresis technology for proteomics, Proteomics 4 (2004) 3665-3685.

[15] M. Hamacher, R. Apweiler, G. Arnold, A. Becker, M. Bluggel, O. Carrette, C. Colvis, M.J. Dunn, T. Frohlich, M. Fountoulakis, A. van Hall, F. Herberg, J. Ji, H. Kretschmar, P. Lewczuk, G. Lubec, K. Marcus, L. Martens, N. Palacios Bustamante, Y.M. Park, S.R. Pennington, J. Robben, K. Stuhler, K.A. Reidegeld, P. Riederer, J. Rossier, J.C. Sanchez, M. Schrader, C. Stephan, D. Tagle, H. Thiehle, J. Wang, J. Wiltfang, J. Shin Yoo, C. Zhang, J. Klose, H.E. Meyer, HUPO Brain Proteome Project: Summary of the Pilot Phase and Introduction of a Comprehensive Data Reprocessing Strategy, Proteomics 6 (2006) 5015-5029. 
[16] T. Hattori, N. Takei, Y. Mizuno, K. Kato, S. Kohsaka, Neurotrophic and neuroprotective effects of neuron-specific enolase on cultured neurons from embryonic rat brain, Neurosci Res 21 (1995) 191-198.

[17] M.Y. Heinke, C.H. Wheeler, J.X. Yan, V. Amin, D. Chang, R. Einstein, M.J. Dunn, C.G. dos Remedios, Changes in myocardial protein expression in pacing-induced canine heart failure, Electrophoresis 20 (1999) 2086-2093.

[18] J.H. Huck, N.M. Verhoeven, E.A. Struys, G.S. Salomons, C. Jakobs, M.S. van der Knaap, Ribose-5-phosphate isomerase deficiency: new inborn error in the pentose phosphate pathway associated with a slowly progressive leukoencephalopathy, Am J Hum Genet 74 (2004) 745-751.

[19] A. Kurtz, A. Zimmer, F. Schnutgen, G. Bruning, F. Spener, T. Muller, The expression pattern of a novel gene encoding brain-fatty acid binding protein correlates with neuronal and glial cell development, Development 120 (1994) 2637-2649.

[20] K.S. Lilley, D.B. Friedman, All about DIGE: quantification technology for differential-display 2D-gel proteomics, Expert Rev Proteomics 1 (2004) 401-409.

[21] Y. Liu, L.D. Longo, M. De Leon, In situ and immunocytochemical localization of EFABP mRNA and protein during neuronal migration and differentiation in the rat brain, Brain Res 852 (2000) 16-27.

[22] L. Luo, Actin cytoskeleton regulation in neuronal morphogenesis and structural plasticity, Annu Rev Cell Dev Biol 18 (2002) 601-635.

[23] W. Nicklas, P. Baneux, R. Boot, T. Decelle, A.A. Deeny, M. Fumanelli, B. IllgenWilcke, Recommendations for the health monitoring of rodent and rabbit colonies in breeding and experimental units, Lab Anim 36 (2002) 20-42.

[24] D.D. Pollak, K. Herkner, H. Hoeger, G. Lubec, Behavioral testing upregulates pCaMKII, BDNF, PSD-95 and egr-1 in hippocampus of FVB/N mice, Behav Brain Res 163 (2005) 128-135.

[25] T. Rabilloud, Two-dimensional electrophoresis of basic proteins with equilibrium isoelectric focusing in carrier ampholyte-pH gradients, Electrophoresis 15 (1994) 278282.

[26] L.S. Ramagli, L.V. Rodriguez, Quantitation of microgram amounts of protein in twodimensional polyacrylamide gel electrophoresis sample buffer., Electrophoresis 6 (1985) 559-563.

[27] L. Rossi, A. De Martino, E. Marchese, S. Piccirilli, G. Rotilio, M.R. Ciriolo, Neurodegeneration in the animal model of Menkes' disease involves Bcl-2-linked apoptosis, Neuroscience 103 (2001) 181-188.

[28] J.C. Sanchez, V. Rouge, M. Pisteur, F. Ravier, L. Tonella, M. Moosmayer, M.R. Wilkins, D.F. Hochstrasser, Improved and simplified in-gel sample application using reswelling of dry immobilized $\mathrm{pH}$ gradients, Electrophoresis 18 (1997) 324-327.

[29] J.N. Schofield, I.N. Day, R.J. Thompson, Y.H. Edwards, PGP9.5, a ubiquitin Cterminal hydrolase; pattern of mRNA and protein expression during neural development in the mouse, Brain Res Dev Brain Res 85 (1995) 229-238.

[30] J.E. Swatton, S. Prabakaran, N.A. Karp, K.S. Lilley, S. Bahn, Protein profiling of human postmortem brain using 2-dimensional fluorescence difference gel electrophoresis (2-D DIGE), Mol Psychiatry 9 (2004) 128-143.

[31] A. Tabernero, E.M. Lavado, B. Granda, A. Velasco, J.M. Medina, Neuronal differentiation is triggered by oleic acid synthesized and released by astrocytes, $\mathrm{J}$ Neurochem 79 (2001) 606-616.

[32] K. Toyo-oka, A. Shionoya, M.J. Gambello, C. Cardoso, R. Leventer, H.L. Ward, R. Ayala, L.H. Tsai, W. Dobyns, D. Ledbetter, S. Hirotsune, A. Wynshaw-Boris, 14-33 epsilon is important for neuronal migration by binding to NUDEL: a molecular explanation for Miller-Dieker syndrome, Nat Genet 34 (2003) 274-285. 
[33] M. Watanabe, T. Nagamine, K. Sakimura, Y. Takahashi, H. Kondo, Developmental study of the gene expression for alpha and gamma subunits of enolase in the rat brain by in situ hybridization histochemistry, J Comp Neurol 327 (1993) 350-358.

[34] J. Weekes, C.H. Wheeler, J.X. Yan, J. Weil, T. Eschenhagen, G. Scholtysik, M.J. Dunn, Bovine dilated cardiomyopathy: proteomic analysis of an animal model of human dilated cardiomyopathy, Electrophoresis 20 (1999) 898-906.

[35] R. Weitzdoerfer, M. Fountoulakis, G. Lubec, Aberrant expression of dihydropyrimidinase related proteins $-2,-3$ and -4 in fetal Down syndrome brain, $\mathrm{J}$ Neural Transm Suppl (2001) 95-107.

[36] M.B. Yaffe, How do 14-3-3 proteins work?-- Gatekeeper phosphorylation and the molecular anvil hypothesis, FEBS Lett 513 (2002) 53-57.

[37] J.X. Yan, A.T. Devenish, R. Wait, T. Stone, S. Lewis, S. Fowler, Fluorescence twodimensional difference gel electrophoresis and mass spectrometry based proteomic analysis of Escherichia coli, Proteomics 2 (2002) 1682-1698.

[38] J.X. Yan, R. Wait, T. Berkelman, R.A. Harry, J.A. Westbrook, C.H. Wheeler, M.J. Dunn, A modified silver staining protocol for visualization of proteins compatible with matrix-assisted laser desorption/ionization and electrospray ionization-mass spectrometry, Electrophoresis 21 (2000) 3666-3672.

[39] S. Zhou, M.J. Bailey, M.J. Dunn, V.R. Preedy, P.W. Emery, A quantitative investigation into the losses of proteins at different stages of a two-dimensional gel electrophoresis procedure, Proteomics 5 (2005) 2739-2747.

[40] C. Zwingmann, D. Leibfritz, Regulation of glial metabolism studied by 13C-NMR, NMR Biomed 16 (2003) 370-399. 


\title{
A Proteomic Investigation of Similarities between Conventional and Herbal Antidepressant Treatments
}

\author{
K. Pennington ${ }^{1,2}$, M. Föcking ${ }^{2}$, C.A. McManus ${ }^{1}$, C.M. Pariante ${ }^{3}$, M.J. Dunn ${ }^{1}$, \\ and D.R. Cotter ${ }^{2}$
}

'Proteome Research Centre, UCD Conway Institute, University College Dublin, Dublin, Ireland;

${ }^{2}$ Department of Psychiatry, Education and Research Centre, Royal College of Surgeons in Ireland, Beaumont Hospital, P.O. Box 1297, Beaumont Road, Dublin 9, Ireland; '3ection and Laboratory of Stress, Psychiatry and Immunology, Department of Psychological Medicine, Institute of Psychiatry, King's College London, London, UK

Journal of Psychopharmacology, 2008 Jun 18 [Epub ahead of print]. published on July 17,2008 as doi: $10.1177 / 0269881108091075$

\begin{abstract}
Increasing clinical evidence for the effectiveness of herbal antidepressants has led to investigations at the molecular level. Using two-dimensional gel electrophoresis, this study investigated similarities in protein expression between clomipramine, St John's wort and a Chinese herbal formula, xiao yao san, often used in mood disorder treatment. HT22 cells, derived from a mouse hippocampal cell line, were treated for 24 hours and protein expression compared with that of the untreated cells ( $n=4 /$ group). Forty-three protein spots were found to be significantly differentially expressed $(p<0.05)$ in more than one of the treatment groups. Twenty-nine of these were identified using mass spectrometry. The most affected proteins were those involved in the cytoskeleton and energy metabolism, and an up-regulation of vimentin by all three treatments was confirmed by western blotting. This study provides preliminary evidence for multiple common molecular targets between conventional and alternative antidepressants, which appear to collectively affect neuronal plasticity.
\end{abstract}

\section{Introduction}

The use of complementary and alternative medicine (CAM) in the treatment of depression is increasing and it has been shown that over $54 \%$ of patients with severe depression using conventional treatments used some form of alternative therapy in the past year of their illness [23]. Perhaps the most commonly associated and most researched CAM for the treatment of depression is the St John's Wort (SJW). Evidence is mounting for its use in the treatment of mild to moderate depression $[16,22,29,45]$ despite findings of interactions with conventional antidepressants and other unrelated medications such the contraceptive pill $[13,15,18]$. Jia-Wei-Xiao-Yao-San (XYS), a Chinese herbal formula given frequently for the treatment of affective disorders in Chinese medicine, has been found to be clinically effective in mood disorders $[49,50]$, and also as an adjunctive treatment with carbamazepine (CBZ) in alleviating the more depressive symptoms in the bipolar patients [51]. It is of interest therefore to compare the molecular actions of these 
herbal antidepressant treatments with pharmaceutical antidepressants in order to investigate whether they may be acting on similar molecular pathways.

The neurobiology of depression and the effects on signalling pathways of antidepressants are reviewed extensively elsewhere [11, 31]. However, of particular interest is the finding that chronic exposure to antidepressants exerts a direct effect on hippocampal neurogenesis in rats [12,30, 42]. In addition, another study [43] investigated the effects antidepressants had on hippocampal volumes using magnetic resonance imaging and found that decreased hippocampal volumes correlated with longer durations of untreated depressive episodes. It was concluded that antidepressants have a neuroprotective action on the hippocampus thus preventing the disease associated reduction previously reported [44].

The HT22 neuronal cell line is a subclone of the HT4 hippocampal cell line, primarily derived from mouse brain tissue [34]. Mature HT-4 cells take on properties of differentiated neurons [28]. As the hippocampus has been shown repeatedly to be an area of abnormality in schizophrenia and mood disorders [19], and an area of key importance in the actions of antidepressants $[12,30,42]$, it is of primary interest to investigate the effects of psychiatric medications on neurons obtained from this brain area. HT22 cells have been used to test the effects of clomipramine and other antidepressants previously [20], and are an ideal cell line to explore the molecular effects of antidepressants.

\section{Aims of current experiment}

This study primarily aimed to identify proteins up- and down-regulated by clomipramine, a conventional tricyclic antidepressant, St John's Wort and XYS. Proteins significantly altered by one or more treatment group were of primary interest. In order to investigate this, treatments were given in vitro to the hippocampal neuronal cell line HT22, and their effects on protein expression analysed using two-dimensional (2D) difference gel electrophoresis.

\section{Experimental procedures}

HT22 cells. HT22 neuronal cells were a gift from the laboratory of Thorsten Trapp in the Max Planck Institute of Neurological Research, Cologne, Germany. Cells were maintained at $37^{\circ} \mathrm{C}$ in Dulbecco's modified Eagle's medium (DMEM) (Biochrom:FG0435) supplemented with 5\% fetal calf serum (Biochrom:S0115), 1\% Penicillin/Streptomycin (Biochrom:A2213) and 0.5\% Amphotericin. Cells were maintained in a humidified atmosphere containing $5 \% \mathrm{CO}_{2}$. The day before cells were to be treated, they were split and cultured with fresh medium. The next morning, the medications were added to the medium and incubated for the required time period. Cells were approximately $90 \%$ confluent at the time of treatment.

Antidepressants and preparation. Clomipramine (C7291; Sigma, Dorset, UK) is a tricyclic antidepressant. Based on previous in vitro studies using clomipramine on neuronal cells $[35,37]$, a $10 \mu \mathrm{M}$ dose was used, made up in $0.1 \mathrm{M} \mathrm{HCl}$ as recommended by the suppliers. This concentration has been demonstrated to resemble the therapeutic plasma and brain levels of tricyclic antidepressants [21].

Powdered extracts of SJW and XYS were obtained from Kingham Herbs and Tinctures. These extracts were prepared individually by Sinecura (www.sinecura.be) who 
process the raw herbs by distillation and extraction. In addition, high performance liquid chromatography is carried out on each batch of herbs to identify the chemical components of each herb and formula in order to know the percentage of 'active ingredient' in each herbal extract. The SJW extract was standardised to $0.3 \%$ hypericin, one of the main active ingredients of the herb and is the substance most extracts used in previous studies have been standardised to [41]. The recipe used for XYS followed the ratios used in a recently published clinical study [50,51]. Table 1 illustrates the herbs this treatment consisted of, the \% of each used and the part of the plant extracted from. Stock solutions of SJW $(30 \mathrm{mg} / \mathrm{ml})$ and XYS $(50 \mathrm{mg} / \mathrm{ml})$ were infused in media by heating and shaking for 3 hours at $37 \mathrm{HC}$. This solution was centrifuged for 5 minutes at $1100 \mathrm{~g}$ and, due to the insoluble nature of some of the plant-based material present in the herbal extracts, the supernatant was removed and stored at $-20 \mathrm{C}$ for further analysis.

\begin{tabular}{|c|c|c|}
\hline Scientific name & $\begin{array}{l}\text { Major chemical composition } \\
\left(\% /{ }_{1}\right)\end{array}$ & $\%$ \\
\hline Bupleurum chinense DC & Saikosapomins (1) & 12.5 \\
\hline Scutellaria baicalensis Georgi & Baicalin (4) & 12.5 \\
\hline Prunus persica (Linn) Batsch & Prunussaponins (15) & 11.2 \\
\hline Paeonia suffruticosa Andr & Paeonol and paeonosides (1) & 9.7 \\
\hline Paeonia lactiflora Pall & Paeony glu cosides (2) & 9.7 \\
\hline Gardenia jasminoides Ellis & Gardenoside (1.8) & 9.7 \\
\hline Angelica sinensis (Oliv.) Diels & Ligustilide $(0.12)$ & 9.7 \\
\hline Atractylodes macrocephala Koidz & Atractylol $\{0.5\}$ & 8.3 \\
\hline Poriae $\operatorname{cocos}($ Schw.) Wolf & B-pachyman (3) & 6.9 \\
\hline Carthamus tinctorius L & Carthamone (2) & 5.6 \\
\hline Glycymriza uralensis Fisch.ex DC & Glycyrrhizin (2.5) & 4.2 \\
\hline
\end{tabular}

Table 1.: Herbs constituting the XYS formula obtained through personal communication with Dr Zhang who used the formula as an adjunctive treatment in patients suffering bipolar disorder [50, 51]. A powdered extract of these herbs in the exact ratios as that described in the left column above was obtained from Kingham Herbs and Tinctures, UK.

Dose ranges. To determine the dose ranges for each of the herbal medications a trypan blue cytotoxicity (dead cell) assay and a modified 3-(4, 5-dimethylthiazolyl-2)-2, 5diphenyltetrazolium bromide (MTT) cell viability (live cell) assay $[3,4]$ were carried out. Control untreated cells and clomipramine treated cells $(10 \mu \mathrm{M})$ were used as comparisons to find suitable dose ranges. Doses having neuronal viability effects similar to the conventional antidepressant were chosen from each of the herbal extracts to ensure comparability.

The modified MTT assay was used as described previously [4]. Briefly, cells were seeded in a $96-$ well plate with 2500 and 5000 cells/well. The following day, cells were either left as untreated controls or treated with clomipramine $(10 \mu \mathrm{M})$, St John's Wort (30, 15,3 , or $0.3 \mu \mathrm{g} / \mathrm{ml}$ ) or xiao yao san $(50$ or $10 \mu \mathrm{g} / \mathrm{ml})$ for 24 hours, with three repeats per treatment for both cell densities. After 24 hours of treatment, $50 \mu 1$ of MTT $(5 \mathrm{mg} / \mathrm{ml}$ in distilled water)/medium solution (ratio 1:10) was added to each well and incubated for 3.5 hours at $37^{\circ} \mathrm{C}$. Cells were lysed by adding $50 \mu$ l of solubilisation solution $(50 \% \mathrm{v} / \mathrm{v}$ dimethyl-formamide: $20 \% \mathrm{v} / \mathrm{v}$ SDS solution) and agitated for $30 \mathrm{mins}$ at room temperature. The absorption of the solution was measured at $570 \mathrm{~nm}$. For evaluation the mean 
background staining was subtracted and the mean optical density (OD) reading of the treated cells calculated as a percentage of the mean control values.

Treatment protocol. Previous cell culture studies on the effect of receptor changes in cells treated with clomipramine used an exposure time of 24 hours [35, 37]. In this study consecutive passages of cells were used with a single dose given at the beginning of the $24 \mathrm{hr}$ treatment period. For the proteomic part of the study, based on the results from the trypan blue and MTT assays, a single dose of each of the medications was given: $10 \mu \mathrm{M}$ for clomipramine, $3 \mathrm{mg} / \mathrm{ml}$ for SJ and $10 \mathrm{~g} / \mathrm{ml}$ for XYS. In order not to alter the contents of the medium and their proportions, only $10 \mu \mathrm{l}$ or less of liquid was added to the $10 \mathrm{ml}$ of media in each Petri dish. Two 10-cm Petri dishes were used per treatment per repeat. The control cases used for each of the repeats were left untreated without vehicle.

Sample preparation. After treatment cells were scraped into the media, collected in a falcon tube and centrifuged at $400 \mathrm{xg}$ for $4 \mathrm{~min}$. The supernatant was discarded and the pellet re-suspended in $1 \mathrm{ml}$ of phosphate buffered saline (PBS). The cells were spun briefly and any trace of the PBS was removed. In all, $500 \mu \mathrm{l}$ of lysis buffer $(9.5 \mathrm{M}$ Urea, $20 \mathrm{mM}$ Tris, 2\% 3-[(3-Cholamidopropyl)dimethylammonio]-1-propanesulfate (CHAPS, pH 8.5) was added to each cell pellet and homogenised using a pestle. The homogenate was vortexed and centrifuged for 5 minutes at $1000 \times \mathrm{g}$. This process was repeated two to three times until the sample was solubilised. As cells in culture often have high levels of salt and other non-protein impurities that interfere with $2 \mathrm{D}$ electrophoresis, each sample was subsequently precipitated using the $2 \mathrm{D}$ clean-up kit (GE Healthcare, Buckinghamshire, UK) following the supplier's protocol. The proteins were then pelleted and subsequently solubilised in the same volume of lysis buffer originally used.

Protein determination. A modified Bradford protein assay [5] was carried out in a 96 well microtitre plate. Each sample was assayed in triplicate. All samples had a protein concentration of between $2-5 \mathrm{mg} / \mathrm{ml}$.

2D difference gel electrophoresis. Two dimensional difference gel electrophoresis (2DDIGE) was carried out as described previously [14, 40]. In the current study, eight gels were run, with each gel containing two experimental samples and one from a pooled internal standard, which were labelled with a fluorescent $\mathrm{CyDye}(\mathrm{Cy} 3, \mathrm{Cy} 5$ or $\mathrm{Cy} 2)$. In order to reduce dye bias effects the samples from each group $(n=4)$ were run in equal numbers using Cy 3 and $\mathrm{Cy} 5$ (see Table 2).

\begin{tabular}{lllll}
\hline \multirow{2}{*}{$\begin{array}{l}\text { Gel } \\
\text { number }\end{array}$} & Condition & \multicolumn{3}{c}{ Fluorescent dye } \\
\cline { 3 - 5 } & & CY3 & CY5 & CY2 - internal standard \\
\hline 1 & Control & P61 & P62 & Pooled sample \\
2 & St Johns Wort & P61 & P62 & Pooled sample \\
3 & Xiao-yado-san & P61 & P62 & Pooled sample \\
4 & Clomipramine & P62 & P61 & Pooled sample \\
5 & Control & P63 & P64 & Pooled sample \\
6 & St Johns Wort & P63 & P64 & Pooled sample \\
7 & Xiao-yao-san & P64 & P63 & Pooled sample \\
8 & Clomipramine & P64 & P63 & Pooled sample \\
\hline
\end{tabular}

Table 2.: Experimental design for nunning 2D DIGE with cell culture samples 
Preliminary work indicated that good protein separation could be achieved with a $25 \mu \mathrm{g}$ protein loading of each sample and $\mathrm{pH}$ 4-7 immobilised $\mathrm{pH}$ gradient (IPG) strips (GE Healthcare) for the first dimension separation. CyDye solutions (GE Healthcare) were made up according to manufacturer's instructions to make a $200 \mathrm{nmol}$ solution of each dye. Cy2 was used as an internal standard to allow normalisation across the gels [1]. The internal standard was made using $40 \mu \mathrm{l}$ per sample of each of the experimental samples. This pool of samples was subsequently run on each gel alongside the experimental samples labelled with $\mathrm{Cy} 3$ or Cy5) and used to adjust for technical gel-to-gel variability across each of the gels [1].

Following in-gel rehydration, IPG strips were subsequently focussed using a Multiphor II Electrophoresis System (GE Healthcare) at $0.05 \mathrm{~mA}$ per strip for 75000 Volthours at $20^{\circ} \mathrm{C}$. Subsequently, strips were equilibrated as described previously [40]. Second dimension SDS-PAGE was performed using $1-\mathrm{mm} 12 \%$ polyacrylamide gels run overnight at $1-1.5 \mathrm{~W}$ per gel at $20^{\circ} \mathrm{C}$ in an Ettan DALT VI (GE Healthcare, UK) according to the supplier's instructions. Gels were scanned using a Typhoon 9410 imaging scanner (GE Healthcare, UK) using optimal photomultiplier tube voltages for each fluorescent image. Gel images were cropped before analysis and imported into the image analysis software. DeCyder 5.0 (GE Healthcare, UK). This software is relatively automated enabling protein spot detection, matching across gel images and quantitative between sample groups. Filtering of spots for detection was set at a limit of an integrated volume of $>40,000$. A master gel was chosen automatically by the software and used $t$ match protein spots across all the internal standard gels (Cy2 image). Individual sample spots are normalised as a ratio of the same spot in each of the internal standard image in each gel. Approximately 100 spots were checked manually for correct matching across gels before carrying out statistical analysis on the normal logged data set.

Statistical analysis. Statistical analysis of the protein spots was carried out using DeCyder 5.0. Independent $t$-tests between the control and each individual treatment group were carried out on all the analysis of variance (ANOVA ) significant protein spots. Protein spots found to be significantly altered between one or more treatment group were identified as being of significant interest $(p<0.05)$. These protein spots were then visually confirmed by checking their matching reliability between gels alongside investigating the size, shape and position of the spot on the gel. Statistical analysis for the MTT assays and Western blots was performed using independent $t$-tests against each individual treatment group versus untreated controls using SPSS 11.0 (SPSS Inc.).

Protein identification. Preparative gels were run to enable the removal and further analysis and identification of differentially expressed proteins using mass spectrometry. For this, a $1.5 \mathrm{~mm}$ gel was run with $400 \mu \mathrm{g}$ protein loading of the pooled homogenate used as the internal standard in the 2D-DIGE experiment. Subsequently, the gel was stained using a modified silver stain (PlusOne silver staining kit; GE Healthcare, UK) with slight modifications to ensure compatibility with mass spectrometry [47].

Protein spots of interest found to be suitable for downstream analysis were excised from the preparative gels, destained and digested with trypsin. Tandem mass spectrometry (LC-MS/MS) was carried out as described previously using a Finnigan LTQ (Thermo Fisher Scientific Inc., Breda, The Netherlands) mass spectrometer connected to a Surveyor chromatography system [14]. All MS/MS spectra were sequence database searched using either SEQUEST or X!Tandem using Proline, an in-house proteomics analysis platform (http://proteomics.ucd.ie). Further details of the search parameters used are described 
previously [40]. The MS/MS spectra were searched against the non-redundant Uniprot database.

Validation using Western Blots. As vimentin was one of the four proteins found to be affected by all three treatments tested, it was chosen to be tested for confirmation of altered expression using Western blotting. In all, $20 \mu \mathrm{g}$ of sample was loaded and resolved on 4$20 \%$ pre-cast gradient mini-gels (Pierce, Rockford, Illinois, USA). The gels were run at 100-mV constant voltage on the Bio-Rad mini-gel system (Hrfordshire, UK) until the dye front had migrated off the end of the gel and were subsequently electrophoretically transferred onto Hybond nitrocellulose membranes (GE Healthcare, UK). Blots were stained with Memcode (Piere, USA), an immunoblot-compatible total protein stain, and scanned to eable normalisation across lanes for equal protein loading. Membranes were blocked overnight (5\% non-fat dried milk in PBS-Tween) at $4^{\circ} \mathrm{C}$ and then incubated for 2.5 $\mathrm{h}$ at room temperature in anti-vimentin polyclonal antibody (a kind gift from Professor Marlene Rose, Imperial College, London) (diluted 1:500). Membranes were washed twice and incubated with anti-rabbit antibody (Promega, Madison, Wisconsin, USA) (diluted 1:7500) for $1 \mathrm{~h}$. After incubation in secondary antibody, the membranes were washed and visualised by enhanced chemluminescence (Pierce exposed to X-ray film and developed accordingly. Each experiment was repeated three times. The OD of the resultant bands was quantified using Quantity One image analysis software (Biorad). Bad densities were normalised against total band densities derived from the Memcode total protein stain; the mean relative expression of each protein was calculated.

\section{Results}

Cytotoxicity assay. Treatments resulting in $>50 \%$ of the cells exhibiting positivity for trypan blue were considered highly toxic to the HT22 cells. Based on these results only two doses of the SJW (10 and $3 \mu \mathrm{g} / \mathrm{ml}$ ) and XYS (50 and $10 \mu \mathrm{g} / \mathrm{ml})$ were considered suitable for further testing and experimental analysis using 2D-DIGE. These treatments in addition to $10 \mu \mathrm{M}$ clomipramine, all exhibited under $3 \%$ trypan blue staining.

Cell viability assay. The results from the MTT assays using the dose ranges determined by the Trypan blue assay are shown in Figure 1. 


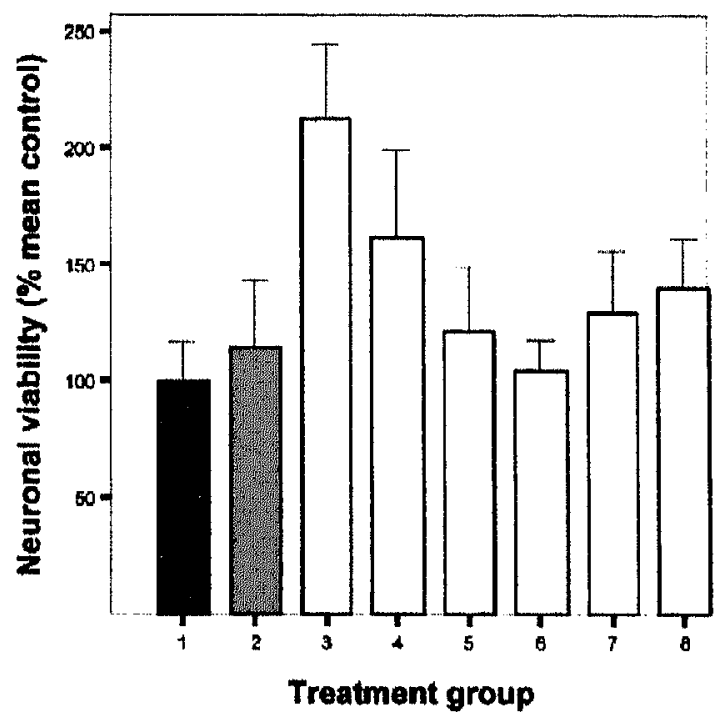

Figure 1 Effects of herbal and conventional psychiatric medication on neuronal viability. Cell viability was assayed using MTT, and all medication effects are expressed as a percentage of mean untreated control viability. Bars show means of each group, error bars show means $\pm 1.0 \mathrm{SD}$. An increase in cell viability was seen in all the treatments and doses investigated. Two of the SJW and XYS treatments were significant $(* 0,05 ; * * 0.01)$ compared with untreated controls using an independent t-test. Treatment groups: $1=$ untreated controls; $2=$ clomipramine $10 \mu \mathrm{M} ; 3=\mathrm{SJW} 30 \mu \mathrm{g} / \mathrm{mL} ; 4=\mathrm{SJW} 15 \mu \mathrm{g} / \mathrm{mL} ; 5=\mathrm{SJW} 3 \mu \mathrm{g} / \mathrm{mL} ; 6=$ SJW $0.3 \mu \mathrm{g} / \mathrm{mL} ; 7=$ XYS $50 \mu \mathrm{g} / \mathrm{mL} ; 8=$ XYS $10 \mu \mathrm{g} / \mathrm{mL}$.

The data presented were generated from the groups treated with 200 cells/well; however, the group treated with 5000 cells/well showed similar effects on neuronal viability. The MTT assay was used primarily to identify the dose for the herbal antidepressants to ensure they were not cytotoxic or causing decreased cell viability in the HT22 cells. Unexpectedly, it can be seen from this graph that the opposite was observed. Both the herbal and conventional antidepressant drug treatments appeared to cause an increase in cell viability compared with the untreated control group.

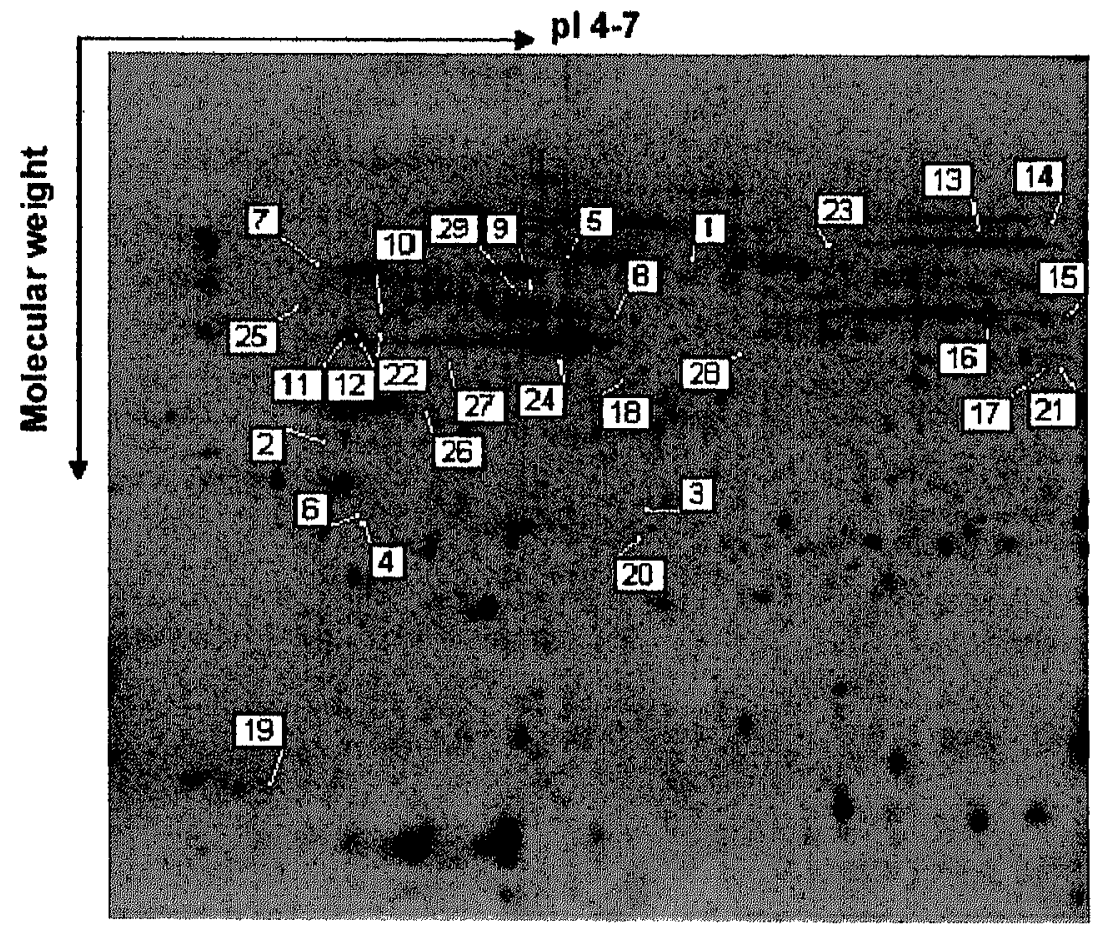

Figure 2.: Identified protein spots found to be significantly differentially expressed by one or more antidepressant treatment after $24 \mathrm{~h}$ exposure to a hippocampal neuronal cell line. 
Proteomic study findings. From the 1616 protein spots analysed in this study, 90 were found to be significantly differentially expressed $(\mathrm{p}<0.05)$ in the clomipramine-treated group, 64 in the SJW-treated group and 40 in the XYS-treated group in comparison with controls. Of these, 43 were found to exhibit significant differential expression in one or more of the three groups.

Following mass spectrometry, 29 of these 43 overlapping proteins were successfully identified and are listed in Table 3 (see Figure 2 for visualisation of these protein spots).

\begin{tabular}{|c|c|c|c|c|c|c|c|c|}
\hline \multirow{2}{*}{$\begin{array}{c}\text { Spot } \\
\text { number }\end{array}$} & \multirow[t]{2}{*}{ Protein } & \multirow{2}{*}{$\begin{array}{c}\text { SWISS } \\
\text { PROT } \\
\text { nccession } \\
\text { number }\end{array}$} & \multicolumn{3}{|c|}{ Fold changes in protein expression } & \multirow{2}{*}{$\begin{array}{l}\text { Number of } \\
\text { peptdes } \\
\text { matched }\end{array}$} & \multirow{2}{*}{$\begin{array}{l}\% \text { sequence } \\
\text { covernge }\end{array}$} & \multirow{2}{*}{$\begin{array}{l}\text { Observed } \\
\text { pI/mans } \\
\text { (KDa) }\end{array}$} \\
\hline & & & $\begin{array}{l}\text { Clomi- } \\
\text { pramine }\end{array}$ & $\begin{array}{l}\text { St John's } \\
\text { Wort }\end{array}$ & $\begin{array}{l}\text { Xtao Yao } \\
\text { San }\end{array}$ & & & \\
\hline \multicolumn{9}{|c|}{ Axonal oatgrowth } \\
\hline 1 & DRP-2 & 008553 & $2.04^{*}$ & $1.98^{*}$ & & 2 & 5.4 & $5.6 / 55.8$ \\
\hline 2 & DRP-2 & & $1.23^{*}$ & $1.18^{*}$ & & 12 & 23.9 & \\
\hline \multicolumn{9}{|c|}{ Calclum ion transport } \\
\hline 3 & $\begin{array}{l}\text { Chloride intracellular channol } \\
1\end{array}$ & Q9Z1Qs & & $-1.28^{*}$ & $-1.37^{*}$ & 1 & 4.7 & $5.5 / 28.7$ \\
\hline \multicolumn{9}{|l|}{ Cell sigmalling } \\
\hline 4 & 14-3-3 alpha/beta & Q9CQV8 & & $1.12^{* *}$ & $1.34^{* *}$ & 3 & 11.4 & $4.7 / 39.0$ \\
\hline 5 & 14-3-3 zeta/delta & P29312 & & $-1.34^{*}$ & $-1.36 *$ & 2 & 10.6 & $4.7 / 39.0$ \\
\hline 6 & 14-3-3 zeta/delta & & & $1.21 * *$ & $1.14^{*}$ & 11 & 21.2 & \\
\hline 7 & Zinc-finger protein 259 & Q62384 & $1.46^{* * *}$ & $1.61 * *$ & & & & $4.3 / 50.7$ \\
\hline \multicolumn{9}{|l|}{ Cytoskeletul } \\
\hline 8 & BRG-1 associated factor $A$ & Q9Z2N8 & & $1.25 * *$ & $1.2^{*}$ & 5 & 14.5 & $4.25 / 47.4$ \\
\hline 9 & Vimentin & P20152 & $1.8^{* * *}$ & & $1.96^{* *}$ & 8 & 20 & $4.3 / 53.5$ \\
\hline 10 & Vimentin & & $2.1^{* *}$ & $1.4^{*}$ & & 18 & 28.2 & \\
\hline 11 & Vimentin & & $2.86^{*}$ & $1.53^{*}$ & & 9 & 54.8 & \\
\hline 12 & Vimentin & & 2.63 *\# & $1.5^{*}$ & & 15 & 31.3 & \\
\hline 13 & WD-repeat protein 1 & 088342 & $-1.7^{* *}$ & $-1.89 * *$ & & 5 & 9.6 & $6.0 / 66.4$ \\
\hline 14 & Lamin A & P48678 & $-1.42^{*}$ & $.1 .31^{*}$ & & 21 & 35.6 & $6.7 / 59.0$ \\
\hline \multicolumn{9}{|c|}{ Energy metabolism } \\
\hline 15 & Alpha enolase & P17182 & $-1.7^{* *}$ & $-1.89 * *$ & & 9 & 13.4 & $5.5 / 57.6$ \\
\hline 16 & Alpha enolase & & $1.14^{*}$ & $1.26^{*}$ & $1.21^{*}$ & 20 & 59.6 & \\
\hline 17 & Alpha enolase & & & $1.19^{*}$ & $1.15^{*}$ & 8 & 32.3 & \\
\hline 18 & Creatine kinase, beta chain & Q04447 & & $-2.56^{*}$ & $-3.1 *$ & 14 & 35.2 & $4.5 / 26.7$ \\
\hline 19 & Creatine kinase, beta chain & & $1.26^{*}$ & $1.44^{* *}$ & $2.16^{*}$ & 3 & 8.9 & \\
\hline 20 & $\begin{array}{l}\text { Guanidinoacetate N- } \\
\text { methyltransforase }\end{array}$ & 035969 & $-1.2^{*}$ & & $-1.27 *$ & 2 & 8.9 & $5.5 / 37.8$ \\
\hline 21 & Pyruvate dehydrogenase & P35486 & $-1.18^{*}$ & $1.3^{* *}$ & & 4 & 8.2 & $6.7 / 47.8$ \\
\hline \multicolumn{9}{|c|}{ Proteln folding } \\
\hline 22 & Heat shock protein 70 & P20029 & $1.59 *$ & $1.9 * * *$ & $1,9 * *$ & 17 & 43.1 & $5.07 / 72.4$ \\
\hline 23 & T-Complex 1 & P80316 & & $-1.24 *$ & $-1.3^{*}$ & 7 & 13.5 & $6.0 / 59.6$ \\
\hline 24 & UBA/UBX protein & Q922Y1 & $1.19^{*}$ & & $1.45 * *$ & 6 & 30.3 & $4,3 / 33,6$ \\
\hline \multicolumn{9}{|c|}{ Proteln metaboliam } \\
\hline 25 & 26 s proteosome non-ATPase & 035226 & $-1.33^{*}$ & $-1.46^{*}$ & & $\mathbf{I}$ & 3.2 & $4.5 / 52.0$ \\
\hline \multicolumn{9}{|c|}{ Proteln synthesis } \\
\hline 26 & Nuoleophosmin & Q61937 & $1.19 * *$ & & $1.12^{*}$ & 3 & 15.4 & $4.9 / 44.9$ \\
\hline 27 & $\begin{array}{l}\text { Heterogenous nuclear } \\
\text { ribonucleoprotein } \mathrm{C} 1 / \mathrm{C} 2\end{array}$ & QZ204 & $1.52^{*}$ & & $1.48 *$ & 5 & 15.7 & $4.8 / 34.4$ \\
\hline 28 & Selenide & Q8BH69 & $-1.43^{*}$ & & $-1.49 *$ & 3 & 10.2 & $5.8 / 48.7$ \\
\hline \multicolumn{9}{|c|}{ Proteln transport } \\
\hline 29 & Ras-related protein Rab-7 & P51150 & $1.23^{*}$ & $1.36^{*}$ & & 4 & 20.3 & $5.2 / 53.1$ \\
\hline
\end{tabular}

Table 3.: Identified protein spots found to be significantly differentially expressed by more than one treatment group. 29 protein spots identified 19 unique proteins of which 7 were associated with the cytoskeleton and 7 with energy metabolism; the two areas most affected by these medications. $*=p<0.05$, $* *$ $=p<0.01, * * *=p<0.001$ (with independent $t$-tests treatment $v s$ control). 
Western Blotting. Levels of vimentin expression were found to be significantly increased in band 2 , but not band 1 or bands 1 and 2 combined, across all of the sample groups (ANOVA; $\mathbf{p}<0.006$ ). Independent t-tests with each of the treatment groups against the controls showed that all groups were significantly up-regulated (XYS, p $<0.019 ; \mathrm{SJW}$, $\mathrm{p}<0.002$; clomipramine, $\mathrm{p}<0.008$. Figure 3 shows the relative expression levels compared with control untreated cells and representative blots.

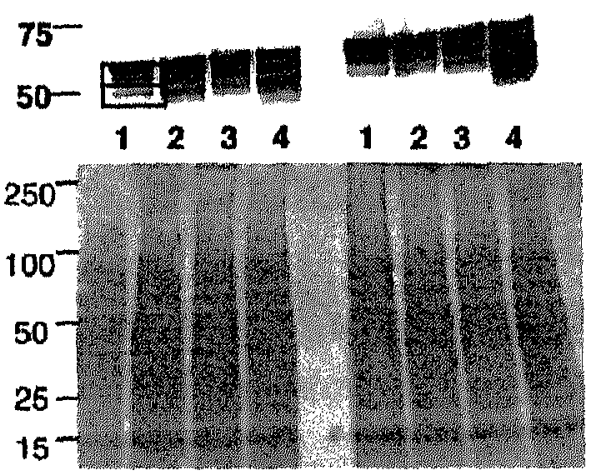

A

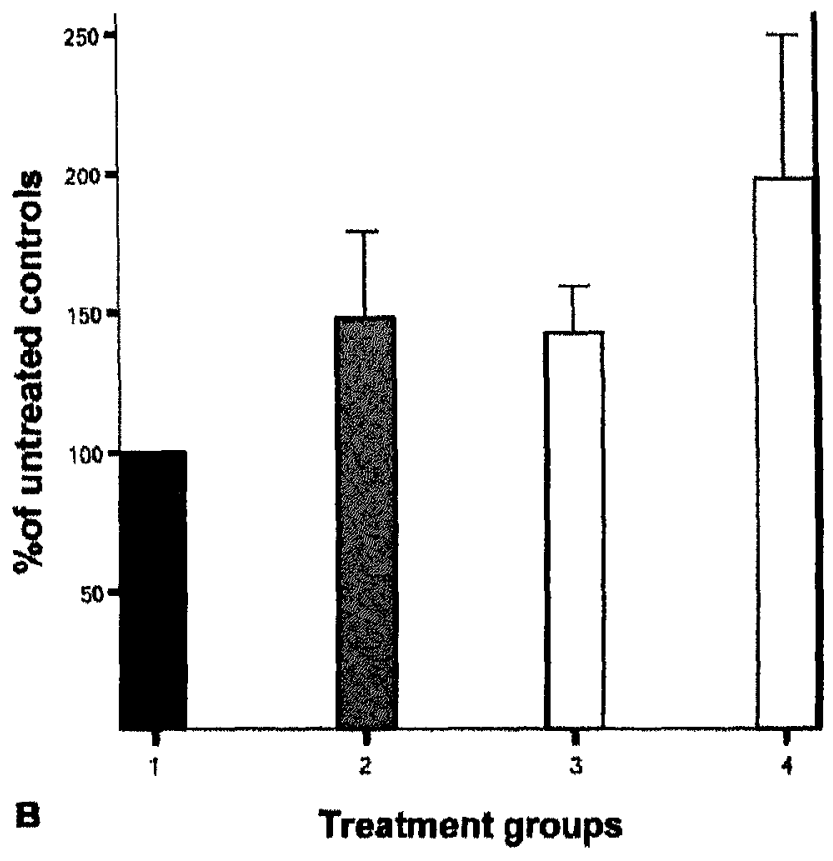

Figure 3.: Figure A shows a representative blot of the optical densities of vimentin in each of the sample groups $(1=$ control untreated; $2=$ xiao yao-san; $3=$ St John's Wort; $4=$ clomipramine $)$. Blots were run in triplicate for each of the four samples in each group. For analysis, the bands were split into two (see box outlines) and their expression levels normalised against the total protein stain (Memcode). Statistical analysis showed significant differences in each of the treatment groups compared with controls $(P<0.05)$ for band 2 only. Figure B shows the relative densities as a percentage of controls for band 2.

\section{Discussion}

In this study, the similarities in effects on protein expression of both conventional and herbal antidepressants in a hippocampal neuronal cell line were investigated. Forty three protein spots were found to be significantly altered $(p<0.05)$ in more than one treatment group with twenty nine of these subsequently identifying nineteen unique proteins. In all but one case (pyruvate dehydrogenase), the direction of change exhibited by the different medications was the same. In addition, there were four proteins that were significantly increased by all three treatment groups (alpha enolase, creatine kinase, heat shock protein70 [HSP70] and vimentin). Functionally, the proteins differentially expressed across treatments were classified into 8 different groups (see Table 3). Proteins involved in the cytoskeleton and energy metabolism were most affected by the antidepressants tested ( $n=7 /$ group) followed by those involved primarily in cell signalling, protein synthesis and protein folding. 
There have been five proteomic studies investigating the effects of antidepressants in vivo and in vitro to date $[6,8,17,24,32]$. Together these studies have found alterations in a number of the proteins presented in Table 3 , suggesting that these may be common molecular targets for antidepressant treatments. More specifically, DRP-2, a protein involved in axonal outgrowth and regeneration, has been found to be down-regulated in the rat hippocampus by a corticotrophin releasing factor receptor 1 inhibitor, and up-regulated by fluoxetine and an NK1 receptor antagonist in the frontal cortex [6]. Clomipramine and SJW were found to increase the expression of two forms of DRP-2 in our study in comparison with no treatment. Members of the HSP-70 family have been found to be increased in this study and in another recent study investigating the effects of treatment of the SSRI, paroxetine [32]. Furthermore, HSP-70 is a component of the multimeric complex comprising the glucocorticoid receptor, another transcription factor whose function has been repeatedly shown to be modified by antidepressant treatment in vitro [35-38]. 14-3-3 zeta/delta, alpha enolase and creatine kinase were found to be both increased and decreased in the current study and previous studies have reported similar findings $[6,8,24,32]$.

Proteins which have been previously implicated in psychiatric brain diseases may be expected to also be found to be differentially expressed by psychiatric medication. Of the proteomic studies which have been carried out investigating mood disorders in postmortem tissue, three proteins have been found to exhibit the same expression differences as those seen in the antidepressant treated neurons. More specifically, DRP-2 has been reported to be increased in major depression in the anterior cingulate cortex [2]. HSP-70 has been found to be increased in the bipolar disorder in the prefrontal cortex grey matter [40]. These findings suggest that some of the previous post-mortem proteomic findings in mood disorders may be due to antidepressant effects on the brain rather than the disease process per se and future work is required to clarify this issue.

\section{Functional implications of proteomic findings: focus on neuronal plasticity}

The proteins most affected by the antidepressant treatments in this study appear to be those involved in the cytoskeleton, energy metabolism, cell signalling, protein folding and protein synthesis. In addition all three treatments were shown to improve cell viability in the HT22 neuronal cells when compared with controls (see Figure 1). It is likely that this increase in cell viability is due to increased cell metabolism as the trypan blue assays did not show significant increases in cell number compared to controls. This supports the findings of significant alterations in metabolic proteins (alpha enolase, creatine kinase, guanidinoacetate $\mathrm{N}$-methyltransferase and pyruvate dehydrogenase) at the proteomic level in response to the antidepressant treatments.

Much of the evidence for clomipramine, SJW and XYS acting to enhance neuronal plasticity arises due to the multiple cytoskeletal proteins found to have altered expression in response to treatment. BRG-1 associated factor $\mathrm{A}$, otherwise known as actin-like protein $6 \mathrm{~A}$, was found to be increased by SJW and XYS, a protein involved in cell motility and the regulation of cell growth. Lamin A, an intermediate filament, was decreased significantly by clomipramine and SJW and is known to interact with zinc finger protein 259, a cell signalling protein found to be significantly increased in the same treatment groups. The protein that was found to exhibit the greatest abnormality was vimentin, where four forms were increased in the clomipramine and either SJW or XYS treatment groups. This is interesting as previous work has shown patients with depression have decreased vimentin in comparison with controls [7] and it has also been shown to be decreased by paroxetine in stem cells [32]. It is known that vimentin phosphorylation increases significantly during cell division when these intermediate filaments are significantly reorganised suggesting that increased expression would occur during cell division or reorganisation. 
Nucleophosmin, involved in protein synthesis, was found to be up-regulated in this study in clomipramine and XYS treated neurons. This protein is known to be anti-apoptotic and has been found to be up-regulated at the gene expression level in hippocampus and cortical regions of rat brain which were treated with an $\mathrm{N}$-methyl-diaspartic acid (NMDA) antagonist [27]. This study also found increases in RAB-2, from the same family of proteins as Ras-related $\mathrm{RAB} 7$ which we found to be increased, which the authors suggested may act to inhibit glutamate activation and reduce glutamate activity [27]. This is interesting given that this system is thought to be compromised in mood disorders [48]. In particular the findings suggest that many antidepressants have NMDA antagonistic actions at the neuronal level [39]. RABla and $4 \mathrm{a}$ of this protein family have also been found to be up-regulated in the hippocampus in a previous proteomic study of venlafaxine and fluoxetine treated rats [24] providing complimentary evidence for the action of antidepressants on this group of proteins.

\section{Antidepressant effects at the transcript level}

To relate our proteomic findings with those at the transcript level, they were compared with those from recent microarray-based studies $[9,10,25,26,33,46]$. Landgrebe, et al. [26] analysed the effects of treatment with paroxetine (a selective inhibitor of the serotonin transporter) and mirtazapine (5-HT2 and 5-HT3 antagonists) in total mouse brain RNA. Paroxetine was found to predominantly affect the regulation of genes involved in metabolic pathways and cell structure, in agreement with our findings at the protein level. In contrast, mirtazapine treatment was found to mostly affect genes involved in cell cycle organisation. In an in vitro investigation using primary hippocampal neuronal culture [9], eight genes were found to be regulated by chronic treatment with desipramine. These were putative $\mathrm{v}$-fos transformation effector protein, vacuolar ATP synthase $16-\mathrm{kDa}$ proteolipid subunit, sodium channel 2 , aldehyde reductase + alcohol dehydrogenase, neuromodulin and cytosolic thymidine kinase were all increased by the treatment. Voltage-dependent P/Q-type calcium channel $\alpha$ lc subunit and somatostatin were all decreased. Although the authors focused on the value of neuromodulin in terms of its effects on neuronal outgrowth, the other transcripts also indicate altered metabolic function as a result of the antidepressant treatment. Another study looking at the effects of tricyclic antidepressants investigated the effects of imipramine on gene expression in the rat prefrontal cortex [25]. Rather than analysing individual genes, alterations in functional class members displaying similar expression profiles after antidepressant treatment were revealed through multivariate analysis. Genes encoding proteins involved in cyclic adenosine monophosphate (CAMP) metabolism, postsynaptic membrane proteins, serine proteases and proto-oncogenes were all overrepresented in their analysis. Again, these findings provide support for altered effects on metabolism of antidepressant drug treatments.

An interesting study [46] looked at SJW- and imipramine-induced gene expression profiles. From a total of 8799 genes; 66 were significantly differentially expressed in the SJW-treated rats and 74 in imipramine-treated rats compared with controls. Of these, six transcripts were altered by both treatments. Two transcripts associated with ribosomal proteins were up-regulated, and one for microtubule-associated protein $1 \mathrm{~A}$ was downregulated by both treatment groups compared with controls. These findings provide additional support for alterations in protein synthesis and cytoskeleton as a result of antidepressant treatment. Subsequent analysis consisting of splitting the significant transcripts into 12 functional groups showed that protein synthesis and energy metabolism were the areas most affected by the two treatments. Perhaps, of most relevance is a recent study [33] that investigated the genetic regulation of behavioural and neuronal responses to fluoxetine. Neuronal responses in the hippocampus were shown, using a whole genome 
microarray, to be associated with an upregulation of genes known to promote neuronal proliferation and survival. More specifically, from a total of 39,000 transcripts, 83 were found to be up-regulated and 17 downregulated by chronic fluoxetine treatment. In relation to the findings in our study, three vimentin transcripts were significantly up-regulated by fluoxetine, as well as two forms of HSP-1 and a transcript for chloride intracellular channel 1. Collectively, these studies appear to support the effect of altered metabolism and protein synthesis by different antidepressant treatments in addition to providing additional confirmation for cytoskeletal-related proteins to be molecular targets for these antidepressant medications. It remains to be established what the functional implications of these molecular actions may be in the depressed human brain.

\section{Limitations and future work}

A limitation of this study common to all high-throughput experimental procedures such as those in the area of proteomics is that at present the statistical analysis used does not generally take into consideration the issue of multiple comparisons. Consequently, from 1616 t-tests, 80 of the 194 protein spots found to be significant at the $5 \%$ level would be expected to be found by chance. However, confirmation of an up-regulation in vimentin using Western blotting suggests that these findings are not false positives. The other potential candidate proteins await confirmation through other methods before their relevance to the molecular actions of antidepressants is confirmed.

As this is the first study to investigate the potential overlapping effects of both herbal and conventional antidepressants at the proteomic level, our main intention was to investigate these substances on their own. However, given the evidence for XYS as an adjunctive treatment with $\mathrm{CBZ}$ for the treatment of bipolar disorder [50,51], it would be of interest to extend this work by looking at the differences between the molecular effects of these treatments alone and in combination at the in vitro level.

\section{Conclusions}

This preliminary study has investigated the protein expression profiles of four separately treated sets of hippocampal neuronal cells exposed to clomipramine, St John's Wort, Xiao Yao San or no treatment. The results from the comparison between the proteomic profiles of these samples suggests that these three treatments do share common molecular targets and that these appear to focus specifically on those proteins involved in the cytoskeleton, energy metabolism, cell signalling, protein synthesis and protein folding. These results support previous work indicating that antidepressants increase neuronal plasticity and provide some novel findings regarding the mechanisms by which they may do this.

\section{Acknowledgements}

KP would like to thank and acknowledge the support received from Dr Susil Kumar and Jamila Mitra Charitable Trust (UK), and the advice provided by Professor Zhang in the design of the Chinese herbal formula, XYS (FEWP). Access to and use of MS instrumentation of Conway Institute is gratefully acknowledged and we thank Dr Niaobh O'Donoghue, Kaspar Pedersen and Kieran Wynne for their technical assistance in mass spectrometry. In addition, we would like to thank the proteomics informatics group (http://proteomics.ucd.ie) for use of their Proline software. 


\section{References}

[1] A. Alban, S.O. David, L. Bjorkesten, C. Andersson, E. Sloge, S. Lewis, I. Currie, A novel experimental design for comparative two-dimensional gel analysis: two-dimensional difference gel electrophoresis incorporating a pooled internal standard, Proteomics 3 (2003) 36-44.

[2] C.L. Beasley, K. Pennington, A. Behan, R. Wait, M.J. Dunn, D. Cotter, Proteomic analysis of the anterior cingulate cortex in the major psychiatric disorders: Evidence for diseaseassociated changes, Proteomics 6 (2006) 3414-3425.

[3] C. Behl, J. Davis, G.M. Cole, D. Schubert, Vitamin E protects nerve cells from amyloid beta protein toxicity, Biochem Biophys Res Commun 186 (1992) 944-950.

[4] C. Behl, M. Widmann, T. Trapp, F. Holsboer, 17-beta estradiol protects neurons from oxidative stress-induced cell death in vitro, Biochem Biophys Res Commun 216 (1995) 473-482.

[5] M.M. Bradford, A rapid and sensitive method for the quantitation of microgram quantities of protein utilizing the principle of protein-dye binding, Anal Biochem 72 (1976) 248-254.

[6] L. Carboni, M. Vighini, C. Piubelli, L. Castelletti, A. Milli, E. Domenici, Proteomic analysis of rat hippocampus and frontal cortex after chronic treatment with fluoxetine or putative novel antidepressants: CRF1 and NKI receptor antagonists, Eur Neuropsychopharmacol 16 (2006) 521-537.

[7] A. Castilla, M.L. Subira, M.P. Civeira, J.I. Cuende, J. Prieto, [Monocytic dysfunction by opioid peptides in patients with major depression], Med Clin (Barc) 99 (1992) 241-243.

[8] D. Cecconi, S. Mion, H. Astner, E. Domenici, P.G. Righetti, L. Carboni, Proteomic analysis of rat cortical neurons after fluoxetine treatment, Brain Res 1135 (2007) 41-51.

[9] B. Chen, J.F. Wang, X. Sun, L.T. Young, Regulation of GAP-43 expression by chronic desipramine treatment in rat cultured hippocampal cells, Biological psychiatry 53 (2003) 530-537.

[10] B. Conti, R. Maier, A.M. Barr, M.C. Morale, X. Lu, P.P. Sanna, G. Bilbe, D. Hoyer, T. Bartfai, Region-specific transcriptional changes following the three antidepressant treatments electro convulsive therapy, sleep deprivation and fluoxetine, Mol Psychiatry 12 (2007) 167-189.

[11] C. D'Sa, R.S. Duman, Antidepressants and neuroplasticity, Bipolar Disord 4 (2002) 183194.

[12] R.S. Duman, S. Nakagawa, J. Malberg, Regulation of adult neurogenesis by antidepressant treatment, Neuropsychopharmacology 25 (2001) 836-844.

[13] E. Ernst, J.I. Rand, C. Stevinson, Complementary therapies for depression: an overview, Arch Gen Psychiatry 55 (1998) 1026-1032.

[14] M. Focking, P.J. Boersema, N. O'Donoghue, G. Lubec, S.R. Pennington, D.R. Cotter, M.J. Dunn, 2-D DIGE as a quantitative tool for investigating the HUPO Brain Proteome Project mouse series, Proteomics 6 (2006) 4914-4931.

[15] A. Fugh-Berman, Herb-drug interactions, Lancet 355 (2000) 134-138.

[16] B. Gaster, J. Holroyd, St John's wort for depression: a systematic review, Arch Intern Med $160(2000) 152-156$.

[17] P.C. Guest, M.R. Knowles, S. Molon-Noblot, K. Salim, D. Smith, F. Murray, P. Laroque, S.P. Hunt, C. De Felipe, N.M. Rupniak, G. McAllister, Mechanisms of action of the antidepressants fluoxetine and the substance $P$ antagonist L-000760735 are associated with altered neurofilaments and synaptic remodeling, Brain Res 1002 (2004) 1-10.

[18] S.D. Hall, Z. Wang, S.M. Huang, M.A. Hamman, N. Vasavada, A.Q. Adigun, J.K. Hilligoss, M. Miller, J.C. Gorski, The interaction between St John's wort and an oral contraceptive, Clin Pharmacol Ther 74 (2003) 525-535.

[19] P.J. Harrison, The hippocampus in schizophrenia: a review of the neuropathological evidence and its pathophysiological implications, Psychopharmacology (Berl) 174 (2004) 151-162. 
[20] A.S. Herr, A.F. Tsolakidou, A. Yassouridis, F. Holsboer, T. Rein, Antidepressants differentially influence the transcriptional activity of the glucocorticoid receptor in vitro, Neuroendocrinology 78 (2003) 12-22.

[21] P.D. Hrdina, T.C. Dubas, Brain distribution and kinetics of desipramine in the rat, Can J Physiol Pharmacol 59 (1981) 163-167.

[22] S. Kasper, I.G. Anghelescu, A. Szegedi, A. Dienel, M. Kieser, Superior efficacy of St John's wort extract WS 5570 compared to placebo in patients with major depression: a randomized, double-blind, placebo-controlled, multi-center trial [ISRCTN77277298], BMC Med 4 (2006) 14.

[23] R.C. Kessler, J. Soukup, R.B. Davis, D.F. Foster, S.A. Wilkey, M.M. Van Rompay, D.M. Eisenberg, The use of complementary and alternative therapies to treat anxiety and depression in the United States, Am J Psychiatry 158 (2001) 289-294.

[24] X. Khawaja, J. Xu, J.J. Liang, J.E. Barrett, Proteomic analysis of protein changes developing in rat hippocampus after chronic antidepressant treatment: Implications for depressive disorders and future therapies, J Neurosci Res 75 (2004) 451-460.

[25] J.E. Knuuttila, P. Toronen, E. Castren, Effects of antidepressant drug imipramine on gene expression in rat prefrontal cortex, Neurochemical research 29 (2004) 1235-1244.

[26] J. Landgrebe, G. Welzl, T. Metz, M.M. van Gaalen, H. Ropers, W. Wurst, F. Holsboer, Molecular characterisation of antidepressant effects in the mouse brain using gene expression profiling, J Psychiatr Res 36 (2002) 119-129.

[27] K.H. Lee, J.I. Ahn, D.H. Yu, H.C. Koh, S.H. Kim, B.H. Yang, Y.S. Lee, Y.S. Lee, Dextromethorphan alters gene expression in rat brain hippocampus and cortex, Int $J \mathbf{~ M o l}$ Med 11 (2003) 559-568.

[28] U. Lendahl, R.D. McKay, The use of cell lines in neurobiology, Trends Neurosci 13 (1990) 132-137.

[29] K. Linde, C.D. Mulrow, M. Berner, M. Egger, St John's wort for depression, Cochrane Database Syst Rev (2005) CD000448.

[30] J.E. Malberg, A.J. Eisch, E.J. Nestler, R.S. Duman, Chronic antidepressant treatment increases neurogenesis in adult rat hippocampus, J Neurosci 20 (2000) 9104-9110.

[31] H.K. Manji, W.C. Drevets, D.S. Charney, The cellular neurobiology of depression, Nat Med 7 (2001) 541-547.

[32] P.C. Mctlugh, G.R, Rogers, B. Loudon, D.M. Glubb, P.R. Joyce, M.A. Kennedy, Proteomic analysis of embryonic stem cell-derived neural cells exposed to the antidepressant paroxetine, J Neurosci Res 86 (2008) 306-316.

[33] B.H. Miller, L.E. Schultz, A. Gulati, M.D. Cameron, M.T. Pletcher, Genetic regulation of behavioral and neuronal responses to fluoxetine, Neuropsychopharmacology 33 (2008) 1312-1322.

[34] B.H. Morimoto, D.E. Koshland, Jr,, Induction and expression of long- and short-term neurosecretory potentiation in a neural cell line, Neuron 5 (1990) 875-880.

[35] C.M. Pariante, A. Hye, R. Williamson, A. Makoff, S. Lovestone, R.W. Kerwin, The antidepressant clomipramine regulates cortisol intracellular concentrations and glucocorticoid receptor expression in fibroblasts and rat primary neurones, Neuropsychopharmacology 28 (2003) 1553-1561.

[36] C.M. Pariante, R.B. Kim, A. Makoff, R.W. Kerwin, Antidepressant fluoxetine enhances glucocorticoid receptor function in vitro by modulating membrane steroid transporters, $\mathrm{Br} \mathrm{J}$ Pharmacol 139 (2003) 1111-1118.

[37] C.M. Pariante, A. Makoff, S. Lovestone, S. Feroli, A. Heyden, A.H. Miller, R.W. Kerwin, Antidepressants enhance glucocorticoid receptor function in vitro by modulating the membrane steroid transporters, Br J Pharmacol 134 (2001) 1335-1343.

[38] C.M. Pariante, B.D. Pearce, T.L. Pisell, M.J. Owens, A.H. Miller, Steroid-independent translocation of the glucocorticoid receptor by the antidepressant desipramine, Mol Pharmacol 52 (1997) 571-581.

[39] I.A. Paul, P. Skolnick, Glutamate and depression: clinical and preclinical studies, Ann N Y Acad Sci 1003 (2003) 250-272. 
[40] K. Pennington, C.L. Beasley, P. Dicker, A. Fagan, J. English, C.M. Pariante, R. Wait, M.J. Dunn, D.R. Cotter, Prominent synaptic and metabolic abnormalities revealed by proteomic analysis of the dorsolateral prefrontal cortex in schizophrenia and bipolar disorder, Mol Psychiatry (2007).

[41] M.D. Perloff, L.L. von Moltke, E. Stormer, R.I. Shader, D.J. Greenblatt, Saint John's wort: an in vitro analysis of $\mathrm{P}$-glycoprotein induction due to extended exposure, $\mathrm{Br} \mathrm{J}$ Pharmacol 134 (2001) 1601-1608.

[42] L. Santarelli, M. Saxe, C. Gross, A. Surget, F. Battaglia, S. Dulawa, N. Weisstaub, J. Lee, R. Duman, O. Arancio, C. Belzung, R. Hen, Requirement of hippocampal neurogenesis for the behavioral effects of antidepressants, Science 301 (2003) 805-809.

[43] Y.I. Sheline, M.H. Gado, H.C. Kraemer, Untreated depression and hippocampal volume loss, Am J Psychiatry 160 (2003) 1516-1518.

[44] Y.I. Sheline, P.W. Wang, M.H. Gado, J.G. Csemansky, M.W. Vannier, Hippocampal atrophy in recurrent major depression, Proc Natl Acad Sci U S A 93 (1996) 3908-3913.

[45] J.W. Williams, Jr., C.D. Mulrow, E. Chiquette, P.H. Noel, C. Aguilar, J. Cornell, A systematic review of newer pharmacotherapies for depression in adults: evidence report summary, Ann Intern Med 132 (2000) 743-756.

[46] M.L. Wong, F. O'Kirwan, J.P. Hannestad, K.J. Irizarry, D. Elashoff, J. Licinio, St John's wort and imipramine-induced gene expression profiles identify cellular functions relevant to antidepressant action and novel pharmacogenetic candidates for the phenotype of antidepressant treatment response, Mol Psychiatry 9 (2004) 237-251.

[47] J.X. Yan, R. Wait, T. Berkelman, R.A. Harry, J.A. Westbrook, C.H. Wheeler, M.J. Dunn, A modified silver staining protocol for visualization of proteins compatible with matrixassisted laser desorption/ionization and electrospray ionization-mass spectrometry, Electrophoresis 21 (2000) 3666-3672.

[48] C.A. Zarate, Jr., J. Du, J. Quiroz, N.A. Gray, K.D. Denicoff, J. Singh, D.S. Charney, H.K. Manji, Regulation of cellular plasticity cascades in the pathophysiology and treatment of mood disorders: role of the glutamatergic system, Ann N Y Acad Sci 1003 (2003) 273-291.

[49] L.D. Zhang, Y.L. Zhang, S.H. Xu, G. Zhou, S,B. Jin, Traditional Chinese medicine typing of affective disorders and treatment, Am J Chin Med 22 (1994) 321-327.

[50] Z.J. Zhang, W.H. Kang, Q. Li, Q.R. Tan, The beneficial effects of the herbal medicine Free and Easy Wanderer Plus (FEWP) for mood disorders: double-blind, placebo-controlled studies, J Psychiatr Res 41 (2007) 828-836.

[51] Z.J. Zhang, W.H. Kang, Q.R. Tan, Q. Li, C.G. Gao, F.G. Zhang, H.H. Wang, X.C. Ma, C. Chen, W. Wang, L. Guo, Y.H. Zhang, X.B. Yang, G.D. Yang, Adjunctive herbal medicine with carbamazepine for bipolar disorders: A double-blind, randomized, placebo-controlled study, J Psychiatr Res 41 (2007) 360-369. 


\title{
Chronic glucocorticoid receptor activation impairs CREB transcriptional activity in clonal neurons
}

\author{
Melanie Föcking, Irmgard Hölker, and Thorsten Trapp \\ Max-Planck-Institute for Neurological Research, Cologne, Germany \\ European Graduate School of Neurosciene (EURON), Maastricht, The Netherlands
}

Biochemical and Biophysical Research Communication 304: 720-723 (2003)

\begin{abstract}
Excessive circulating levels of glucocorticoids are thought to be associated with cognitive impairment. We provide evidence that chronic activation of the glucocorticoid receptor (GR) in clonal neurons inhibits the transcriptional activity of the cyclic AMP response element-binding protein (CREB) which is believed to be involved in memory processes. To investigate the underlying mechanism we studied the phosphorylation of CREB and found altered phosphorylation kinetics in neurons chronically treated with glucocorticoids. Our results demonstrate a hitherto unrecognized crosstalk between the cyclic AMP and glucocorticoid pathway and may provide the molecular basis for the effects of long-term glucocorticoid exposure on cognitive function.
\end{abstract}

\section{Introduction}

The mammalian organism responds to stress with increased secretion of glucocorticoids that act long lasting by altering gene expression $[1,2]$. The genomic effects of glucocorticoids are mediated by binding to two types of intracellular corticosteroid receptors, the mineralocorticoid and the glucocorticoid receptor (GR). Both receptors are ligand-activated transcription factors that belong to the steroid/thyroid hormone receptor superfamily [3, 4]. Via these receptor systems glucocorticoids modulate mood, behavior, memory and neuroendocrine function in the central nervous system [2, 5]. Moreover, physiological concentrations of glucocorticoids are crucial for neuronal survival, as both under- and overexposure to these hormones can accelerate degeneration of specific neurons $[5,6,7]$. It is common believe that excessive circulating levels of glucocorticoids due to chronic stress, hypersecretion in pathological conditions such as Cushing's disease, or the administration of exogenous glucocorticoids for therapeutic purposes are associated with cognitive impairment $[8,9]$.

CREB is a nuclear protein that modulates the transcription of genes regulated by CAMP-responsive promoters and therefore it couples synaptic activity to the expression of neuronal gene products that are important for survival, differentiation and synaptogenesis $[10,11,12]$. Moreover, there is increasing evidence from rodents, Aplysia and Drosophila that CREB-regulated gene expression is decisively involved in the complex pattern of memory formation and plays a role in addiction [13, 14, 15].

To gain further insight into the molecular mechanisms that underly the action of chronic glucocorticoid exposure on neurons and to test the hypothesis that CREB may be 
involved in glucocorticoid stress-modulated signal transduction we analysed CREB transcriptional activity in clonal neurons that were treated chronically with high concentration of the synthetic glucocorticoid dexamethasone by transient transfection with cyclic AMP responsive reporter gene plasmids.

\section{Materials and methods}

Cell culture. HT22 cells (murine hippocampal cell line; [16, 17]) were grown in Dulbecco's modified Eagle's medium supplemented with $10 \%$ fetal calf serum (FCS). For glucocorticoid long-term treatment $1 \mu \mathrm{M}$ dexamethasone was added every $24 \mathrm{~h}$ in fresh medium for at least 14 days. Control cells were treated in the same way with vehicle,

Transfection and reporter gene assay. Transfections were performed by lipofection using FuGene according to the instructions of the manufacturer (Roche Diagnostics, Mannheim, Germany). For the reporter gene assay cells were cotransfected with $1 \mu \mathrm{g}$ reporter plasmid (pMMTV-LUC [4], pCRE-LUC (BD Clontech, Heidelberg, Germany) or pTAL-LUC (BD Clontech, Heidelberg, Germany)) and $1 \mu \mathrm{g} \beta$-galactosidase expression vector ( $\mathrm{pCH} 110$, Pharmacia LKB, Freiburg, Germany). Transfected cells were incubated with substances as indicated in the figure legends. After $24 \mathrm{~h}$, cells were harvested and extracts were assayed for luciferase [18] and B-galactosidase [19] activity as a control for transfection efficiency. Luciferase activity was determined according to the instructions of the manufacturer (BD Clontech, Heidelberg, Germany). For the measurement of $\beta$-galactosidase activity $10 \mu \mathrm{l}$ cell extract and $25 \mu \mathrm{l}$ o-nitrophenyl- $\beta$-Dgalactopyranoside dissolved at a concentration of $2 \mathrm{mg} / \mathrm{ml}$ were added to $100 \mu \mathrm{l}$ assay buffer containing $60 \mathrm{mM} \mathrm{Na}_{2} \mathrm{HPO}_{4}, 40 \mathrm{mM} \mathrm{NaH}_{2} \mathrm{PO}_{4}, 10 \mathrm{mM} \mathrm{KCl}, 1 \mathrm{mM} \mathrm{MgCl}_{2}$ and 50 $\mathrm{mM}$ B-mercaptoethanol. After $15 \mathrm{~min}$ incubation at $37{ }^{\circ} \mathrm{C}$, the reaction was stopped by adding $50 \mu 11 \mathrm{M} \mathrm{Na}_{2} \mathrm{CO}_{3}$ and the optical density was determined.

Western blot. Hippocampal neurons (HT22) treated for different periods of time with $3 \mu \mathrm{M}$ forskolin or vehicle were harvested and boiled immediately in loading buffer containing $20 \%$ glycerol, $3 \%$ sodium dodecyl sulphate (SDS), 3\% 2-mercaptoethanol and bromophenol-blue for $10 \mathrm{~min}$. After measurement of total protein concentration, proteins (20 $\mu$ g/lane) were separated on a $12 \%$ SDS-polyacrylamide gel. Following tank blotting onto a nitrocellulose membrane (Amersham, Braunschweig, Germany) blots were blocked with 5\% blocking-grade (Bio-Rad Laboratories $\mathrm{GmbH}$, München, Germany) in phosphate buffered saline containing $0.05 \%$ Tween (PBS-T). The membranes were incubated at $4^{\circ} \mathrm{C}$ for about $12 \mathrm{~h}$ with a polyclonal antibody that specifically interacts with CREB phosphorylated at serine-133 (pCREB, 1:5000; Upstate Biotechnology Inc., Buckingham, UK). After five washes for $5 \mathrm{~min}$ in PBS-T, blots were incubated with horseradish-coupled anti-rabbit secondary antibody (1:2000; Amersham, Braunschweig, Germany) at room temperature for $1 \mathrm{~h}$. Finally, membranes were washed again and developed by using the Amersham ECL-system according to the manufacturer's instructions. Following stripping of the blot, membranes were incubated at $4^{\circ} \mathrm{C}$ for about $12 \mathrm{~h}$ with a polyclonal CREB-1 antibody (CREB-1 antibody, 1:500; Santa Cruz, Santa Cruz, USA) or the monoclonal antineuronal nuclei antibody (NeuN antibody MAB377, 1:3000; Chemicon, Hofheim, Germany). After five washes of 5 min each in PBS-T, blots were incubated with horseradish-coupled anti-mouse secondary antibody or anti-rabbit secondary antibody (both 1:2000; Amersham, Braunschweig, Germany) at room temperature for $1 \mathrm{~h}$. Once more, membranes were washed and developed using the Amersham ECL-system. 


\section{Results and discussion}

Clonal murine hippocampal neurons (HT22; [16]) were transfected transiently with the glucocorticoid-responsive MMTV-LUC reporter plasmid which encodes the mouse mammary tumor virus (MMTV) promoter that contains several glucocorticoid response elements (GREs) upstram of the luciferase (LUC) gene. Stimulation of transfected hippocampal cells with increasing concentrations of the synthetic GR agonist dexamethasone (Fig. 1) or the endogenous GR ligand corticosterone (data not shown) revealed dose-dependent reporter gene expression indicating the presence of functional GR which makes this cell line suitable for the purpose of our study.

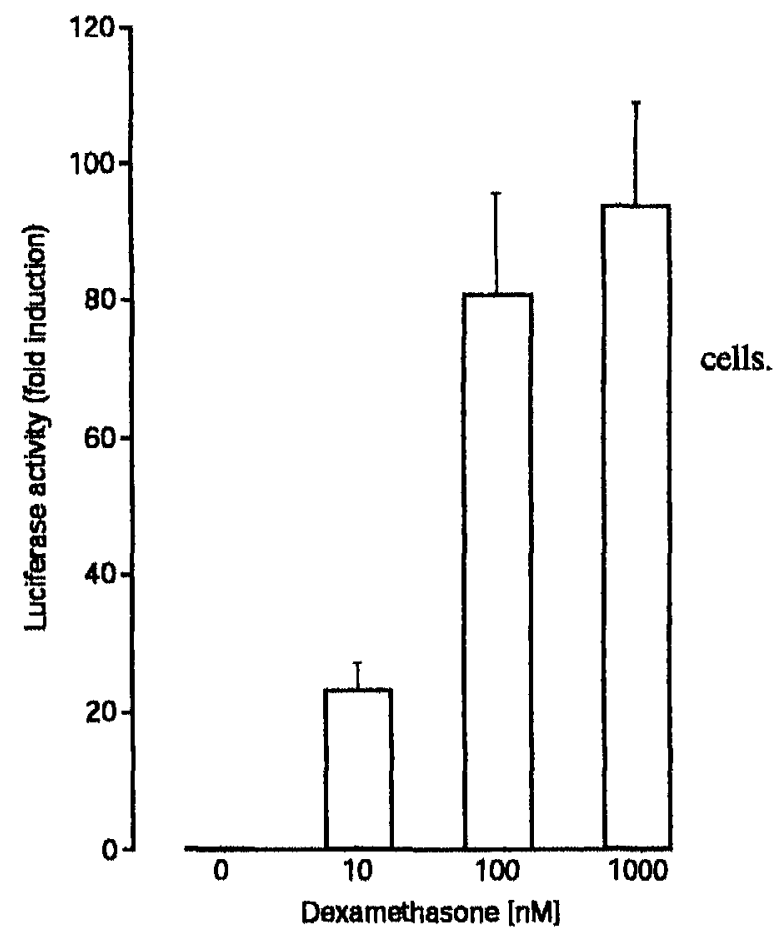

Fig. 1. Functional GRs are expressed in HT22

HT22 cells were transfected with $1 \mu \mathrm{g}$ of pMMTVLUC reporter plasmid and $1 \mu \mathrm{g}$ of $\beta$-galactosidase expression plasmid. Transfected hippocampal cells were stimulated with vehicle or dexamethasone in concentrations as indicated. The results are shown as fold induction of luciferase activity corrected for transfection efficiency by the corresponding $\beta$ galactosidase activity and are presented as the mean of three independent transfection experiments $\pm \mathrm{SEM}$.

Next, we analyzed the effect of chronical treatment of HT22 neurons with $1 \mu \mathrm{M}$ of the synthetic glucocorticoid dexamethasone on cyclic AMP-driven gene expression applying transient transfection of these cells with a reporter gene plasmid that encodes the LUC gene under the control of a cyclic AMP response element (CRE)- containing promoter. Activation of CREB with forskolin $(3 \mu \mathrm{M})$ resulted in a pronounced induction of the LUC reporter gene in control cells (Fig. 2). However, in clonal neurons chronically treated with dexamethasone, incubation with forskolin resulted in a much lesser induction of the reporter gene in comparison to control cells indicating an impairment of CREB function by long-term GR activation (Fig. 2). To ensure that the inhibition of transcriptional activity is specific for CREB-modulated transactivation and to normalize for transfection efficiency we cotransfected a plasmid constitutively expressing the $B$ galactosidase gene and corrected cyclic AMP-driven LUC expression by B-galactosidase activity. Transient transfection of a plasmid encoding the LUC structural gene regulated by a control promoter without a CRE (pTAL-LUC) revealed no difference in reporter gene expression between dexamethasone- and vehicle-treated neurons at the basal level and 
after forskolin exposure (Fig.2) once more indicating that chronic glucocorticoid treatment specifically influences CREB-modulated transactivation and does not act via an influence on the basic transcriptional or translational machinery.

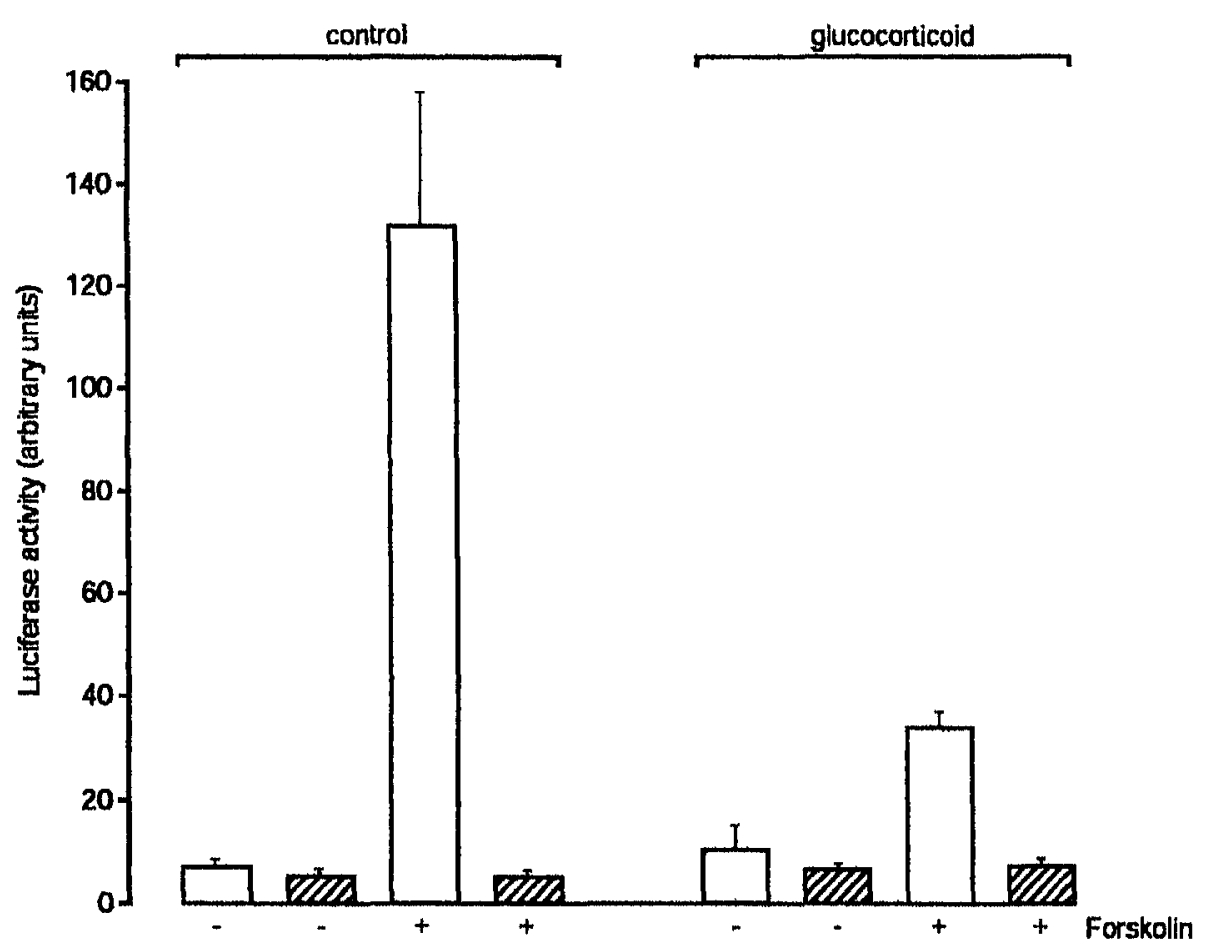

Fig. 2. Effects of chronic glucocorticoid exposure on the transcriptional activity of CREB. Long-term vehicle- (control) or dexamethasone-treated (glucocorticoid) HT22 cells were transfected with $1 \mu \mathrm{g}$ of pCRE-LUC (white bars) or pTAL-LUC (striped bars) reporter plasmid and $1 \mu \mathrm{g}$ of $\beta$-galactosidase expression plasmid. Transfected hippocampal cells were stimulated with vehicle or $3 \mu \mathrm{M}$ forskolin as indicated. The results are shown as arbitrary units of luciferase activity corrected for transfection efficiency by the corresponding $\beta$-galactosidase activity and are presented as the mean of three independent transfection experiments \pm SEM.

To gain further insight into the molecular mechanisms of the crosstalk between cyclic AMP- and glucocorticoid-modulated pathways, we studied the phosphorylation kinetics of CREB in vehicle- and dexamethasone-treated cells applying immunoblots and an antibody that specifically recognizes CREB phosphorylated at serine-133. Incubation with forskolin $(3 \mu \mathrm{M})$ resulted in a rapid phosphorylation of CREB after $15 \mathrm{~min}$ and a nearly complete dephosphorylation after $180 \mathrm{~min}$ in control cells (Fig. 3). However, in cells chronically treated with glucocorticoids phosphorylation as well as dephosphorylation was much less pronounced than in control cells (Fig. 3), which indicates a drastic change in the phosphorylation kinetics of CREB after chronic dexamethasone exposure. The specificity of these results is demonstrated by the fact that forskolin treatment as well as long-term glucocorticoid exposure did not influence the level of unphosphorylated CREB and neuronal nuclear proteins (NeuN; Fig. 3). Since it is well known that the dynamics of CREB phosphorylation and dephosphorylation account for differences in the activity of CRE-containing promotors $[20,21]$, our western blot results make likely that the impairment of CREB transcriptional activity in clonal neurons chronically treated with glucocorticoids is at least partly due to alterations of the phosphorylation kinetics of 
CREB. However, we can not exclude that in addition to this proposed mechanism chronic activation of the GR impairs CREB function also via other pathways.
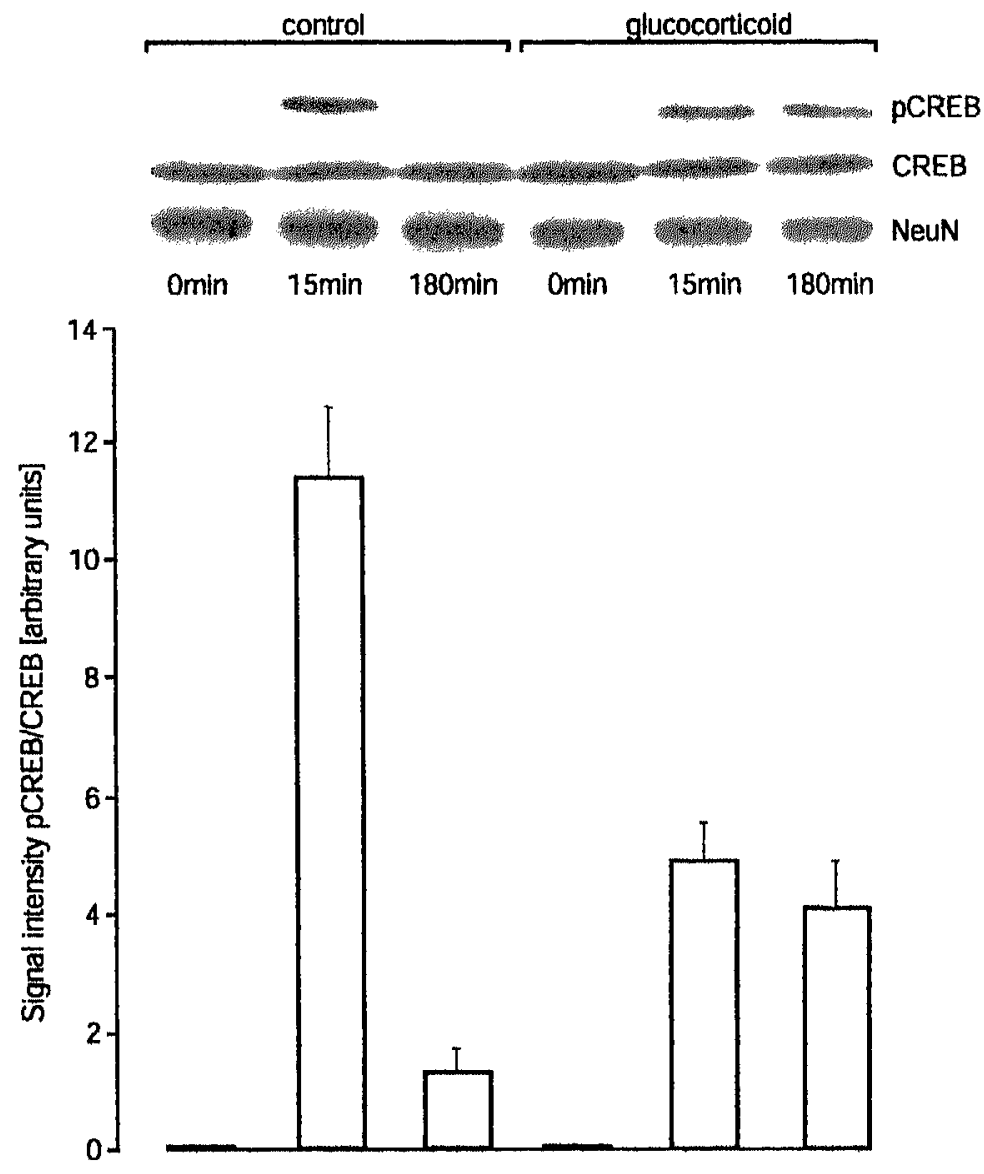

Fig. 3. Effects of chronic glucocorticoid exposure on the phosphorylation kinetics of CREB. Western blots were prepared using lysates of HT22 cells chronically exposed to vehicle (control) or $1 \mu \mathrm{M}$ dexamethasone (glucocorticoid) and treated for 0,15 and $180 \mathrm{~min}$ with forskolin. Immunoblots were incubated with antibodies that specifically recognize phosphorylated CREB (pCREB) at $43 \mathrm{kDa}$, unphosphorylated CREB (CREB) at $43 \mathrm{kDa}$ and $\mathrm{NeuN}$ at $66 \mathrm{kDa}$. The upper image shows a typical blot and the lower one represents the signal intensity of PCREB measured by densitometry and corrected by the signal intensity of unphosphorylated CREB. The mean of three independent experiments \pm SEM is presented.

Our results provide evidence that long-term activation of the GR in clonal neurons inhibits CRE-regulated gene expression which indicates that a hitherto unrecognized crosstalk between the glucocorticoid pathway and CREB exists. Previous studies have demonstrated that the activated GR is able to interact with different transcription factors, like NFkB [22], c-Jun [23], the nuclear orphan receptor ERR2 [24], and Stat5 [25]. Thereby, glucocorticoids are able to modulate the activity of promoters that do not contain GREs which drastically extends their potential to regulate gene expression. Whereas it is well documented that the activity of the GR can be enhanced by cAMP [26], this is the first report that demonstrates that long-term activation of the GR strongly modulates cAMPregulated gene expression. This new kind of interaction may be of importance especially in the central nervous system since CREB and the GR are widely co-localized in the brain and co-expressed in neurons. Moreover, since excessive circulating levels of 
glucocorticoids are believed to be associated with cognitive impairment and CREB is a key modulator of learning and memory, the crosstalk between the glucocorticoid pathway and CREB demonstrated in this study may provide the molecular basis for the effects of longterm glucocorticoid exposure on cognitive function.

\section{Acknowledgements}

This study has been supported by grants from the European Community (BIO4-CT98-0293 and QLG3-CT-2000-00934) and by a Marie Curie Fellowship of the European Community programm „Quality of Life and Management of Living Resources", under contract number QLK6-CT-2000-60042. The authors are grateful to P. Janus and D. Schmiegelt for excellent technical assistance and B. Huth for artwork. Moreover, we thank Dr. P. Maher for the gift of HT22 cells.

\section{References}

[1] H. Selye, Montreal Acta Medica, 1950.

[2] B. S. McEwen, J. M. Weiss, L. S. Schwartz, Selective retention of corticosterone by limbic structures in rat brain, Nature 220 (1968) 911-912.

[3] R. M. Evans, The steroid and thyroid hormone receptor superfamily, Science 240 (1988) 889-895.

[4] T. Trapp, R. Rupprecht, M. Castren, J. M. Reul, F. Holsboer, Heterodimerization between mineralocorticoid and glucocorticoid receptor: a new principle of glucocorticoid action in the CNS, Neuron 13 (1994) 1457-1462.

[5] P. W. Landfield, J. C. Waymire, G. Lynch, Hippocampal aging and adrenocorticoids: quantitative correlations, Science 202 (1978) 1098-1102.

[6] R. S. Sloviter, G. Valiquette, G. M. Abrams, E. C. Ronk, A. L. Sollas, L. A. Paul, S. Neubort, Selective loss of hippocampal granule cells in the mature rat brain after adrenalectomy, Science 243 (1989) 535-538.

[7] R. M. Sapolsky, Stress hormones: good and bad, Neurobiol. Dis. 7 (2000) 540-542.

[8] J. K. Belanoff, K. Gross, A. Yager, A. F. Schatzberg, Corticosteroids and cognition, J. Psychiatr. Res. 35 (2001) 127-145.

[9] E. R. de Kloet, M. S. Oitzl, M. Joels, Stress and cognition: are corticosteroids good or bad guys?, Trends Neurosci. 22 (1999) 422-426.

[10] P. K. Dash, K. A. Karl, M. A. Colicos, R. Prywes, E. R. Kandel, cAMP response elementbinding protein is activated by $\mathrm{Ca} 2+/$ calmodulin- as well as cAMP-dependent protein kinase, Proc. Natl. Acad. Sci. USA 88 (1991) 5061-5065.

[11] V. Delmas, M. C. A., E. Lalli, R. de Groot, N. S. Foulkes, D. S. Masquilier, P. SassoneCorsi, Complexity and versatility of the transcriptional response to cAMP, Rev. Physiol. Biochem. Pharmacol. 124 (1994) 1-24.

[12] A. E. West, E. C. Griffith, M. E. Greenberg, Regulation of transcription factors by neuronal activity, Nat. Rev. Neurosci. 3 (2002) 921-931.

[13] D. A. Frank, M. E. Greenberg, CREB: a mediator of long-term memory from mollusks to mammals, Cell 79 (1994) 5-8.

[14] A. J. Silva, J. H. Kogan, P. W. Frankland, S. Kida, CREB and memory, Annu. Rev. Neurosci. 21 (1998) 127-148.

[15] E. J. Nestler, Molecular basis of long-term plasticity underlying addiction., Nat. Rev. Neurosci. 2 (2001) 119-128.

[16] J. B. Davis,P. Maher, Protein kinase C activation inhibits glutamate-induced cytotoxicity in a neuronal cell line, Brain Res. 652 (1994) 169-173. 
[17] T. Trapp, L. Olah, I. Holker, M. Besselmann, C. Tiesler, K. Maeda, K. A. Hossmann, GTPase RhoB: an early predictor of neuronal death after transient focal ischemia in mice, Mol. Cell. Neurosci. 17 (2001) 883-894.

[18] J. R. de Wet, K. V. Wood, M. DeLuca, D. R. Helinsk, S. Subramani, Firefly luciferase gene: structure and expression in mammalian cells., Mol. Cell. Biol. 7 (1987) 725-737.

[19] P. Herbomel, B. Bourachot, M. Yaniv, Two distinct enhancers with different cell specificities coexist in the regulatory region of polyoma, Cell 39 (1984) 653-662.

[20] F. C. Liu,A. M. Graybiel, Spatiotemporal dynamics of CREB phosphorylation: transient versus sustained phosphorylation in the developing striatum, Neuron 17 (1996) 1133-1144.

[21] H. Bito, K. Deisseroth, R. W. Tsien, CREB phosphorylation and dephosphorylation: a $\mathrm{Ca}(2+)$ - and stimulus duration-dependent switch for hippocampal gene expression, Cell 87 (1996) 1203-1214.

[22] E. Caldenhoven, J. Liden, S. Wissink, A. Van de Stolpe, J. Raaijmakers, L. Koenderman, S. Okret, J. A. Gustafsson, P. T. Van der Saag, Negative cross-talk between RelA and the glucocorticoid receptor: a possible mechanism for the antiinflammatory action of glucocorticoids, Mol. Endocrinol. 9 (1995) 401-412.

[23] H. F. Yang-Yen, J. C. Chambard, Y. L. Sun, T. Smeal, T. J. Schmidt, J, Drouin, M. Karin, Transcriptional interference between c-Jun and the glucocorticoid receptor: mutual inhibition of DNA binding due to direct protein-protein interaction, Cell 62 (1990) 12051215 .

[24] T. Trapp, F. Holsboer, Nuclear orphan receptor as a repressor of glucocorticoid receptor transcriptional activity, J. Biol. Chem. 271 (1996) 9879-9882.

[25] E. Stocklin, M. Wissler, F. Gouilleux, B. Groner, Functional interactions between Stat5 and the glucocorticoid receptor, Nature 383 (1996).

[26] P.N. Rangarajan, K. Umesono, R. M. Evans, Modulation of glucocorticoid receptor function by protein kinase A, Mol. Endocrinol. 6 (1992) 1451-1457. 


\title{
Proteomics of experimental stroke in mice
}

\author{
M. Föcking ${ }^{2,3}$, M. Besselmann ${ }^{2,4}$, T. Trapp ${ }^{1,2}$
}

${ }^{1}$ Laboratory for Molecular Pathology and Neuroregeneration, Institute for Transplantation Diagnostics and Cell Therapeutics, Medical Center, Heinrich-Heine-University, Moorenstr. 5, Building 14.80, 40225 Düsseldorf, Germany; ${ }^{2}$ Max-Planck-Institute for Neurological Research, Gleueler Str. 50, 50931 Cologne, Germany; Department of Psychiatry, Education and Research Centre, Royal College of Surgeons in Ireland, Beaumont Hospital, P.O. Box 1297, Beaumont Road, Dublin 9, Ireland; ${ }^{4}$ Department of Neurology, University Medical Center Münster, AlbertSchweitzer-Str. 33, 48129 Münster, Germany

Acta Neurobiologiae Experimentalis 66:273-278 (2006)

\begin{abstract}
Multi-Western blots of more than 400 proteins were performed from brain extracts of mice submitted to transient focal ischemia induced by $1 \mathrm{~h}$ middle cerebral artery (MCA) thread occlusion. Measurements were carried out in groups of six animals in sham-operated controls, at the end of $1 \mathrm{~h}$ ischemia, and after 3 and $12 \mathrm{~h}$ recirculation. After MCA occlusion up to $45 \%$ of proteins were up- or downregulated in the ipsilateral hemisphere by a factor of 1.5 or more, as compared to sham-operated controls. The temporal regulation of several proteins in the ischemia-affected hemisphere after $1 \mathrm{~h} \mathrm{MCA}$ thread occlusion is described. In the non-ischemic hemisphere the number of regulated proteins was close to $50 \%$, indicating a hitherto unrecognized involvement of the opposite side. The proteomic approach of brain injury analysis goes beyond previous screenings of gene expression at the transcriptional level and although our study provides further evidence for the complexity of multi-injury pathways in the evolution of ischemic brain damage it may help to identify key mediators of ischemic injury.
\end{abstract}

\section{Introduction}

Brain ischemia produces tissue injury by two basically different mechanisms, which are broadly referred to as hemodynamic and molecular, respectively $[6,17]$. Hemodynamic injury results from the decline of blood flow below the threshold of energy failure, which in rodents amounts to approximately $20 \%$ of control flow and is histologically manifested as primary necrosis [12]. Molecular injury evolves in the absence of impaired energy metabolism, e.g. in the penumbra range of reduced blood flow during permanent vascular occlusion [25], or in areas in which energy metabolism recovers after transient vascular occlusion. Examples of molecular injury are delayed neuronal death in the selectively vulnerable areas of the brain after brief global ischemia [15], or delayed brain infarction after longer than 30 minutes of transient focal ischemia [7]. Histologically, this type of injury may be manifested as necrosis, apoptosis or a combination of both $[2,18,21,32]$. 
Intensive research into the mechanisms of molecular injury has led to the identification of a great number of injury pathways, which in specially sensitized experimental models can be alleviated by a multitude of pharmalogical interventions [6, $16,31]$. However, all of these drugs failed to improve ischemic brain damage under clinical conditions, indicating that the key mediator of this type of injury remains elusive $[5,9]$.

Searching for hitherto unknown molecular injury pathways, differential gene profiling techniques are increasingly used $[13,24,29,30]$. cDNA microarray studies from various laboratories suggest that the number of genes up- or downregulated after ischemia at the transcriptional level is very high, and even if only those genes are considered that are regulated by a factor of more than 10 , still close to $7 \%$ of the genome are involved [27]. However, a large part of these changes is only indirectly linked to the disease process. As molecular ischemic injury is heralded by an inhibition of global protein synthesis, many genes are superinduced due to the release of feedback control $[1,8]$. Others respond to periinfarct depolarization which leads to the sharp upregulation of various immediate-early genes [14]. Finally, the breakdown of the energy state in the core of the ischemic territory results in inhibition of transcription which may be misinterpreted as active down regulation. A more reliable association between molecular changes and injury evolution can, therefore, be expected when changes of gene products are analyzed at the translational level.

With the development of multi-Western blot techniques, such investigations have become feasible with high throughput. Here, we describe a study in which we take advantage of this new technology for the analysis of injury evolution after one-hour transient focal brain ischemia in the mouse.

\section{Methods}

Animal preparation. Focal cerebral ischemia was induced in C57Black/6J mice by occluding the MCA with the intraluminal filament technique [11]. Under light halothane anesthesia, a midline neck incision was made and the common and external carotid arteries were isolated and ligated. An 8-0 nylon monofilament (Ethilon; Ethicon, Norderstedt, Germany) coated with silicon resin (Xantopren, Bayer Dental, Osaka, Japan) was introduced through a small incision into the common carotid artery and advanced about $9 \mathrm{~mm}$ distal to the carotid bifurcation for occlusion of the MCA. The diameter of the silicon tip was matched to the body weight of the animal [11], and the correct position of the filament was identified by recording Laser-Doppler flow (LDF) from the ipsilateral parietal cortex. Recirculation was initiated at $1 \mathrm{~h}$ after MCA occlusion by removal of the intraluminal thread. Only those experiments were included for further analysis in which LDF declined to below $20 \%$ of control during thread insertion and promptly returned to above $80 \%$ of control after thread withdrawal. During surgery and up to the beginning of recirculation, rectal temperature was kept constant at $37^{\circ} \mathrm{C}$, using a feedback controlled heating lamp. For longer survival times, animals were returned to the cages with water and food ad libitum.

Multi-Western blots. Measurements were carried out in sham-operated controls, $1 \mathrm{~h}$ after MCA occlusion and at $3 \mathrm{~h}$ and $12 \mathrm{~h}$ reperfusion following $1 \mathrm{~h}$ MCA occlusion. Animals were sacrificed under anesthesia by decapitation. Brains were immediately removed, and ipsilateral and contralateral hemispheres were homogenized in lysis buffer (10 mM Tris, $\mathrm{pH}$ $7.4 ; 1 \mathrm{mM}$ sodium ortho-vanadate, $1 \%$ SDS). After adding an equal volume of 
electrophoresis buffer (125 mM Tris, $\mathrm{pH} \quad 6.8 ; 4 \%$ SDS; $10 \%$ glycerol; $0.006 \%$ bromophenol blue; $2 \% \beta$-mercaptoethanol) samples were heated at $95^{\circ} \mathrm{C}$ for 3 minutes. Electrophoresis was performed by BD PharMingen (Heidelberg) in triplicate on pooled samples from 6 animals in 5-15\% gradient SDS-polyacrylamide gels $(0.1 \times 16 \times 16 \mathrm{~cm})$. By using such a gradient system a wide range of proteins can be detected on the same gel (Fig. 1). Fourhundred micrograms of protein were loaded in one big well across the entire width of the gel. This translates into $\sim 15 \mu \mathrm{g}$ per lane on a standard 25 well gel. Gels were run overnight at room temperature and constant current in the $\mathrm{mA}$ range. Applying a wet electrophoretic transfer apparatus (TE Series, Hoefer) gels were then transferred to Immobilion-P nylon membrane (Millipore) for 1 hour at $1 \mathrm{~A}$. After transfer, membranes were blocked for one hour with $5 \%$ milk powder. Next, membranes were clamped with a Western blotting manifold that isolates 45 channels across the membrane. In each channel, a complex antibody cocktail (BD Biosciences, Heidelberg, Germany) is added and allowed to hybridize for one hour. Blots were removed from the manifold, washed and hybridized for 30 minutes with secondary goat anti-mouse horseradish peroxidase. Membranes were washed and bands were visualized by chemiluminescence. Data analysis includes raw and normalized digital data from each blot.

\section{Results}

The evolution of ischemic injury after one hour MCA thread occlusion in C57Black/6J mice has been described before $[10,26]$. At the end of ischemia, both energy metabolism and protein biosynthesis are severely suppressed in the territory of the occluded MCA, the area of the cerebral protein synthesis (CPS) disturbance at the coronal level of caudate/putamen being about $50 \%$ larger than that of energy failure. After restoration of blood flow energy metabolism promptly recovers. CPS returns more slowly after recirculation times of more than six hours and is restored only in the most peripheral parts of the MCA territory, but never in the core region. In the area of persisting CPS, ATP secondarily fails, starting at three hours in the core of the MCA territory and then gradually expanding towards the more peripheral parts.

Secondary post-ischemic energy failure is accompanied by DNA fragmentations, as demonstrated by in situ nick translation (ISNT) for single and terminal-deoxynucleotidyl transferase-mediated dUTP-biotin nick end-labeling (TUNEL) for double-strand breaks. Single-strand breaks may become visible already at one hour after the beginning of recirculation, occasionally preceding energy failure $[20,26]$. In contrast, double-strand breaks either accompany or follow the secondary depletion of ATP [10].

Protein extracts were prepared from the ipsilateral (ischemic) and the contralateral (non-ischemic) hemisphere at the end of one hour MCA thread occlusion, and after 3 and 12 hours recirculation, respectively. Multi-Western blots (Fig. 1) were obtained from over 400 proteins, covering a wide spectrum of gene products associated with different physiological and pathological cell functions. 


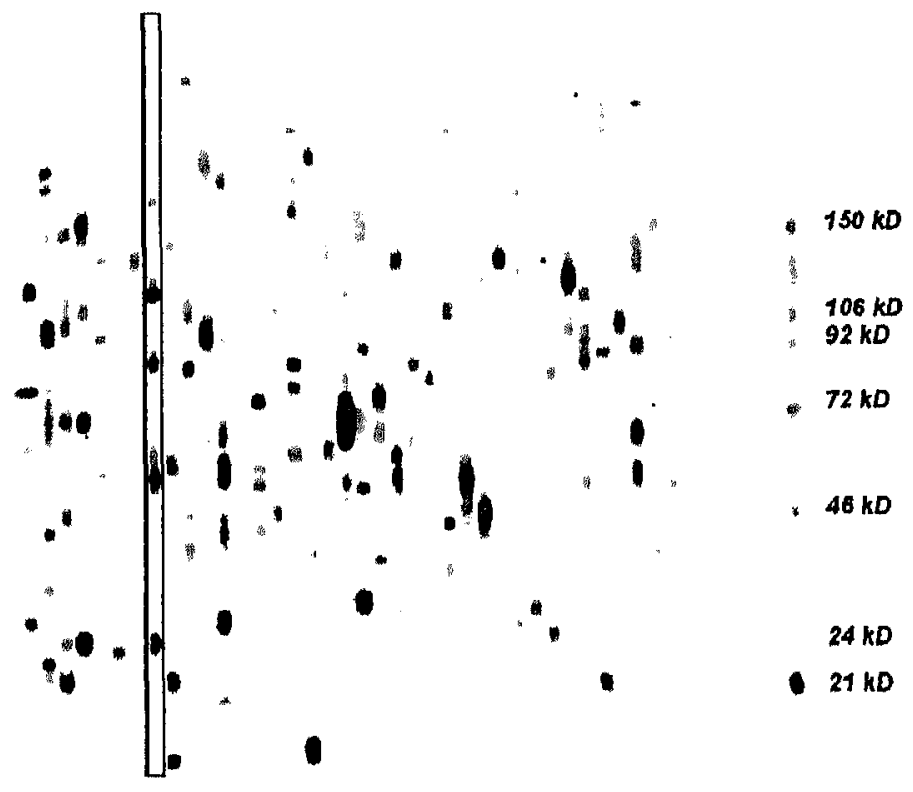

Fig. 1. Multi-Western blot of proteins extracted from mouse brain after $1 \mathrm{~h} \mathrm{MCA}$ occlusion. Proteins are arranged in 45 lanes per template, using up to 6 antibodies per lane for simultaneous detection of proteins with widely differing molecular weights. This results in simultaneous detection of up to 270 proteins per template. Proteins detected in one lane are exemplarily shown for lane 9 by framing.

Proteins were considered to be regulated during or after ischemia when the change compared to sham-operated controls - exceeded a factor of at least 1.5 in at least two of the three runs. Using this criterion, up to $45 \%$ of proteins were regulated in the ipsilateral and up to $49 \%$ in the contralateral hemisphere (Fig. 2).

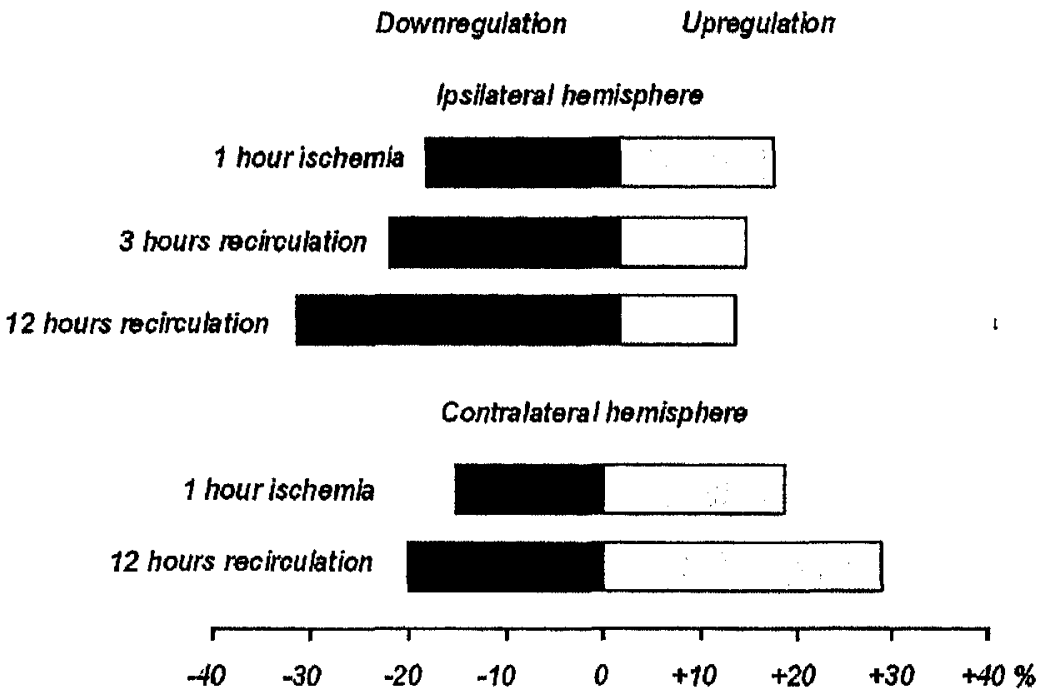

Fig. 2. Diagrammatic representation of protein regulation after $1 \mathrm{~h} \mathrm{MCA}$ occlusion, followed by 3 and $12 \mathrm{~h}$ recirculation in the ischemic hemisphere and $12 \mathrm{~h}$ recirculation in the non-ischemic hemisphere. Regulation was defined as a change by the factor of at least 1.5 as compared to sham-operated controls in at least two of the triplicate nuns. Note inverse shift of up- and downregulated genes in the ischemic hemisphere during recirculation, and the high number of both, up- and downregulated genes in the contralateral hemisphere. 
At the end of one-hour ischemia, the percentage of up- and downregulated proteins was $16 \%$ and $20 \%$ in the ischemic, and $19 \%$ and $15 \%$ in the non-ischemic hemisphere, respectively. During recirculation $(12 \mathrm{~h})$, both the number of upregulated proteins $(29 \%)$ and down-regulated proteins $(20 \%)$ increased in the non-ischemic hemisphere, but in the ischemic hemisphere the up-and downregulated proteins shifted inversely in accordance with the evolution of secondary injury ( $3 \mathrm{~h}$ recirculation: $13 \%$ and $24 \%, 12 \mathrm{~h}$ recirculation: $12 \%$ and $33 \%$ for up- and downregulation, respectively). The temporal dynamics of regulation differed greatly for different proteins, with all combinations of early or late up- or downregulation being possible. In the following we refer to downregulation if at one or more time points protein concentration decreased as compared to the sham-operated controls (excluding upregulations at other times) and to upregulation if at one or more time points protein concentration increased (including downregulations at other times).

Regulated proteins could be grouped into functionally related classes. Not surprisingly, both up- and downregulations were present in most protein classes, but a few groups deviated from this rule: in the ischemic hemisphere all proteins classified as protein phosphatases were upregulated whereas the majority of protein kinases and associated proteins were downregulated. There was also a remarkably high incidence of downregulation among proteins associated with cell adhesion, extracellular matrix and synaptic transmission whereas all proteins related to neurodegeneration and all but one protein involved in cell splicing were upregulated.

In Fig. 3 the temporal regulation profile of several proteins in the ischemia-affected hemisphere after $1 \mathrm{~h} \mathrm{MCA}$ thread occlusion is described. Proteins that show the same regulation at the end of cerebral ischemia and after 3 and 12 hours of recirculation are grouped.

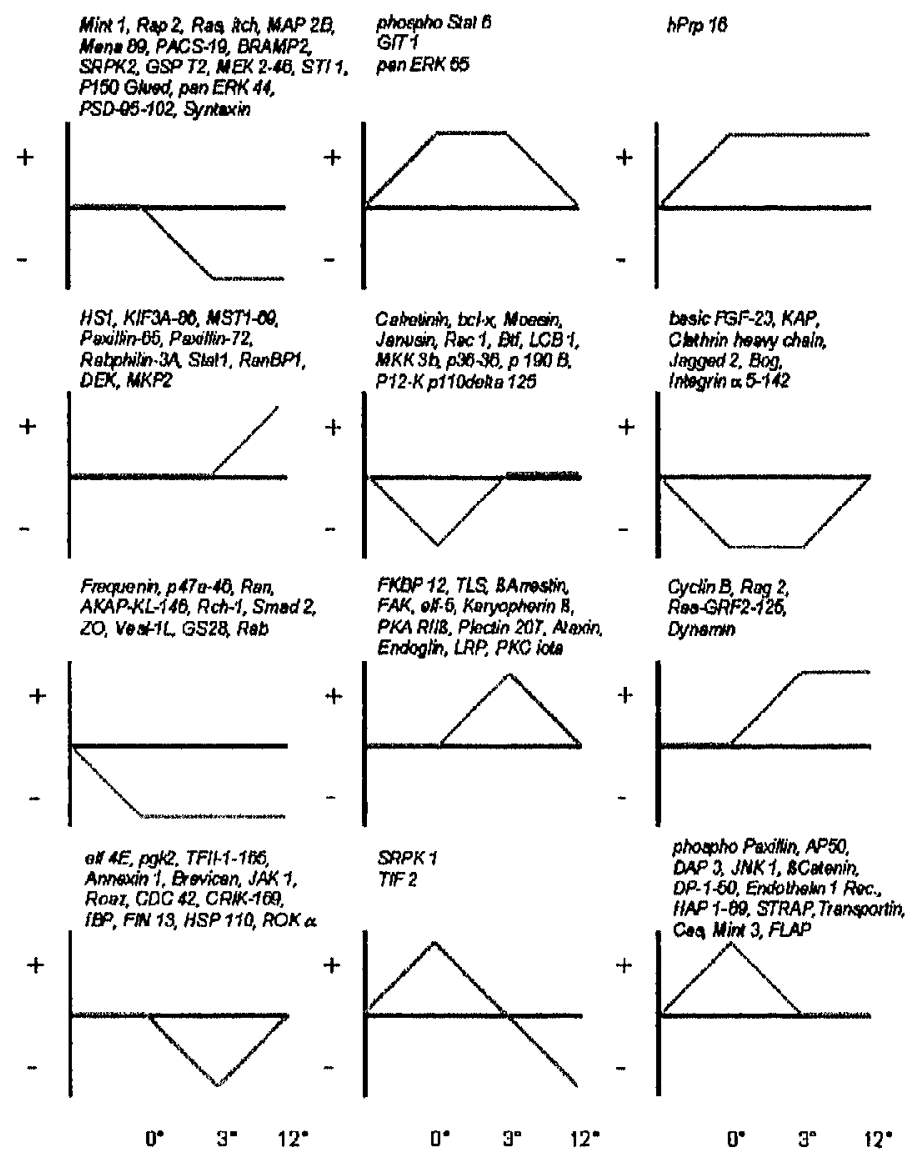

Fig. 3. Diagrammatic representation of protein regulation after $1 \mathrm{~h} \mathrm{MCA}$ occlusion, followed by 3 and $12 \mathrm{~h}$ recirculation in the ischemic hemisphere and $12 \mathrm{~h}$ recirculation in the non-ischemic hemisphere. Regulation was defined as a change by the factor of at least 1.5 as compared to sham-operated controls in at least two of the triplicate runs. Note inverse shift of up- and downregulated genes in the ischemic hemisphere during recirculation, and the high number of both, up- and downregulated genes in the contralateral hemisphere. 


\section{Discussion}

The reproducibility and reliability of the multi-Western blot approach was tested by triple repetition and by comparing the multi-blot measurements of selected proteins with conventional Western blots. Although the sensitivity of measurements varied in each of the three runs, only few of the triplicate recordings exhibited incoherent results, as compared to the sham-operated controls, demonstrating that the sign of expression - up- or downregulation - could be determined with high reproducibility. The reliability of measurements was also supported by the conventional Western blots which were in full agreement with multi-blot data.

The present results also agree well with previously published data. Although few of the investigated proteins have been studied under similar experimental conditions before, most of these were regulated in a similar way. Examples of concordant alterations are the upregulation of hypoxia-inducible factor-1 (HIF-1) [3], phosphotyrosine [4], cyclin [28] or the signal transducer and activator of transcription STAT3 [23]. For some proteins such as heat shock protein Hsp70 [19], ubiquitin (Ubc) [22] or synapsin [4] either the present or the earlier measurements failed to document significant changes.

An unexpected result was the large number of proteins that were up- or downregulated in the opposite, non-ischemic hemisphere. It has been established that acute focal ischemia evokes depolarizations which spread into the peri-infarct tissue and which lead to the upregulation of immediate early genes that function as transcription factors for a great number of other genes $[10,14]$. However, this response is strictly confined to the ipsilateral hemisphere and never spreads to the opposite side. The pronounced contralateral response must, therefore, be due to another mechanism, the kind of which remains to be clarified. It would be tempting to speculate that this phenomenon is associated with brain plasticity and/or transhemispheric diachisis but other - possibly unspecific - reactions are equally possible.

\section{Conclusions}

At the present state of the analysis, it is difficult to predict if this approach leads to the expected identification of a key mediator of ischemic injury. However, the diversity of the changes observed clearly demonstrates, that high-throughput screening methods are the only way to explore the full spectrum of pathophysiological changes and, therefore, are mandatory for approaching this goal. The investigation of the spatio-temporal regulation of selected proteins by immunohistochemistry has to clarify which of the proteins that show an interesting regulation pattern in our study are really associated with neuronal death or survival.

\section{Acknowledgements}

This study has been supported by grants from the European Community (BIO4-CT98-0293 and QLG3-CT-2000-00934) to T. Trapp. The authors are grateful to U. Beckmann, P. Janus, and D. Schmiegelt for excellent technical assistance. 


\section{References}

[1] Altus, M.S., Pearson, D., Horiuchi, A. and Nagamine, Y., Inhibition of protein synthesis in LLC-PK1 cells increases calcitonin-induced plasminogen-activator gene transcription and mRNA stability, Biochem J, 242 (1987) 387-92.

[2] Asahi, M., Hoshimaru, M., Uemura, Y., Tokime, T., Kojima, M., Ohtsuka, T., Matsuura, N., Aoki, T., Shibahara, K. and Kikuchi, H., Expression of interleukin-1 beta converting enzyme gene family and bcl-2 gene family in the rat brain following permanent occlusion of the middle cerebral artery, J Cereb Blood Flow Metab, 17 (1997) 11-8.

[3] Bergeron, M., Yu, A.Y., Solway, K.E., Semenza, G.L. and Sharp, F.R, Induction of hypoxia-inducible factor-1 (HIF-1) and its target genes following focal ischaemia in rat brain, Eur J Neurosci, 11 (1999) 4159-70.

[4] Bolay, H., Gursoy-Ozdemir, Y., Sara, Y., Onur, R., Can, A. and Dalkara, T., Persistent defect in transmitter release and synapsin phosphorylation in cerebral cortex after transient moderate ischemic injury, Stroke, 33 (2002) 1369-75.

[5] Del Zoppo, G.J., Why do all drugs work in animals but none in stroke patients? 1. Drugs promoting cerebral blood flow, J Intern Med, 237 (1995) 79-88.

[6] Dirnagl, U., Iadecola, C. and Moskowitz, M.A., Pathobiology of ischaemic stroke: an integrated view, Trends Neurosci, 22 (1999) 391-7.

[7] Du, C., Hu, R., Csernansky, C.A., Hsu, C.Y. and Choi, D.W., Very delayed infarction after mild focal cerebral ischemia: a role for apoptosis?, J Cereb Blood Flow Metab, 16 (1996) 195-201.

[8] Franco, A.R., Gee, M.A. and Guilfoyle, T.J., Induction and superinduction of auxinresponsive mRNAs with auxin and protein synthesis inhibitors, J Biol Chem, 265 (1990) 15845-9.

[9] Grotta, J., Why do all drugs work in animals but none in stroke patients? 2. Neuroprotective therapy, J Intern Med, 237 (1995) 89-94.

[10] Hata, R., Maeda, K., Hermann, D., Mies, G. and Hossmann, K.A., Evolution of brain infarction after transient focal cerebral ischemia in mice, J Cereb Blood Flow Metab, 20 (2000) 937-46.

[11] Hata, R., Mies, G., Wiessner, C., Fritze, K., Hesselbarth, D., Brinker, G. and Hossmann, K.A., A reproducible model of middle cerebral artery occlusion in mice: hemodynamic, biochemical, and magnetic resonance imaging, J Cereb Blood Flow Metab, 18 (1998) 36775.

[12] Hossmann, K.A., Viability thresholds and the penumbra of focal ischemia, Ann Neurol, 36 (1994) 557-65.

[13] Jin, K., Mao, X.O., Eshoo, M.W., Nagayama, T., Minami, M., Simon, R.P. and Greenberg, D.A., Microarray analysis of hippocampal gene expression in global cerebral ischemia, Ann Neurol, 50 (2001) 93-103.

[14] Kiessling, M. and Gass, P., Stimulus-transcription coupling in focal cerebral ischemia, Brain Pathol, 4 (1994) 77-83.

[15] Kirino, T., Tamura, A. and Sano, K., Selective vulnerability of the hippocampus to ischemia--reversible and irreversible types of ischemic cell damage, Prog Brain Res, 63 (1985) 39-58.

[16] Kuroda, S. and Siesjo, B.K., Reperfusion damage following focal ischemia: pathophysiology and therapeutic windows, Clin Neurosci, 4 (1997) 199-212.

[17] Lipton, P., Ischemic cell death in brain neurons, Physiol Rev, 79 (1999) 1431-568.

[18] Martin, L.J., Al-Abdulla, N.A., Brambrink, A.M., Kirsch, J.R., Sieber, F.E. and PorteraCailliau, C., Neurodegeneration in excitotoxicity, global cerebral ischemia, and target deprivation: A perspective on the contributions of apoptosis and necrosis, Brain Res Bull, 46 (1998) 281-309.

[19] Massa, S.M., Longo, F.M., Zuo, J., Wang, S., Chen, J. and Sharp, F.R., Cloning of rat grp75, an hsp70-family member, and its expression in normal and ischemic brain, $J$ Neurosci Res, 40 (1995) 807-19. 
[20] Mies, G., Trapp, T., Kilic, E., Olah, L., Hata, R. and Hermann, D.M., Relationship between DNA fragmentation, energy state and protein synthesis after transient focal cerebral ischemia in mice. In T. Kuroiwa (Ed.), Maturation Phenomenon in Cerebral Ischemia IV, Springer Verlag, Berlin, Heidelberg, New York, 2001, pp. 85-92.

[21] Nicotera, P., Leist, M. and Manzo, L., Neuronal cell death: a demise with different shapes, Trends Pharmacol Sci, 20 (1999) 46-51.

[22] Noga, M. and Hayashi, T., Ubiquitin gene expression following transient forebrain ischemia, Brain Res Mol Brain Res, 36 (1996) 261-7.

[23] Planas, A.M., Soriano, M.A., Berruezo, M., Justicia, C., Estrada, A., Pitarch, S. and Ferrer, I., Induction of Stat3, a signal transducer and transcription factor, in reactive microglia following transient focal cerebral ischaemia, Eur J Neurosci, 8 (1996) 2612-8.

[24] Read, S.J., Parsons, A.A., Harrison, D.C., Philpott, K., Kabnick, K., S, O.B., Clark, S., Brawner, M., Bates, S., Gloger, I., Legos, J.J. and Barone, F.C., Stroke genomics: approaches to identify, validate, and understand ischemic stroke gene expression, J Cereb Blood Flow Metab, 21 (2001) 755-78.

[25] Siesjo, B.K., Katsura, K., Zhao, Q., Folbergrova, J., Pahlmark, K., Siesjo, P. and Smith, M.L., Mechanisms of secondary brain damage in global and focal ischemia: a speculative synthesis, J Neurotrauma, 12 (1995) 943-56.

[26] Trapp, T., Olah, L., Holker, I., Besselmann, M., Tiesler, C., Maeda, K. and Hossmann, K.A., GTPase RhoB: an early predictor of neuronal death after transient focal ischemia in mice, Mol Cell Neurosci, 17 (2001) 883-94.

[27] Trendelenburg, G., Prass, K., Priller, J., Kapinya, K., Polley, A., Muselmann, C., Ruscher, K., Kannbley, U., Schmitt, A.O., Castell, S., Wiegand, F., Meisel, A., Rosenthal, A. and Dimag1, U., Serial analysis of gene expression identifies metallothionein-II as major neuroprotective gene in mouse focal cerebral ischemia, J Neurosci, 22 (2002) 5879-88.

[28] van Lookeren Campagne, M. and Gill, R., Increased expression of cyclin G1 and p21WAF1/CIP1 in neurons following transient forebrain ischemia: comparison with early DNA damage, J Neurosci Res, 53 (1998) 279-96.

[29] Wang, H., Zhan, Y., Xu, L., Feuerstein, G.Z. and Wang, X., Use of suppression subtractive hybridization for differential gene expression in stroke: discovery of CD44 gene expression and localization in permanent focal stroke in rats, Stroke, 32 (2001) 10207.

[30] Wang, X., Barone, F.C., White, R.F. and Feuerstein, G.Z., Subtractive cloning identifies tissue inhibitor of matrix metalloproteinase-1 (TIMP-1) increased gene expression following focal stroke, Stroke, 29 (1998) 516-20.

[31] White, B.C., Sullivan, J.M., DeGracia, D.J., O'Neil, B.J., Neumar, R.W., Grossman, L.I., Rafols, J.A. and Krause, G.S., Brain ischemia and reperfusion: molecular mechanisms of neuronal injury, J Neurol Sci, 179 (2000) 1-33.

[32] Zeng, Y.S. and $\mathrm{Xu}, \mathrm{Z} . \mathrm{C}$., Co-existence of necrosis and apoptosis in rat hippocampus following transient forebrain ischemia, Neurosci Res, 37 (2000) 113-25. 


\title{
Statins potentiate caspase-3 activity in immortalized neurons
}

\author{
M. Föcking, M. Besselmann, T. Trapp
}

Max-Planck-Institute for Neurological Research, Gleueler Strasse 50, D-50931 Cologne, Germany, European Graduate School for Neuroscience (EURON), Maastricht, The Netherlands

Neuroscience letters 355: 41-44 (2004)

\begin{abstract}
Statins are lipid-lowering drugs that have been shown to reduce atherosclerotic cardiovascular morbidity and mortality. However, there is growing evidence from epidemiological studies that long-term treatment with statins has unwanted effects on extrahepatic tissue and increases the risk for neuropathy. To investigate underlying molecular mechanisms we analyzed whether statins influence the activity of caspase- 3 in immortalized neurons. Lovastatin and mevastatin are not able to activate caspase- 3 but they strongly potentiate its activity when apoptotic signal transduction was initiated by staurosporine. The increase in caspase-3 activity after coincubation with statins and staurosporine was paralleled by an increase in the protein level of the pro-apoptotic GTPase RhoB. Our data provide evidence that statins sensitize neurons to apoptosis and therefore give reasons for a careful evaluation when patients with neurological diseases are treated with these drugs.
\end{abstract}

\section{Introduction}

Statins are inhibitors of hydroxymethylglutaryl coenzyme A (HMG CoA) reductase, that catalyzes the rate-limiting step in cholesterol synthesis. Therefore statins are frequently prescribed in order to prevent coronary artery disease if satisfactory lowering of blood lipids is not achieved through life style changes [14]. Although large clinical trials revealed the efficacy and relative safety of statins, there is growing evidence that after long-term treatment with these drugs adverse effects may arise. The recent withdrawal of cerivastatin from the world market focused attention on the risk of myotoxicity that is associated with statins [17]. However, whereas myopathy is a recognized risk associated with the use of lipid-lowering drugs, epidemiological studies provide evidence that long-term treatment with HMG CoA reductase inhibitors also increases the risk for neuropathy $[6,11]$. The mechanism by which statins have impact on the survival of neurons is largely unknown. In order to evaluate a potential involvement of statins in neuronal apoptotic signal transduction, we studied caspase- 3 activity and expression of the pro-apoptotic GTPase RhoB in statin-treated clonal neurons. 


\section{Material and Methods}

Murine hippocampal neurons (HT22; [3]) were cultured in Dulbecco's modified Eagle's medium (DMEM; Gibco, Germany) supplemented with $5 \%$ fetal calf serum (Biochrom, Berlin, Germany) under an atmosphere of $95 \% \mathrm{O}_{2}$ and $5 \% \mathrm{CO}_{2}$ at $37^{\circ} \mathrm{C}$. The activity of caspase-3 was determined using the Biomol QuantiZyme ${ }^{\mathrm{TM}}$ assay system (Biomol, Hamburg, Germany). HT22 cells that were incubated for different periods of time with vehicle, staurosporine $(300 \mathrm{nmol})$ and/or activated lovastatin or mevastatin $(10 \mu \mathrm{M}$; Sigma, Deisenhofen, Germany) were homogenized in cell lysis buffer (50 mM HEPES, $100 \mathrm{mM} \mathrm{NaCl}, 0.1 \%$ CHAPS, $10 \mathrm{mM}$ DTT, $0.1 \mathrm{mM}$ EDTA, pH 7.4). Homogenates were centrifuged at $10,000 \mathrm{~g}$ for $10 \mathrm{~min}$ at $4^{\circ} \mathrm{C}$ and the supernatant was stored at $-70^{\circ} \mathrm{C}$. After determination of the protein concentration of the extracts using standard methods, the cell lysate was incubated in assay buffer with $200 \mu \mathrm{M}$ of the caspase-3 substrate Ac-DEVDpNA (Biomol, Hamburg, Germany). The reaction was monitored by reading the plate absorbance at $405 \mathrm{~nm}$ in a microtiter plate-reader and readings were taken at 1-10 min intervals for $240 \mathrm{~min}$. To test specificity of the reaction the caspase-3 inhibitor Ac-DEVDCHO (0.1 $\mu \mathrm{M}$; Biomol, Hamburg, Germany) was included in selected experiments. Statistics were completed with the sigma plot program. Hippocampal neurons (HT22) treated with vehicle, staurosporine $(300 \mathrm{nM})$ and/or activated lovastatin or mevastatin (10 $\mu \mathrm{M}$; Sigma, Deisenhofen, Germany) were harvested and boiled in loading buffer containing 20\% glycerol, 3\% SDS, 3\% 2-mercaptoethanol and bromophenol-blue for 10 min. After measurement of total protein concentration, proteins $(20 \mu \mathrm{g} /$ lane $)$ were separated on a $12 \%$ SDS-polyacrylamide gel. Following tank blotting onto a nitrocellulose membrane (Amersham, Braunschweig, Germany) blots were blocked with 5\% blockinggrade (Amersham, Braunschweig, Germany) in PBS containing 0.05\% Tween (PBS-T). The membranes were incubated at $4^{\circ} \mathrm{C}$ for about $12 \mathrm{~h}$ with a RhoB antibody (RhoB antibody 119, 1:3000; Santa Cruz, Santa Cruz, USA). After five washes for $5 \mathrm{~min}$ in PBS$T$, blots were incubated with horseradish-coupled anti-rabbit secondary antibody (1:2000; Amersham, Braunschweig, Germany) at room temperature for $1 \mathrm{~h}$. Finally, membranes were washed again and developed by using the Amersham ECL-system according to the manufacturers' instructions. Following stripping of the blot, membranes were incubated at $4^{\circ} \mathrm{C}$ for about $12 \mathrm{~h}$ with the monoclonal anti-neuronal nuclei antibody (NeuN antibody MAB377, 1:3000; Chemicon, Hofheim, Germany). After five washes of 5 min each in PBS-T, blots were incubated with horseradish-coupled anti-mouse secondary antibody (1:2000; Amersham, Braunschweig, Germany) at room temperature for $1 \mathrm{~h}$. Once more, membranes were washed and developed using the Amersham ECL-system.

\section{Results and Discussion}

To evaluate whether statins influence the activity of caspase-3, the final orchestrator of apoptosis, we first characterized the kinetics of neuronal caspase-3 activity after initiating pro-apoptotic signal transduction with staurosporine. Clonal murine neurons (HT22) were incubated with staurosporine and caspase-3 activity was determined after 0 , $3,6,10$ and $24 \mathrm{~h}$ of incubation. As demonstrated in Fig. 1 caspase-3 activity increased with time and was most pronounced after $24 \mathrm{~h}$. Specificity of caspase-3 activity was tested by coincubation with Ac-DEVD-CHO, a specific inhibitor of caspase-3, which resulted in a complete loss of metabolization of the substrate of caspase-3 (data not shown). 


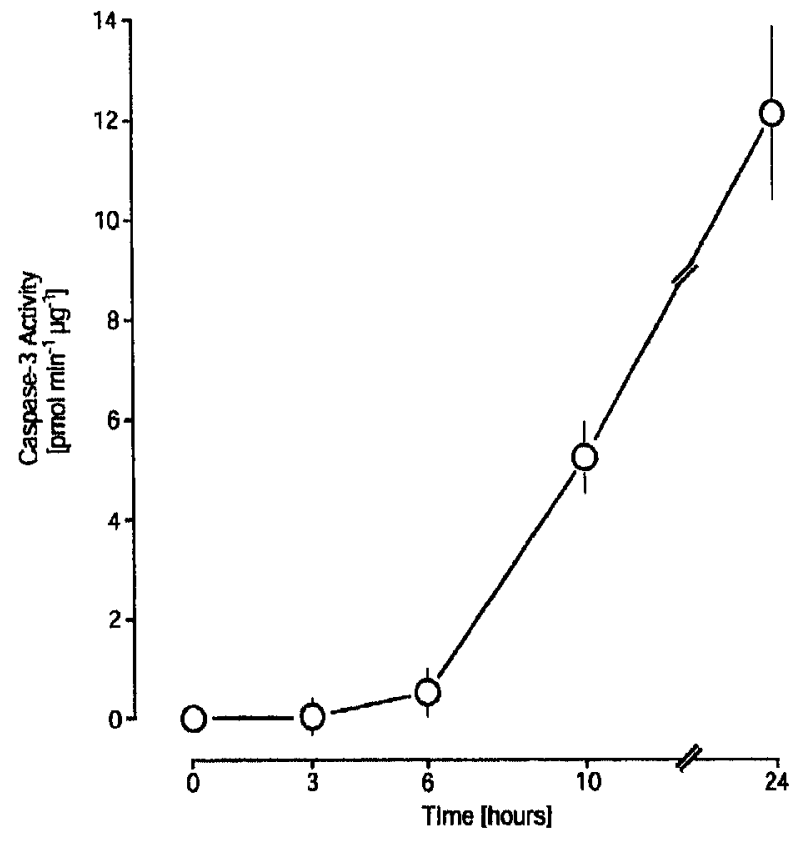

Fig. 1.Caspase-3 activity in HT22 cells in response to a $0,3,6,10$ or $24 \mathrm{~h}$ incubation period with $300 \mathrm{nM}$ of the apoptosis-inducing substance staurosporine. Activity is presented as pmol metabolized substrate per min and $\mu \mathrm{g}$ protein and represent the means \pm SEM of results from at least 3 independent experiments.

Next, we exposed HT22 cells to the HMG CoA reductase inhibitors lovastatin and mevastatin or cells were coincubated with statins and staurosporine. Lovastatin as well as mevastatin are not able to initiate proapoptotic pathways since caspase activity was not detectable in statin-treated cell cultures. However, both statins greatly increased caspase-3 activity, when apoptotic signal transduction was initiated by staurosporine (Fig. 2).

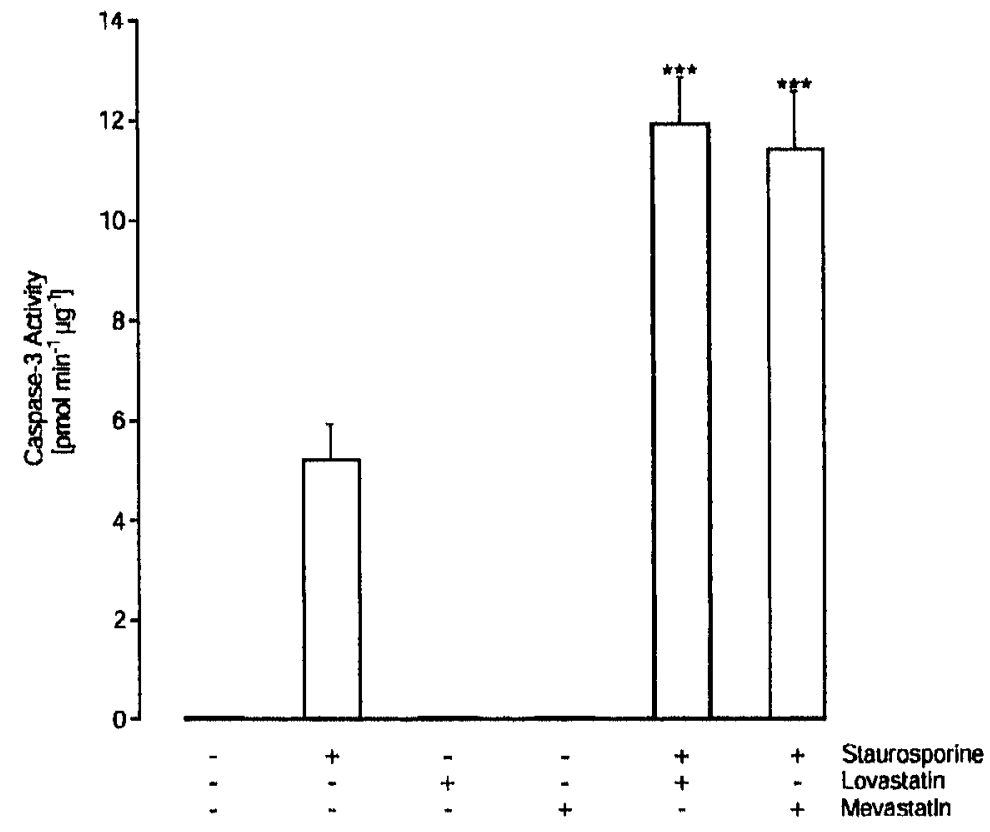

Fig. 2. Caspase-3 activity in HT22 cells in response to a $10 \mathrm{~h}$ incubation period with vehicle, staurosporine $(300 \mathrm{nM})$ and/or the HMG CoA reductase inhibitors lovastatin and mevastatin $(10 \mu \mathrm{M})$. Activity is presented as pmol metabolized substrate per min and $\mu \mathrm{g}$ protein and represent the means \pm SEM of results from at least 3 independent experiments. 
Since there is evidence from non-neuronal cells that inhibition of HMG CoA reductase increases the protein level of GTPase RhoB which is believed to play a role in apoptosis $[10,15,5,13]$, we tested the hypothesis that statin-potentiation of caspase- 3 activity is paralleled by an increase in RhoB. As shown in Fig. 3, initiation of neuronal apoptosis by staurosporine resulted in an induction of $\mathrm{RhoB}$ protein. Lovastatin as well as mevastatin induce RhoB at a low level, but in line with our hypothesis, coincubation of HT22 cells with statins and staurosporine drastically increases the level of RhoB.

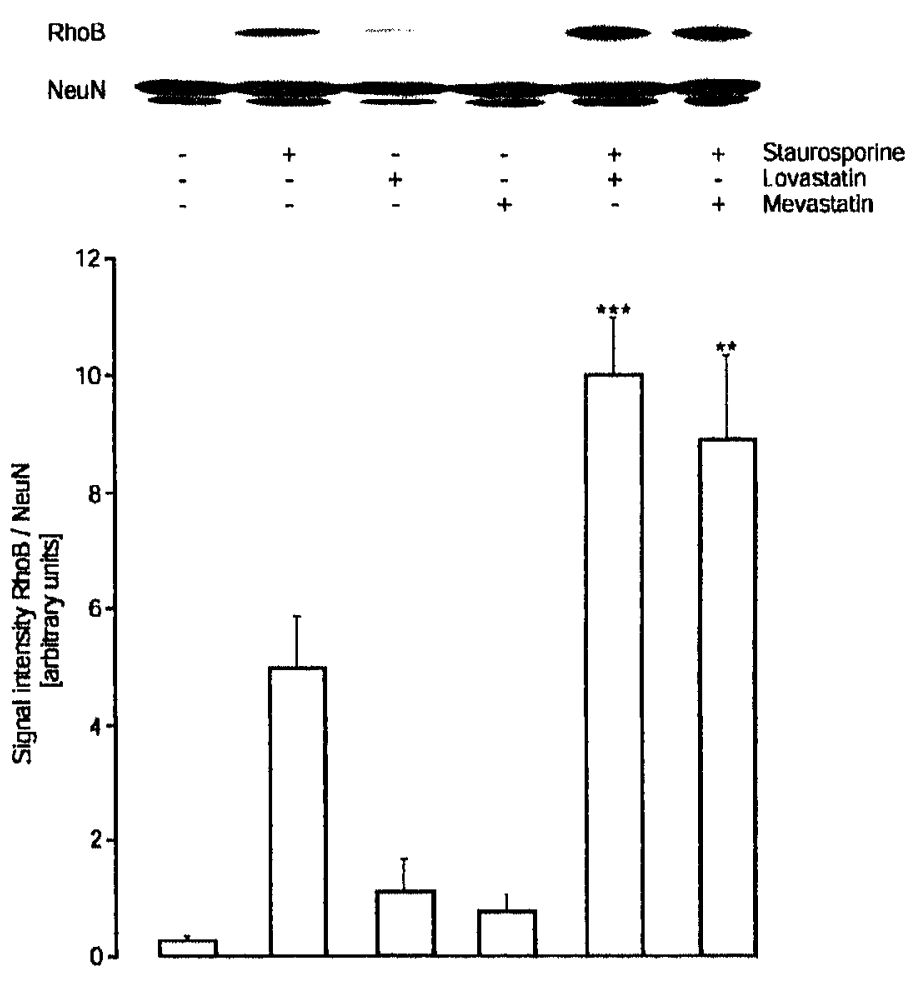

Fig. 3. Western blot of RhoB and NeuN in HT22 neurons which were treated for $10 \mathrm{~h}$ with vehicle or staurosporine (300 $\mathrm{nM})$ and/or lovastatin and mevastatin (10 $\mu \mathrm{M})$. A representative Western blot from 3 independent experiments is shown. The RhoB-band migrated slightly slower than the $21,5 \mathrm{kDalton}$ marker-band.

Our results demonstrate for the first time that statins potentiate caspase- 3 activity in neurons and therefore sensitize neuronal cells to apoptosis. In contrast to studies in other cell types and tissues, which demonstrate that statins itself induce apoptosis $[2,7,8]$, our results provide evidence that statins potentiate apoptosis, but do not initiate apoptotic pathways in clonal neurons. The enhancement of caspase- 3 activity by inhibitors of HMG CoA reductase is paralleled by an increase in the protein level of the pro-apoptotic GTPase RhoB. We recently reported that RhoB protein is drastically increased in neuronal apoptosis [16] and studies in non-neuronal cell types provide evidence that statins increase the level of RhoB by moderate induction of gene expression as well as by inhibiting degradation of $\mathrm{RhoB}$ protein $[10,15]$. These data are in line with our results, demonstrating a moderate induction of $\mathrm{RhoB}$ by lovastatin and mevastatin but a strong potentiation of the increase in the protein level of $\mathrm{RhoB}$ when clonal neurons were coincubated with statins and staurosporine. Although inhibition of the isoprenylation of RhoB may abolish some of its functions like the activation of the endothelin-1 promoter [9] it is well possible that a neuronal pro-apoptotic function of RhoB is conserved in an unisoprenylated state as it has been shown for the activation of the serum-response element-dependent transcription [12]. In spite of the fact that there is a good linkage between the enhancement of caspase- 3 activity and the protein levels of the pro-apoptotic 
GTPase RhoB, we cannot exclude that other mechanisms are causally linked to the enhancement of caspase-3 activity after inhibition of HMG CoA reductase.

Taken together these data demonstrate that statins enhance but do not initiate neuronal apoptosis. Therefore, in spite of the beneficial effects of statins by lowering blood lipids and by increasing endothelial NO, as recently reported [1,4], our results provide evidence for a careful evaluation whether patients with neurological diseases should be treated with statins or not.

\section{Acknowledgements}

This research program has been supported by grants from the European Community (BIO4-CT98-0293 and QLG3-CT-2000-00934) and by a Marie Curie Fellowship of the European Community program "Quality of Life and Management of Living Resources", under contract number QLK6-CT-2000-60042. The authors are grateful to I. Hölker, P. Janus and D. Schmiegelt for excellent technical support and B. Huth for artwork.

\section{References}

[1] Amin-Hanjani, S., Stagliano, N.E., Yamada, M., Huang, P.L., Liao, J.K. and Moskowitz, M.A, Mevastatin, an HMG-CoA reductase inhibitor, reduces stroke damage and upregulates endothelial nitric oxide synthase in mice, Stroke, 32 (2001) 980-986.

[2] Blanco-Colio, L.M., Villa, A., Ortego, M., Hernandez-Presa, M.A., Pascual, A., Plaza, J.J. and Egido, J., 3-Hydroxy-3-methyl-glutaryl coenzyme A reductase inhibitors, atorvastatin and simvastatin, induce apoptosis of vascular smooth muscle cells by downregulation of Bcl-2 expression and Rho A prenylation, Atherosclerosis, 161 (2002) 17-26.

[3] Davis, J.B. and Maher, P., Protein kinase C activation inhibits glutamate-induced cytotoxicity in a neuronal cell line, Brain Res., 652 (1994) 169-173.

[4] Endres, M., Laufs, U., Huang, Z., Nakamura, T., Huang, P., Moskowitz, M.A. and Liao, J.K., Stroke protection by 3-hydroxy-3-methylglutaryl (HMG)-CoA reductase inhibitors mediated by endothelial nitric oxide synthase, Proc. Natl. Acad. Sci. USA, 95 (1998) 8880 8885.

[5] Fritz, G. and Kaina, B., Ras-related GTPase RhoB forces alkylation-induced apoptotic cell death, Biochem. Biophys. Res. Commun., 268 (2000) 784-789.

[6] Gaist, D., Jeppesen, U., Andersen, M., Garcia Rodriguez, L.A., Hallas, J. and Sindrup, S.H., Statins and risk of polyneuropathy; a case-control study.[comment], Neurology, 58 (2002) 1333-1337.

[7] Garcia-Roman, N., Alvarez, A.M., Toro, M.J., Montes, A. and Lorenzo, M.J., Lovastatin induces apoptosis of spontaneously immortalized rat brain neuroblasts: involvement of nonsterol isoprenoid biosynthesis inhibition, Mol. Cell. Neurosci., 17 (2001) 329-341.

[8] Guijarro, C., Blanco-Colio, L.M., Ortego, M., Alonso, C., Ortiz, A., Plaza, J.J., Diaz, C., Hernandez, G. and Egido, J., 3-Hydroxy-3-methylglutaryl coenzyme a reductase and isoprenylation inhibitors induce apoptosis of vascular smooth muscle cells in culture, Circ. Res., 83 (1998) 490-500.

[9] Hernandez-Perera, O., Perez-Sala, D., Soria, E. and Lamas, S., Involvement of Rho GTPases in the transcriptional inhibition of preproendothelin-1 gene expression by simvastatin in vascular endothelial cells. [comment], Circ. Res., 87 (2000) 616-622.

[10] Holstein, S.A., Wohlford-Lenane, C.L. and Hohl, R.J., Consequences of mevalonate depletion. Differential transcriptional, translational, and post-translational up-regulation of Ras, Rapla, RhoA, AND RhoB, J. Biol. Chem., 277 (2002) 10678-10682.

[11] Jeppesen, U., Gaist, D., Smith, T. and Sindrup, S.H., Statins and peripheral neuropathy, Eur. J. Clin. Pharmacol., 54 (1999) 835-838. 
[12] Lebowitz, P.F., Du, W. and Prendergast, G.C., Prenylation of RhoB is required for its cell transforming function but not its ability to activate serum response element-dependent transcription, J. Biol. Chem., 272 (1997) 16093-16095.

[13] Prendergast, G.C., Actin' up: RhoB in cancer and apoptosis, Nat. Rev. Cancer, 1 (2001) 162-168.

[14] Shepherd, J., Cobbe, S.M., Ford, I., Isles, C.G., Lorimer, A.R., MacFarlane, P.W., McKillop, J.H. and Packard, C.J., Prevention of coronary heart disease with pravastatin in men with hypercholesterolemia. West of Scotland Coronary Prevention Study Group. [comment], N. Engl. J. Med., 333 (1995) 1301-1307.

[15] Stamatakis, K., Cernuda-Morollon, E., Hernandez-Perera, O. and Perez-Sala, D., Isoprenylation of $\mathrm{RhoB}$ is necessary for its degradation. A novel determinant in the complex regulation of RhoB expression by the mevalonate pathway, J. Biol. Chem., 277 (2002) 49389-49396.

[16] Trapp, T., Olah, L., Holker, I., Besselmann, M., Tiesler, C., Maeda, K. and Hossmann, K.A., GTPase RhoB: an early predictor of neuronal death after transient focal ischemia in mice, Mol. Cell. Neurosci., 17 (2001) 883-894.

[17] Yan, L., Lan, F., Wang, Z.G. and Li, Y.P., Statins and myotoxicity, Trends Pharmacol. Sci., 24(3) (2003) 113-114. 


\section{General Discussion}

\section{Clinical implications}

The last 25 years have seen remarkable progress in the understanding of the pathophysiology of ischemic stroke.

The total incidence of stroke is projected to increase considerably over the next two decades. This is because of the rapid increase in the elderly population. It is predicted that stroke will account for $6.2 \%$ of the total burden of illness in 2020 . Thus, without more effective strategies for the prevention, treatment, and rehabilitation of stroke, the cost of this disease will increase dramatically [54].

Depression is currently the leading cause of disability in the US as well as other countries and according to the World Health Organization is expected to become the second leading cause of disability worldwide by the year 2020 .

Even though progress has been made to elucidate mechanisms of action no real cure has been found for both diseases. Both stroke and depression are multifactorial and treatments inadequate to date.

\section{Our studies}

The present investigations demonstrate the usefulness of the Proteomics technique for detecting changes in protein expression in both the ischemia-damaged murine brain and a cell culture model of antidepressant treatment. In addition, we obtained insights into statin treatment as a possible medication for stroke and data on the function of CREB in longterm stress. To reflect:

- We demonstrated that the 2-D DIGE approach is a potentially fruitful approach for analyzing brain development. First, the DIGE labelling is a sensitive technique with a large dynamic range, which makes the detection of proteins of both low and high abundance possible and quantitation robust. Secondly, the high significance levels that are reached reflect the reliability of the quantitative analysis and the normalization power when using an internal standard. Thirdly, the proteins that we identified showed expression patterns that are similar to expression patters revealed in previous studies by using other techniques.

- The similarities in effects on protein expression of both conventional and herbal antidepressants in a hippocampal neuronal cell line were investigated. Forty-three 
protein spots were found to be significantly altered in more than one treatment group with twenty-nine of these subsequently identifying nineteen unique proteins as well as four proteins that were significantly increased by all three treatment groups. Functionally, the proteins differentially expressed across treatments were classified into those involved in the cytoskeleton and energy metabolism, cell signalling, protein synthesis and protein folding.

In addition all three treatments were shown to improve cell viability in the HT22 neuronal cells when compared with controls. It is likely that this increase in cell viability is due to increased cell metabolism

- Excessive circulating levels of glucocorticoids are thought to be associated with cognitive impairment. We provide evidence that chronic activation of the glucocorticoid receptor (GR) in clonal neurons inhibits the transcriptional activity of the cyclic AMP response element-binding protein (CREB) which is believed to be involved in memory processes. To investigate the underlying mechanism we studied the phosphorylation of CREB and found altered phosphorylation kinetics in neurons chronically treated with glucocorticoids.

Our results provide evidence that long-term activation of the GR in clonal neurons inhibits CRE-regulated gene expression which indicates that a hitherto unrecognized crosstalk between the glucocorticoid pathway and CREB exists.

- Multi-Western blot PowerBlot ${ }^{\mathrm{TM}}$ of more than 400 proteins were performed from brain extracts of mice submitted to transient focal ischemia. After MCA occlusion up to $45 \%$ of proteins were up- or downregulated in the ipsilateral hemisphere by a factor of 1.5 or more, as compared to sham-operated controls. The temporal regulation of several proteins in the ischemia-affected hemisphere after $1 \mathrm{~h} \mathrm{MCA}$ thread occlusion is described. In the non-ischemic hemisphere the number of regulated proteins was close to $50 \%$, indicating a hitherto unrecognized involvement of the opposite side. The proteomic approach of brain injury analysis goes beyond previous screenings of gene expression at the transcriptional level and although our study provides further evidence for the complexity of multiinjury pathways in the evolution of ischemic brain damage it may help to identify key mediators of ischemic injury.

- Our results demonstrated that statins potentiate caspase-3 activity in neurons and provide evidence that statins potentiate apoptosis, but do not initiate apoptotic pathways in clonal neurons. The enhancement of caspase-3 activity by inhibitors of HMG CoA reductase is paralleled by an increase in the protein level of the proapoptotic GTPase RhoB. These data are in line with previous results, and we could demonstrate a moderate induction of RhoB by lovastatin and mevastatin but a strong potentiation of the increase in the protein level of $\mathrm{RhoB}$ when clonal neurons were co-incubated with statins and staurosporine.

\section{Methodological considerations}

\section{Advantages and Limitations of Proteomics studies}

High throughput gene expression techniques allow for the massive gathering of biological data. Although the functional activity of a protein, such as substrate phosphorylation, and 
levels of activated protein are the best estimation of biological activity, the next levels of analysis of biological activity are protein levels (followed by mRNA levels).

Proteomics remains technically challenging and can present with enormous difficulties at the levels of complexity and dynamic ranges in body fluids and tissues are difficult to measure and analyse [22]. For example, the number of proteins expressed at a given time under defined biological conditions is likely to be in a range of several thousand for simple prokaryotic organisms and up to at least 10,000 in eukaryotic cell extracts [29]. Moreover, some proteomic studies are plagued with problems of abundant or housekeeping proteins, e.g. albumin in serum, whereas proteins such as receptor molecules are present in much lower concentrations and are not detected. As a result improved methods for enrichment of low-abundance proteins are required such as pre-fractionation procedures or more sensitive quantisation methods

While 2D-GE and 2D-DIGE have proven successful tools for identification of subtle pathological changes on a cellular level, these gel based methods are still limited by a number of methodological problems such as gel-to-gel variation, and labour intensive data analysis [23]. Proteomic data is both voluminous and complex, which can make its interpretation difficult [70]. Appropriate experimental design and scientific rigor, particularly regarding sample size for sufficient statistical power, pooling, repeatability, CyDye bias, and statistical analysis, are factors that must be taken into consideration as a means of quality control when planning a large scale gel experiment. Nevertheless, gel based proteomics is proving an invaluable research tool and holds much promise for future investigations.

Dramatic technological advances in both gel and non-gel based methods have been made recently. Mass Spectrometry based techniques for targeted quantitative analysis of nonredundant sets of peptides, e.g. multiple reaction monitoring (MRM), have been developed [2]. MRM involves adding reference peptides to each sample prior to MS, yielding precise quantitative information on targeted proteins. Future work utilising 2D-GE in conjunction with MRM for validation work would overcome a major bottleneck in discovery proteomics and such investigations hold much promise for future hypothesis driven research.

In addition to 2D gel electrophoresis coupled to Mass spectrometry, the commercial Western Blot format PowerBlot ${ }^{\mathrm{TM}}$ analysis of protein changes provides a comprehensive protein screening method, where samples are subjected to semi-quantitative comparative immunostaining with a whole range of specific antibodies. The output displays ratios of protein levels between two samples.

To date this format is only possible/ available in industrial settings and therefore not in use extensively. A major disadvantage is that the search for regulated proteins is limited to the number of antibodies in the company's portfolio.

\section{Using animal models for ischemia research}

Ischemia causes injury to the brain that is multifactorial. A range of physiological events are commonly associated with this disease. Further complexity arises from the contributions of different cell types and brain regions, and the neuronal connections between different regions in the adult brain that underlie why certain brain structures are more readily damaged by an ischemic insult than others. The inter-play of all these factors 
have demonstrable consequences on brain injury outcome following ischemia, meaning we must have models that reproduce these environments faithfully or we will miss factors critical to the maturation outcome of such injuries.

Mice and rats are the least phylogenetically similar (sentient) mammalian species to share the necessary human characteristics of stroke. The overwhelming use of rats and mice for ischemia research means the greatest is known about them experimentally including their neuroanatomy, physiology and response to brain injury in a large number of experimental models employed in academia and industry. In addition, the largest technical support in terms of surgical equipment and supplies exists for rats and mice. Finally, the mouse is the only species which allows genetic manipulation, i.e. the generation of transgenic animals.

In vitro (cell culture) models alone are inadequate to model ischemia. Neuronal connections between different brain regions cannot be reproduced in cell culture, and such connections have major influences on whether cells die after injury. Culture techniques typically only use one or two cell types derived from immature or neonatal animals or from cancerous cell lines. Lacking the necessary physiological complexity, the diversity of cell types involved and the mature connections between different brain regions, any such system can only answer certain research questions as a model of ischemia.

In vitro slice preparations from brain represent a possible alternative. While anatomical connections exist and some cell diversity, such preparations are typically from single brain regions (e.g. the hippocampus), are often isolated from immature brain and can only be studied in an artificial solution in the absence of blood flow and physiological changes (blood pressure).

\section{Particular usefulness of the HT22 cell line}

Cells lines have the advantage of a homogenous population, are easily accessible and easy to cultivate.

Cells of the immortalised mouse hippocampal cell line, HT22, a sub-clone of the original clone HT4 [57] are particularly vulnerable to glutamate [20]. It has been shown o be negative for both, ionotropic glutamate receptors as well as monoamine synthesis[52]. Therefore these clonal hippocampal cells provide a good model system for studying neuronal cell degeneration [10]. 95\% of the cells are neuronal, as confirmed by staining with neuron-specific enolase and by the absence of glial fibrillary acidic protein positive cells [9].

Nevertheless an in vitro system would not be capable to mimic the complex system of glial cells and neurons.

\section{D-DIGE as a valuable proteomics tool for investigating complex samples}

Investigations of the foetal and aged brain increase our knowledge of neuronal life in health and disease. Some studies on normal and diseased foetal and aged brains have been undertaken already $[8,21,26]$. In this study, we identified a number of differentially expressed proteins belonging to different functional groups and most of them have been described in the literature to be changed in different stages during brain development. However, to date we have not been able to identify all the proteins that we found to be differentially expressed in the different developmental stages. Moreover, as discussed 
above, a 2-D gel-based proteomic approach is not able to provide full coverage of the brain proteome. Our study has been limited to the use of pH 4-7 IPG IEF in the first dimension. While proteomic coverage could be extended using IPG strips covering other $\mathrm{pH}$ ranges, including narrow range "zoom" IPG, there will still be proteins whose $\mathrm{p} /$ values are extremely basic or extremely acidic so that they will fall outside of the $\mathrm{pH}$ range of the strips. Secondly, current labelling and staining methods are not sensitive enough for the detection of less abundant protein spots and more abundant spots can mask protein spots with a lower abundance [29]. In addition, proteins might be lost during sample preparation [74].

These problems apply to all 2-DE-based proteomic approaches, whether they employ CBB, silver staining or CyDye-labelling for protein detection. The major point that makes a 2-D DIGE approach superior to other 2-D gel-based techniques is the use of a "pooled" internal standard sample labelled with $\mathrm{Cy} 2$ for normalisation between gels. This makes gel-to-gel comparison and spot quantitation much more rigorous $[1,18,60,67,71]$, and we have clearly demonstrated that advantage in our study.

Several aspects of the current study demonstrate that the 2-D DIGE approach is a potentially fruitful approach for analyzing brain development. First, the DIGE labelling is a sensitive technique with a large dynamic range, which makes the detection of proteins of both low and high abundance possible and quantitation robust. Secondly, the high significance levels that are reached reflect the reliability of the quantitative analysis and the normalization power when using an internal standard. Thirdly, the proteins that we identified showed expression patterns that are similar to expression patters revealed in previous studies by using other techniques. These results make us confident that further proteomic analysis using 2-D DIGE will reveal new insights in brain development, possibly discovering new proteins or new functions for known proteins.

On the other hand, with the growth in neuroproteomics, the use of standardised protocols and analysis has become imperative. The Human Proteome Organisation Brain Proteome Project (HUPO BPP) has been established to carry out neuroproteomic studies of human and animal model brain tissue, specifically in relation to neurodegenerative diseases. The results and analysis of the first stage were published in September 2006 (for an overview see [33]). The most notable outcome was the high degree in variability. Despite large differences in the number of proteins identifies, almost one third of any data set were unique. The reasons for these differences appear to be intrinsic to the specific methods used for protein and peptide isolation, peptide identification and data analysis $[5,34]$.

On a different note, recent trends in neuroproteomics show the need for sub-cellular fractionation given the complex morphology of neurons, the need for understanding mechanisms of synaptic transmission and plasticity, enrichment of receptors and phosphopetides as well as investigations into post-translational modifications (cp [5] and citations therein).

\section{D-DIGE for investigating stress and depression related changes}

\section{Stress and depression}

Antidepressants are widely prescribed in the treatment of depression, although the mechanism of how they exert their therapeutic effects is poorly understood. Chronic administration of antidepressants is required for their efficacy, suggesting the involvement of long-term modifications. Although each compound induced a specific pattern of protein 
modulation, data suggest that antidepressants share the ability of modulating neural plasticity [14].

In order to investigate the effects of antidepressants we and others $[14,15,31,41,53]$ used proteomics methods to shed further light on their mode of action.

What can we learn about stress and depression by looking at the influence of treatment and are we able to relate this back to the disease?

This seems so far a question that is not easily to be answered. The few studies undertaken are very different in terms that they used for instance synaptosomal preparations from rat brain, rat primary cultures, mixed neuronal and glial cells derived from mouse embryonic stem cells as well as guinea pig. In addition they used a variety of different antidepressants. More important even is they all have done their experiments on 'healthy controls' instead of a disease model. This is very difficult to interpret as long-term stress causes such a variety of homeostatic disturbances to the brain. Further proteomic profiles therefore would be needed to compare the plethora of different findings to a disease model to clarify whether these findings are due to antidepressant effects on the brain per se or the disease process.

Some patients with Major Depression and other neurological afflictions display hyperactivity of the hypothalamic-pituitary-adrenal (HPA) axis. HPA hyperactivity may be due to impaired feedback inhibition and manifested as increased levels of circulating cortisol. Another very interesting study used a proteomics approach and identified alterations in cellular morphology and cell death pathways in mouse brain after chronic corticosterone treatment [65]. They concluded that further elucidation of these pathways could lead to identification of biomarkers for the development of pharmacological therapies targeted at stress-related disorders.

To get to the point, a recent review by Holsboer [38] suggested that when data from genomics, proteomics, metabolomics, neuroimaging and neuroendocrinology are used in combination, they could lead to the development of effective personalised antidepressant treatment that is based on both genotypes and biomarkers. This process will require many further steps and collaboration between basic and clinical neuroscience.

\section{Ischemia}

In a review in 2008 Kochanek et al [44] reasoned that multifaceted cellular, biochemical, and molecular monitoring of proteins and lipids is logical as an adjunct to guiding therapies and improving outcomes in (traumatic and) ischemic brain injury and we appear to be on the verge of a breakthrough with the use of these markers as diagnostic, prognostic, and monitoring adjuncts.

Where do we stand?

Apart from our own investigations only a few studies have been published using proteomics and ischemia. One study [40] used proteomics to identify regulated proteins following cerebral ischemia in a rat model subjected to reversible middle cerebral artery occlusion and proteins were extracted from the peri-infarcted and the corresponding contralateral area at days 3 and 14 post ischemia. Proteins were analysed by twodimensional gel electrophoresis and mass spectrometry. An isoform of annexin A3 (ANXA3) was among the up-regulated proteins in the postischemic rat brain. Confirmation of these findings by immunostaining with neuronal and microglia/macrophagic markers demonstrated that ANXA3 is produced by resting microglia in control tissue and by 
activated microglial/macrophage cells in the infarcted area. The authors suggested that ANXA3 could serve as a novel marker of brain microglia, which should be of substantial value in future studies of microglial cells and its role in the postischemic brain.

Another study [16] of focal cerebral ischemia in rats performed global protein analysis after $24 \mathrm{~h}$ on the lesioned and sham-control cerebral cortex using two-dimensional gel electrophoresis and resolved about 1500 protein spots of which only 12 were significantly upregulated by 3-46-fold.

At the present state, it is difficult to predict if these approach leads to the expected identification of a key mediator of ischemic injury. Again, studies undertaken so far are very diverse and have used lots of different models for ischemia as well as different proteomics methods and overlap between different experiments in terms of findings is sparse.

The investigation of selected proteins by immunohistochemistry has to clarify which of the proteins that show an interesting regulation pattern in our study are really associated with neuronal death or survival.

We have started to confirm and validate our findings. One of the proteins that was identified by the Multi-Western Blot approach was a so-called novel Protein Kinase C, PKC $\theta$. The Western blot experiments revealed a caspase 3-mediated cleavage of PKC theta in the experimental stroke model used.

Few insights are available regarding the functional roles of PKC $\theta$. Whereas PKC transcripts are found ubiquitously, PKC $\theta$ is predominantly expressed in haematopoietic cells and skeletal muscle [7]. Studies in T cells have demonstrated that PKC $\theta$ is involved in antigen-specific activation [55]. PKC $\theta$ is also involved in AP-1-mediated transcription [6]. Unlike the conventional PKCs and PKC $\delta$, there are no reports of proteolytic cleavage of the PKC $\theta$ isoform.

In line with our findings is a study, recently undertaken in human leukaemia cells, that demonstrates that PKC $\theta$ is cleaved to an activated form in cells induced to undergo apoptosis. The results indicate that PKC $\theta$ is cleaved by the caspase- 3 protease. It was also shown that over-expression of the PKC $\theta$ catalytic fragment induces characteristics of apoptosis. It was concluded that the finding that the cleaved fragment of PKC $\theta$ induces characteristics typical of apoptosis further supports a role for PKC $\theta$ in mediating apoptotic events and not simply a bystander effect of caspase-3 activation [19].

For our own study on PKC $\theta$ we cannot show causality right now, but in neuronal apoptosis and cerebral ischemia cleavage for neurons by this PKC isoform has never been described before.

\section{Impact of cyclic AMP response element-binding protein on stress}

\section{Longterm stress}

Glucocorticoid overexposure has been implicated in hippocampal dysfunctioning and neuronal loss. In major depression, hypercortisolemia, hypothalamic-pituitaryadrenocortical-axis alterations, and reduced hippocampal volumes are commonly observed, hippocampal neurodegeneration is also expected [50]. Considerable controversy exists in the literature as to whether long-lasting stress exposure and/or elevated glucocorticoids 
induce transient structural changes or result in irreversible neurodegeneration (cp. [36] and citations herein).

The molecular pathways that contribute to the damage associated with depression and antidepressant-mediated plasticity are a major focus of scientific investigations. The transcription factor cyclic AMP response element binding protein (CREB) (and the neurotrophin brain-derived neurotrophic factor (BDNF)) are targets of diverse classes of antidepressants and have been described to be regulated in animal depression models as well as in humans with depression. Given their role in plasticity, CREB (and BDNF) have emerged as molecules that may play an important role in modulating mood [59].

Phosphorylation, and hence activation, of CREB can be accomplished by a number of upstream signalling cascades. The pathway that leads to CREB phosphorylation is the cAMP-protein kinase A pathway [56, 59]. The PKA cascade is known to be perturbed in animal models of depression and also serves as a target for antidepressant treatments [63, 69].

A very recent study aimed to investigate how dexamethasone and norepinephrine, interact to affect neuronal plasticity. It was found (see [72]) that norepinephrine increased differentiation of the cells, manifested as an increase in neurite length, neurite number and gene expression, while dexamethasone reduced these parameters. Opposite effects were also observed in the expression of the transcription factor CREB with norepinephrine upregulating pCREB levels, while dexamethasone downregulated pCREB levels. pCREB levels were robustly enhanced by co-treatment, as compared to both control and norepinephrine treated cells, providing a possible explanation for the morphological increase in differentiation. These results suggest that in order for cells to combat the deleterious effects of glucocorticoids, a hyperactivation of pCREB may be necessary to restore differentiation and plasticity.

\section{Ischemia}

Glucocorticoids have also been shown to intensify neuronal damage in the hippocampus during ischemia and excitotoxicity through mechanisms that modulate synaptic glutamate concentrations. Conversely, the absence of adrenal steroids has been shown to regulate both neurogenesis and neuronal loss in the dentate gyrus of the hippocampus. Evidence continues to accumulate which suggests that glucocorticoid-induced neuronal death in all these physiological and pathophysiological settings occurs by apoptosis [62]. A study by Mabuchi et al. [51] nicely demonstrated that transient exposure to glutamate micmics the increase $f$ extracellular glutamate concentration during and after transient global ischemia. They could demonstrate that transient CREB phosphorylation occurred after exposure to glutamate in culture neurons and after an ischemic insult in adult gerbil hippocampal neurons directly after the ischemic insult and returned to control levels within 60 min after reperfusion. It has also been shown that in a focal ischemia model CREB phosphorylation was marked in the peri-infarct area [68]. However the temporal profile of CREB phosphorylation immediately after ischemia has not been fully examined, although it was argued that early phosphorylation of CREB can be expected from the expression pattern of immediate early genes after ischemia [42], exposure to glutamate and electrical stimulation and may represent the cellular protective response against metabolic stress [51].

\section{Are statins able to become one possible treatment in stroke prevention/therapy?}

Statins are potent inhibitors of cholesterol biosynthesis. In clinical trials, statins are beneficial in the primary and secondary prevention of coronary heart disease. However, the 
overall benefits observed with statins appear to be greater than what might be expected from changes in lipid levels alone, suggesting effects beyond cholesterol lowering. Indeed, recent studies indicate that some of the cholesterol-independent effects of statins involve improving endothelial function, enhancing the stability of atherosclerotic plaques, decreasing oxidative stress and inflammation, and inhibiting the thrombogenic response [47]. Many of these pleiotropic effects are mediated by inhibition of isoprenoids, which serve as lipid attachments for intracellular signaling molecules. Inhibition of small GTPbinding proteins, Rho, Ras, and Rac, whose proper membrane localization and function are dependent on isoprenylation, has been shown to be the mechanism by which statins induce apoptotic cell death [28].

Accumulating evidence suggested that statins have a prominent role in secondary prevention of stroke. In mouse models of cerebral ischemia, chronic treatment with statins elevates cerebral blood flow by eNOS up-regulation and NO generation. Accordingly, treatment with statins results in smaller cerebral infarction following MCA occlusion [45, 46]. When we started our investigations, this was the hypothesis underlying the experiments. As demonstrated, the results did not match these expectations. Hence, the results were totally unexpected. These studies were undertaken just before Bayer withdrew cerivastatin from the market

Recent experimental studies demonstrate that statins reduce the activity of neuronal glutamate receptors and protect neurons from excitotoxicity [73]. At higher doses, however, statins may also inhibit neurite sprouting and even induce neuronal apoptosis [11].

There is also clinical evidence that withdrawal of statin medication acutely impairs vascular function and negatively affects outcome [24].

The controversy discussion is going on.

\section{Future perspectives}

Our understanding of the pathogenesis and the pharmacological treatment of depression is still inadequate. Therefore we need to improve our understanding of the molecular basis of disease so we can identify disease-associated signalling pathways. We also need to improve understanding how currently used therapeutic drug work, so that we can identify novel therapeutic pathways, and distinguish drug-induced from diseased-induced protein changes. These proteins represent potential biomarkers of disease with the potential to identify those at risk for disease, disease progression and differential therapeutic responses.

Tissue plasminogen activator (t-PA) is the only drug approved for intravenous thrombolysis of acute ischemic stroke to date. It is also known that only a short therapeutic window of a few hours is available for re-opening the blood supply to the ischemic brain.

A new range of vision for the treatment of stroke has been opened utilising strategies to induce the brain's own mechanisms of protection and regeneration. This has led to treatment with stem cells. Stem cells have the capacity to migrate towards lesions in the adult central nervous system (see e.g. [37]) and may have the potential to enhance regeneration after brain injury. Work is underway further investigate these findings.

Imaging technologies like perfusion- and diffusion-weighted MRI allow the identification of tissue at risk and can be used to identify patients in which brain protective therapy is likely to be successful. 


\section{In conclusion}

The new enabling technologies in functional genomics and proteomics are powerful tools to study complex multi-factorial disease. Microarrays have proven very useful to acquire large data sets of differential expressed gene expression at the transcriptional level $[13,48$, 49]. However, transcript levels do not necessarily reflect the amount of protein that represents the actual functional entity of a gene $[3,4,17,27,30,32]$. The complexity of protein profile exceeds that of the RNA profiles due to post-transcriptional and posttranslational generation of different protein species [43]. 2-DE coupled to mass spectrometry yields valuable insights into the molecular composition of cells and tissues. However, technical difficulties impede or even prevent the display of certain proteins and the limited dynamic range results in a bias towards abundant proteins.

Over the last years proteomics has been proven to be successfully applied to a number of neurodegenerative diseases ranging from Alzheimer's disease (see i.e. $[12,58]$, Huntington's disease [25, 66], Parkinson's [64], traumatic brain injury [61], ischemia [16, $35,39]$.

The present investigation illustrates the successful application of the Proteomics technique to the discovery of unexpected gene expression following cerebral ischemia and neurons treated with antidepressants, respectively. Our results demonstrate a huge plethora of differentially expressed proteins which need to be followed up to make use of their full potential to find even more insights into stroke and depression.

They also show that statins should be cautiously managed in the treatment of ischemia and that CREB may be important for the effects of long-term glucocorticoid exposure on cognitive function.

\section{References}

[1] A. Alban, S.O. David, L. Bjorkesten, C. Andersson, E. Sloge, S. Lewis, I. Currie, A novel experimental design for comparative two-dimensional gel analysis: two-dimensional difference gel electrophoresis incorporating a pooled internal standard, Proteomics 3 (2003) 36-44,

[2] L. Anderson, C.L. Hunter, Quantitative mass spectrometric multiple reaction monitoring assays for major plasma proteins, Mol Cell Proteomics 5 (2006) 573-588.

[3] L. Anderson, J. Seilhamer, A comparison of selected mRNA and protein abundances in human liver, Electrophoresis 18 (1997) 533-537.

[4] N.L. Anderson, N.G. Anderson, Proteome and proteomics: new technologies, new concepts, and new words, Electrophoresis 19 (1998) 1853-1861.

[5] E.C. Andrade, D.D. Krueger, A.C. Nairn, Recent advances in neuroproteomics, Current opinion in molecular therapeutics 9 (2007) 270-281.

[6] G. Baier-Bitterlich, F. Uberall, B. Bauer, F. Fresser, H. Wachter, H. Grunicke, G. Utermann, A. Altman, G. Baier, Protein kinase C-theta isoenzyme selective stimulation of the transcription factor complex AP-1 in T lymphocytes, Mol Cell Biol 16 (1996) 18421850 .

[7] G. Baier, D. Telford, L. Giampa, K.M. Coggeshall, G. Baier-Bitterlich, N. Isakov, A. Altman, Molecular cloning and characterization of PKC theta, a novel member of the protein kinase C (PKC) gene family expressed predominantly in hematopoietic cells, J Biol Chem 268 (1993) 4997-5004. 
[8] M. Bajo, J. Fruehauf, S.H. Kim, M. Fountoulakis, G. Lubec, Proteomic evaluation of intermediary metabolism enzyme proteins in fetal Down's syndrome cerebral cortex, Proteomics 2 (2002) 1539-1546.

[9] C. Behl, F. Lezoualc'h, T. Trapp, M. Widmann, T. Skutella, F. Holsboer, Glucocorticoids enhance oxidative stress-induced cell death in hippocampal neurons in vitro, Endocrinology 138 (1997) 101-106.

[10] C. Behl, M. Widmann, T. Trapp, F. Holsboer, 17-beta estradiol protects neurons from oxidative stress-induced cell death in vitro, Biochem Biophys Res Commun 216 (1995) 473-482.

[11] J. Bosel, M. Endres, [Direct neuronal effects of statins], Nervenarzt 77 (2006) 289-290, 292-283

[12] P. Brechlin, O. Jahn, P. Steinacker, L. Cepek, H. Kratzin, S. Lehnert, S. Jesse, B. Mollenhauer, H.A. Kretzschmar, J. Wiltfang, M. Otto, Cerebrospinal fluid-optimized twodimensional difference gel electrophoresis (2-D DIGE) facilitates the differential diagnosis of Creutzfeldt-Jakob disease, Proteomics 8 (2008) 4357-4366.

[13] P.O. Brown, D. Botstein, Exploring the new world of the genome with DNA microarrays, Nat Genet 21 (1999) 33-37.

[14] L. Carboni, M. Vighini, C. Piubelli, L. Castelletti, A. Milli, E. Domenici, Proteomic analysis of rat hippocampus and frontal cortex after chronic treatment with fluoxetine or putative novel antidepressants: CRF1 and NK1 receptor antagonists, Eur Neuropsychopharmacol 16 (2006) 521-537.

[15] D. Cecconi, S. Mion, H. Astner, E. Domenici, P.G. Righetti, L. Carboni, Proteomic analysis of rat cortical neurons after fluoxetine treatment, Brain Res 1135 (2007) 41-51.

[16] A. Chen, W.P. Liao, Q. Lu, W.S. Wong, P.T. Wong, Upregulation of dihydropyrimidinaserelated protein 2 , spectrin alpha II chain, heat shock cognate protein 70 pseudogene 1 and tropomodulin 2 after focal cerebral ischemia in rats-a proteomics approach, Neurochem Int 50 (2007) 1078-1086.

[17] G. Chen, T.G. Gharib, C.C. Huang, J.M. Taylor, D.E. Misek, S.L. Kardia, T.J. Giordano, M.D. Iannettoni, M.B. Orringer, S.M. Hanash, D.G. Beer, Discordant protein and mRNA expression in lung adenocarcinomas, Mol Cell Proteomics 1 (2002) 304-313.

[18] W. Chen, J. Ji, X. Xu, S. He, B. Ru, Proteomic comparison between human young and old brains by two-dimensional gel electrophoresis and identification of proteins, Int $\mathrm{J}$ Dev Neurosci 21 (2003) 209-216.

[19] R. Datta, H. Kojima, K. Yoshida, D. Kufe, Caspase-3-mediated cleavage of protein kinase $C$ theta in induction of apoptosis, J Biol Chem 272 (1997) 20317-20320.

[20] J.B. Davis, P. Maher, Protein kinase $\mathbf{C}$ activation inhibits glutamate-induced cytotoxicity in a neuronal cell line, Brain Research 652 (1994) 169-173.

[21] A. De Iuliis, J. Grigoletto, A. Recchia, P. Giusti, P. Arslan, A proteomic approach in the study of an animal model of Parkinson's disease, Clin Chim Acta 357 (2005) 202-209.

[22] B. Domon, R. Aebersold, Challenges and opportunities in proteomics data analysis, Mol Cell Proteomics 5 (2006) 1921-1926.

[23] A.W. Dowsey, M.J. Dunn, G.Z. Yang, ProteomeGRID: towards a high-throughput proteomics pipeline through opportunistic cluster image computing for two-dimensional gel electrophoresis, Proteomics 4 (2004) 3800-3812.

[24] M. Endres, U. Laufs, Effects of statins on endothelium and signaling mechanisms, Stroke 35 (2004) 2708-2711.

[25] Q. Fang, A. Strand, W. Law, V.M. Faca, M.P. Fitzgibbon, N. Hamel, B. Houle, X. Liu, D.H. May, G. Poschmann, L. Roy, K. Stuhler, W. Ying, J. Zhang, Z. Zheng, J.J. Bergeron, S. Hanash, F. He, B.R. Leavitt, H.E. Meyer, X. Qian, M.W. McIntosh, Brain-specific proteins decline in the cerebrospinal fluid of humans with Huntington disease, Mol Cell Proteomics 8 (2009) 451-466.

[26] M. Fountoulakis, J.F. Juranville, M. Dierssen, G. Lubec, Proteomic analysis of the fetal brain, Proteomics 2 (2002) 1547-1576.

[27] B. Futcher, G.I. Latter, P. Monardo, C.S. McLaughlin, J.I. Garrels, A sampling of the yeast proteome, Mol Cell Biol 19 (1999) 7357-7368. 
[28] N. Garcia-Roman, A.M. Alvarez, M.J. Toro, A. Montes, M.J. Lorenzo, Lovastatin induces apoptosis of spontaneously immortalized rat brain neuroblasts: involvement of nonsterol isoprenoid biosynthesis inhibition, Molecular \& Cellular Neurosciences 17 (2001) 329341.

[29] A. Gorg, W. Weiss, M.J. Dunn, Current two-dimensional electrophoresis technology for proteomics, Proteomics 4 (2004) 3665-3685.

[30] T.J. Griffin, S.P. Gygi, T. Ideker, B. Rist, J. Eng, L. Hood, R. Aebersold, Complementary profiling of gene expression at the transcriptome and proteome levels in Saccharomyces cerevisiae, Mol Cell Proteomics 1 (2002) 323-333.

[31] P.C. Guest, M.R. Knowles, S. Molon-Noblot, K. Salim, D. Smith, F. Murray, P. Laroque, S.P. Hunt, C. De Felipe, N.M. Rupniak, G. McAllister, Mechanisms of action of the antidepressants fluoxetine and the substance $P$ antagonist L-000760735 are associated with altered neurofilaments and synaptic remodeling, Brain Res 1002 (2004) 1-10.

[32] S.P. Gygi, Y. Rochon, B.R. Franza, R. Aebersold, Correlation between protein and mRNA abundance in yeast, Mol Cell Biol 19 (1999) 1720-1730.

[33] M. Hamacher, R. Apweiler, G. Arnold, A. Becker, M. Bluggel, O. Carrette, C. Colvis, M.J. Dunn, T. Frohlich, M. Fountoulakis, A. van Hall, F. Herberg, J. Ji, H. Kretschmar, P. Lewczuk, G. Lubec, K. Marcus, L. Martens, N. Palacios Bustamante, Y.M. Park, S.R. Pennington, J. Robben, K. Stuhler, K.A. Reidegeld, P. Riederer, J. Rossier, J.C. Sanchez, M. Schrader, C. Stephan, D. Tagle, H. Thiehle, J. Wang, J. Wiltfang, J. Shin Yoo, C. Zhang, J. Klose, H.E. Meyer, HUPO Brain Proteome Project: Summary of the Pilot Phase and Introduction of a Comprehensive Data Reprocessing Strategy, Proteomics 6 (2006) 5015-5029.

[34] M. Hamacher, K. Marcus, A. van Hall, H.E. Meyer, C. Stephan, The HUPO Brain Proteome Project--no need to hurry?, J Neural Transm 113 (2006) 963-971.

[35] A.S. Haqqani, J. Kelly, E. Baumann, R.F. Haseloff, I.E. Blasig, D.B. Stanimirovic, Protein markers of ischemic insult in brain endothelial cells identified using 2D gel electrophoresis and ICAT-based quantitative proteomics, Journal of proteome research 6 (2007) 226-239.

[36] V.M. Heine, S. Maslam, J. Zareno, M. Joels, P.J. Lucassen, Suppressed proliferation and apoptotic changes in the rat dentate gyrus after acute and chronic stress are reversible, Eur J Neurosci 19 (2004) 131-144.

[37] M. Hoehn, E. Kustermann, J. Blunk, D. Wiedermann, T. Trapp, S. Wecker, M. Focking, H. Arnold, J. Hescheler, B.K. Fleischmann, W. Schwindt, C. Buhrle, Monitoring of implanted stem cell migration in vivo: a highly resolved in vivo magnetic resonance imaging investigation of experimental stroke in rat, Proc Natl Acad Sci U S A 99 (2002) 1626716272.

[38] F. Holsboer, How can we realize the promise of personalized antidepressant medicines?, Nat Rev Neurosci 9 (2008) 638-646.

[39] X. Hu, H.C. Rea, J.E. Wiktorowicz, J.R. Perez-Polo, Proteomic analysis of hypoxia/ischemia-induced alteration of cortical development and dopamine neurotransmission in neonatal rat, Journal of proteome research 5 (2006) 2396-2404.

[40] H. Junker, Y. Suofu, S. Venz, M. Sascau, J.G. Herndon, C. Kessler, R. Walther, A. PopaWagner, Proteomic identification of an upregulated isoform of annexin A3 in the rat brain following reversible cerebral ischemia, Glia 55 (2007) 1630-1637.

[41] X. Khawaja, J. Xu, J.J. Liang, J.E. Barrett, Proteomic analysis of protein changes developing in rat hippocampus after chronic antidepressant treatment: Implications for depressive disorders and future therapies, J Neurosci Res 75 (2004) 451-460.

[42] M. Kiessling, K.A. Hossmann, Focal cerebral ischemia: molecular mechanisms and new therapeutic strategies, Brain Pathology 4 (1994) 21-22.

[43] J. Klose, Genotypes and phenotypes, Electrophoresis 20 (1999) 643-652.

[44] P.M. Kochanek, R.P. Berger, H. Bayir, A.K. Wagner, L.W. Jenkins, R.S. Clark, Biomarkers of primary and evolving damage in traumatic and ischemic brain injury: diagnosis, prognosis, probing mechanisms, and therapeutic decision making, Current opinion in critical care 14 (2008) 135-141. 
[45] U. Laufs, M. Endres, N. Stagliano, S. Amin-Hanjani, D.S. Chui, S.X. Yang, T. Simoncini, M. Yamada, E. Rabkin, P.G. Allen, P.L. Huang, M. Bohm, F.J. Schoen, M.A. Moskowitz, J.K. Liao, Neuroprotection mediated by changes in the endothelial actin cytoskeleton, Journal of Clinical Investigation 106 (2000) 15-24.

[46] U. Laufs, J.K. Liao, Direct vascular effects of HMG-CoA reductase inhibitors, Trends in Cardiovascular Medicine 10 (2000) 143-148.

[47] J.K. Liao, U. Laufs, Pleiotropic effects of statins, Annual review of pharmacology and toxicology 45 (2005) 89-118.

[48] R.J. Lipshutz, S.P. Fodor, T.R. Gingeras, D.J. Lockhart, High density synthetic oligonucleotide arrays, Nat Genet 21 (1999) 20-24.

[49] D.J. Lockhart, E.A. Winzeler, Genomics, gene expression and DNA arrays, Nature 405 (2000) 827-836.

[50] P.J. Lucassen, M.B. Muller, F. Holsboer, J. Bauer, A. Holtrop, J. Wouda, W.J. Hoogendijk, E.R. De Kloet, D.F. Swaab, Hippocampal apoptosis in major depression is a minor event and absent from subareas at risk for glucocorticoid overexposure, Am J Pathol 158 (2001) 453-468.

[51] T. Mabuchi, K. Kitagawa, K. Kuwabara, K. Takasawa, T. Ohtsuki, Z. Xia, D. Storm, T. Yanagihara, M. Hori, M. Matsumoto, Phosphorylation of cAMP response element-binding protein in hippocampal neurons as a protective response after exposure to glutamate in vitro and ischemia in vivo, Journal of Neuroscience 21 (2001) 9204-9213.

[52] P. Maher, J.B. Davis, The role of monoamine metabolism in oxidative glutamate toxicity, J Neurosci 16 (1996) 6394-6401.

[53] P.C. McHugh, G.R. Rogers, B. Loudon, D.M. Glubb, P.R. Joyce, M.A. Kennedy, Proteomic analysis of embryonic stem cell-derived neural cells exposed to the antidepressant paroxetine, J Neurosci Res 86 (2008) 306-316.

[54] S. Meairs, N. Wahlgren, U. Dirnagl, O. Lindvall, P. Rothwell, J.C. Baron, K. Hossmann, B. Engelhardt, J. Ferro, J. McCulloch, M. Kaste, M. Endres, J. Koistinaho, A. Planas, D. Vivien, R. Dijkhuizen, A. Czlonkowska, A. Hagen, A. Evans, G. De Libero, Z. Nagy, D. Rastenyte, J. Reess, A. Davalos, G.L. Lenzi, P. Amarenco, M. Hennerici, Stroke research priorities for the next decade--A representative view of the European scientific community, Cerebrovasc Dis 22 (2006) 75-82.

[55] C.R. Monks, H. Kupfer, I. Tamir, A. Barlow, A. Kupfer, Selective modulation of protein kinase C-theta during T-cell activation, Nature 385 (1997) 83-86.

[56] M. Montminy, Transcriptional regulation by cyclic AMP, Annu Rev Biochem 66 (1997) 807-822.

[57] B.H. Morimoto, D.E. Koshland, Jr., Induction and expression of long- and short-term neurosecretory potentiation in a neural cell line, Neuron 5 (1990) 875-880.

[58] T. Muller, K. Jung, A. Ullrich, A. Schrotter, H.E. Meyer, C. Stephan, R. Egensperger, K. Marcus, Disease state, age, sex, and post-mortem time-dependent expression of proteins in AD vs. control frontal cortex brain samples, Current Alzheimer research 5 (2008) 562-571.

[59] A. Nair, V.A. Vaidya, Cyclic AMP response element binding protein and brain-derived neurotrophic factor: molecules that modulate our mood?, Journal of biosciences 31 (2006) 423-434.

[60] D.D. Pollak, K. Herkner, H. Hoeger, G. Lubec, Behavioral testing upregulates pCaMKII, BDNF, PSD-95 and egr-1 in hippocampus of FVB/N mice, Behav Brain Res 163 (2005) 128-135.

[61] D.A. Prieto, X. Ye, T.D. Veenstra, Proteomic analysis of traumatic brain injury: the search for biomarkers, Expert Rev Proteomics 5 (2008) 283-291.

[62] L.P. Reagan, B.S. McEwen, Controversies surrounding glucocorticoid-mediated cell death in the hippocampus, Journal of chemical neuroanatomy 13 (1997) 149-167.

[63] R.C. Shelton, Cellular mechanisms in the vulnerability to depression and response to antidepressants, The Psychiatric clinics of North America 23 (2000) 713-729.

[64] A. Sinha, N. Srivastava, S. Singh, A.K. Singh, S. Bhushan, R. Shukla, M.P. Singh, Identification of differentially displayed proteins in cerebrospinal fluid of Parkinson's disease patients: a proteomic approach, Clin Chim Acta 400 (2009) 14-20. 
[65] H.A. Skynner, D.P. Amos, F. Murray, K. Salim, M.R. Knowles, I. Munoz-Sanjuan, L.M. Camargo, T.P. Bonnert, P.C. Guest, Proteomic analysis identifies alterations in cellular morphology and cell death pathways in mouse brain after chronic corticosterone treatment, Brain Res 1102 (2006) 12-26.

[66] M.A. Sorolla, G. Reverter-Branchat, J. Tamarit, I. Ferrer, J. Ros, E. Cabiscol, Proteomic and oxidative stress analysis in human brain samples of Huntington disease, Free radical biology \& medicine 45 (2008) 667-678.

[67] J.E. Swatton, S. Prabakaran, N.A. Karp, K.S. Lilley, S. Bahn, Protein profiling of human postmortem brain using 2-dimensional fluorescence difference gel electrophoresis (2-D DIGE), Mol Psychiatry 9 (2004) 128-143.

[68] K. Tanaka, S. Nogawa, E. Nagata, S. Suzuki, T. Dembo, A. Kosakai, Y. Fukuuchi, Temporal profile of CREB phosphorylation after focal ischemia in rat brain, NeuroReport 10 (1999) 2245-2250.

[69] D. Tardito, J. Perez, E. Tiraboschi, L. Musazzi, G. Racagni, M. Popoli, Signaling pathways regulating gene expression, neuroplasticity, and neurotrophic mechanisms in the action of antidepressants: a critical overview, Pharmacological reviews 58 (2006) 115-134.

[70] M.R. Wilkins, Biomarker Identification: The Role of Experimental Design, Statistics, and Data Sharing. In: J.E. van Eyk, Dunn, M.J. (Ed.), Clinical Proteomics- From Diagnosis to Therapy, Wiley-VCH, 2007, pp. 113-120.

[71] J.X. Yan, A.T. Devenish, R. Wait, T. Stone, S. Lewis, S. Fowler, Fluorescence twodimensional difference gel electrophoresis and mass spectrometry based proteomic analysis of Escherichia coli, Proteomics 2 (2002) 1682-1698.

[72] S.P. Yaniv, D. Ben-Shachar, E. Klein, Norepinephrine-glucocorticoids interaction does not annul the opposite effects of the individual treatments on cellular plasticity in neuroblastoma cells, European journal of pharmacology 596 (2008) 14-24.

[73] A. Zacco, J. Togo, K. Spence, A. Ellis, D. Lloyd, S. Furlong, T. Piser, 3-hydroxy-3methylglutaryl coenzyme A reductase inhibitors protect cortical neurons from excitotoxicity, J Neurosci 23 (2003) 11104-11111.

[74] S. Zhou, M.J. Bailey, M.J. Dunn, V.R. Preedy, P.W. Emery, A quantitative investigation into the losses of proteins at different stages of a two-dimensional gel electrophoresis procedure, Proteomics 5 (2005) 2739-2747. 


\section{Summary}

The aim of the studies described in this thesis was to use the recently developed Proteomics technology in order to investigate differentially expressed proteins in an in vivo model of focal cerebral ischemia and an in vitro stress model and to get new insights into drug related findings.

Cell death and survival pathways in the brain are highly complex coordinated events, and we still know little about which proteins are the most important, how best to intervene in their function and what impact this has for the brain during recovery.

We hypothesised that protein expression patterns can be detected by high throughput techniques and eventually uncover surrogate end point biomarkers and novel mechanisms.

The models used in this thesis were chosen due to their ability to induce stress to the cerebral system on different pathways with distinct stress patterns and varying morphological changes, during and after the direct hit of the event.

These in vivo and in vitro models mimic the human situation to and certain extend and are well established and accepted in the analysis of ischemia and long-term stress.

Chapter 1 is a general introduction to this thesis and outlines the scientific background to stress generally and stress in two distinct diseases, ischemia and long-term stress as well as some background on Proteomics techniques.

In Chapter 2 we demonstrated that the 2-D DIGE approach is a potentially fruitful proteomics technique for analysing brain development. First, the DIGE labelling is a sensitive technique with a large dynamic range, which makes the detection of proteins of both low and high abundance possible and quantitation robust. Secondly, the high significance levels that are reached reflect the reliability of the quantitative analysis and the normalization power when using an internal standard. Thirdly, the proteins that we identified showed expression patterns that are similar to expression patters revealed in previous studies by using other techniques.

The similarities in effects on protein expression of both conventional and herbal antidepressants in a hippocampal neuronal cell line are described in Chapter 3. This study has investigated the protein expression profiles of hippocampal neuronal cells exposed to clomipramine, St John's Wort, Xiao Yao San or no treatment. The results from the comparison between the proteomic profiles of these samples suggest that the three treatments do share common molecular targets and that these appear to focus specifically on those proteins involved in the cytoskeleton, energy metabolism, cell signalling, protein synthesis and protein folding. They support previous work indicating that antidepressants increase neuronal plasticity and provide some novel findings regarding the mechanisms by which they may do this. 
In Chapter 4 we studied that chronic glucocorticoid receptor activation is related to the cyclic AMP response element-binding protein (CREB) transcriptional activity in clonal neurons. Excessive circulating levels of glucocorticoids are thought to be associated with cognitive impairment. We provide evidence that chronic activation of the glucocorticoid receptor in clonal neurons inhibits the transcriptional activity of CREB which is believed to be involved in memory processes. To investigate the underlying mechanism we studied the phosphorylation of CREB and found altered phosphorylation kinetics in neurons chronically treated with glucocorticoids. Our results provide evidence that long-term activation of the GR in clonal neurons inhibits CRE-regulated gene expression that indicates that a hitherto unrecognized crosstalk between the glucocorticoid pathway and CREB exists.

In Chapter 5 the Multi-Western blot PowerBlot ${ }^{\mathrm{TM}}$ technique was used to investigate more than 400 proteins with brain extracts of mice submitted to transient focal ischemia. After MCA occlusion up to $45 \%$ of proteins were up- or downregulated in the ipsilateral hemisphere by a factor of 1.5 or more, as compared to sham-operated controls. In the nonischemic hemisphere the number of regulated proteins was close to $50 \%$, indicating a hitherto unrecognized involvement of the opposite side. The study provides further evidence for the complexity of multi-injury pathways in the evolution of ischemic brain damage it may help to identify key mediators of ischemic injury.

Chapter 6 describes our findings that statins potentiate apoptosis in immortalised neurons. Statins are lipid-lowering drugs that have been shown to reduce atherosclerotic cardiovascular morbidity and mortality. Our results demonstrated that statins potentiate caspase-3 activity in neurons and provide evidence that statins potentiate apoptosis, but do not initiate apoptotic pathways in clonal neurons. Therefore, in spite of the beneficial effects of statins by lowering blood lipids and by increasing endothelial NO our results provide evidence for a careful evaluation of whether patients with neurological diseases should be treated with statins.

In Chapter 7 the results obtained are critically discussed in terms of their overall applicability and latest findings of work in progress are put into the context of the results presented.

In conclusion, the present work stresses the potential of using high throughput technologies to identify differentially expressed proteins, giving clues which proteins are the most important, how best to intervene in their function and what impact this has for the brain. This improves our understanding of the process of cell death following stroke and long-term stress. By using drug approaches on both, disease models as well as healthy controls, new insights can be obtained. Future studies are warranted to unravel how best to target this to protect the brain. 


\section{Samenvatting}

Het doel van de studies beschreven in dit proefschrift was om gebruik te maken van de onlangs ontwikkelde proteomics technologie teneinde onderzoek te verrichten aan verschillende eiwitten in zowel een in vivo model van brein ischemie als een in vitro stress model om zodoende inzicht te krijgen in medicijn gerelateerde bevindingen.

Celdood en overlevings transductie routes in het brein zijn zeer gecompliceerde processen, en wij weten nog steeds weining over welke eiwitten het meest belangrijk zijn, hoe te interveniëren in hun functie en wat voor een invloed dit heeft op het brein tijdens herstel na een specifiek voorval.

Wij veronderstelden dat eiwit expressie patronen gedetecteerd kunnen worden met high throughput technieken welke uiteindelijk zowel biomarkers als nieuwe werkingsmechanismen opleveren.

De modellen die in deze proefschrift gebruikt zijn, werden gekozen omdat zij de mogelijkheid bieden stress te induceren aan het hersen-systeem op verschillende transductie routes met specifieke stress patronen en verschillende morfologische veranderingen, gedurende en na een specifiek voorval.

Deze in vivo en in vitro modellen bootsen de humaan situatie tot zekere hoogte na en zijn geacepteerd om ischemie en langaanhoudende stress te bestuderen.

Hoofdstuk 1 is een algemene inleiding en geeft een beschrijving van de wetenschappelijke achtergrond voor stress in het algemeen en in het bijzonder voor stress bij twee specifieke indicaties, namelijk ischemie en chronische stress. Daarnaast wordt enige achtergrond informatie gegeven over de proteomics technologie.

In Hoofdstuk 2 hebben wij aangetoond dat de 2D-DIGE benadering in potentie een geschikte proteomics technologie is om de ontwikkeling van de hersenen te bestuderen.. Ten eerste, DIGE labelling is een sensitieve technologie met een groot dynamische bereik, wat de detektie van eiwitten in zowel lage als hoge hoeveelheden mogelijk maakt met een robuuste kwantificatie. Ten tweede, de hoge significantie niveaus die bereikt worden geven de betrouwbaarheid van deze kwantitatieve methode weer en de normalisatie capaciteit als het gebruikt wordt als een interne standaard. Ten derde, de eiwitten die wij hebben geïdentificeerd lieten expressie patronen zien die gelijk waren aan eerdere studies waarbij andere technieken gebruikt werden.

De overeenkomsten in effecten op eiwit expressie van zowel conventionele als ook kruidachtige antidepressiva in een hippocampale neuronale cellijn zijn beschreven in Hoofdstuk 3. De eiwit expressie profielen van hippocampale neuronale cellen werden onderzocht na behandeling met clomipramine, hypericum, Xiao Yao San of geen behandeling. Een vergelijking tussen de proteomics profielen van deze behandelingen toont aan dat ze alle drie gemeenschappelijke moleculaire doelen hebben en dat deze specifiek focussen op eiwitten die betrokken zijn bij het cytoskelet, energie metabolisme, signaal transductie, eiwit synthese en eiwit modificaties. Dit bevestigt eerder werk dat 
aangaf dat antidepressiva de neuronale plasticiteit verhoogden en geeft nieuwe inzichten in mogelijke werkingsmechnismen hierbij.

In Hoofdstuk 4 beschrijft de relatie tussen chronische glucocorticoïd receptor activatie en de transcriptie activiteit van cyclic AMP responsive element binding protein (CREB) in clonal neurons. Extreem hoge niveaus van glucocortoïden worden verondersteld geassocieerd te zijn met een cognitieve achteruitgang. Wij leveren bewijs dat chronische activatie van de glucocorticoïd receptor in clonal neuronen de transcriptionele activiteit van CREB, welke verondersteld wordt in geheugen processen een rol te spelen, remt. Om het onderliggend mechanisme te onderzoeken hebben wij de fosforylering van CREB in neuronen bestudeerd die chronisch behandeld werden met glucocorticoïden. Onze resultaten tonen aan dat chronische activatie van de glucocorticoïd receptor in clonale neuronen de CRE-gereguleerde gen expressie remt en dat wijst op een tot dusver niet veronderstelde cross-talk tussen de glucocorticoïd transductie route en CREB.

In Hoofdstuk 5 beschrijtt een Multi-Western blot PowerBlot ${ }^{\mathrm{TM}}$ technologie welke gebruikt werd om meer dan 400 eiwitten met brein extracten van muizen met kortdurende focale ischemie te onderzoeken. $\mathrm{Na}$ medial cerebral artery (MCA) occlusie waren $45 \%$ of meer eiwitten op- of af-gereguleerd in de betrokken hemisfeer met een factor 1.5 of meer in vergelijking met sham geopereerde controle dieren. In de gezonde controle hemisfeer was het aantal van gereguleerde eiwitten bijna $50 \%$ wat op een tot dusver niet-aangenomen betrokkenheid van de niet-aangedane hemisfeer wijst. Deze studie levert tevens bewijs voor de complexiteit van multi-beschadiging routes in het ontstaan van ischemische hersenschade. Maar dit kan ons wel helpen om de sleutelspelers bij ischemische schade aan te wijzen.

Hoofdstuk 6 beschrijft de bevindingen van de door statines versterkte geprogammeerde celdood in neuronen. Statines zijn lipide verlagende drugs die atherosklerotische cardiovasculaire morbiditeit en mortaliteit verminderen. De resultaten tonen aan dat statines de caspase-3 activiteit in neuronen laat toenemen en geeft aan dat statines de geprogammeerde celdood versterken, maar niet de apoptosische routes in clonal neuronen initieert. Dus, ongeacht de positieve effecten van statines om zowel vetten in het bloed te verlagen als endotheliaal NO te laten toenemen, zijn er aanwijzingen dat een statine behandeling van patiënten met een neurologische ziekte zorgvuldig overwogen moet worden.

In Hoofdstuk 7 worden de resultaten kritisch besproken in het kader van hun toepasbaarheid en de meest recente data wordt in de context van de huidige resultaten besproken.

\section{Eindconclusies}

Het gepresenteerde werk benadrukt het potentieel van een high throughput methode om differentieel tot expressie komende eiwitten te bepalen, geeft een aanwijzing welke eiwitten het meest belangrijk zijn, hoe het best te intervenieren is in hun functie en welke impact dit heeft op het brein. Dit verbetert ons inzicht is de processen van celdood bij ischemie en chronische stress. Door middel van een benadering met specifieke drugs kunnen nieuwe inzichten verkregen worden, zowel in ziekte als in gezondheid. Toekomstig onderzoek is nodig om te bepalen hoe dit het beste gedaan kan worden om voldoende het brein te kunnen beschermen. 


\section{Publications}

T. Trapp, G. Kögler, A. El-Khattouti, R.V. Sorg, M. Besselmann, M. Föcking, C.P. Bührle, I. Trompeter, J.C. Fischer, and P. Wernet

Hepatocyte growth factor/C-met-axis mediated tropism of cord blood derived unrestricted somatic stem cells for neuronal injury.

Journal of Biological Chemistry 283(47):32244-53 (2008).

K. Pennington, M. Föcking, C.A. McManus, C.M. Pariante, M.J. Dunn, and D.R. Cotter

A proteomic investigation of similarities between conventional and herbal antidepressant treatments

Journal of Psychopharmacology, $2008 \mathrm{Jul} 17$ [Epub ahead of print].

M. Föcking, M. Besselmann, and Thorsten Trapp

Proteomics of experimental stroke in mice.

Acta Neurobiologiae Experimentalis 66: 273-278 (2006).

M. Föcking, P.J. Boersema, N. O'Donoghue, G. Lubec, S.R. Pennington, D.R. Cotter, and M.J. Dunn

2-D DIGE as a quantitative tool for investigating the HUPO Brain Proteome Project mouse series. Proteomics 6(18): 4914-4931 (2006).

M. Föcking, D. Schmiegelt, and T. Trapp

Caffeine-mediated enhancement of glucocorticoid receptor activity in human osteoblastic cells.

Biochemical and Biophysical Research Communication 337(2): 435-439 (2005)

M. Föcking, M. Besselmann, and T. Trapp

Statins potentiate caspase- 3 activity in immortalized neurons.

Neuroscience letters 355: 41-44 (2004).

F. Erdö, C. Bührle, J. Blunk, M. Hoehn, Y. Xia, B. Fleischmann, M. Föcking, E. Küstermann, E. Kolossov, J. Hescheler, K.-A. Hossmann, and T. Trapp

Host-Dependent Tumorigenesis of Embryonic Stem Cell Transplantation in Experimental Stroke. Journal of Cerebral Blood Flow \& Metabolism 23: 780-785 (2003).

M. Föcking, I. Hölker and T. Trapp

Chronic glucocorticoid receptor activation impairs CREB transcriptional activity in clonal neurons. Biochemical and Biophysical Research Communication 304: 720-723 (2003).

M. Hoehn, E. Kuestermann, J. Blunk, D. Wiedermann, T. Trapp, S. Wecker, M. Föcking, H. Arnold, J. Hescheler, B.K. Fleischmann, W.Schwindt, and C. Bührle

Monitoring of implanted stem cell migration in vivo: A highly resolved in vivo magnetic resonance imaging investigation of experimental stroke in rats.

Proceedings of the National Academy of Sciences U S A 99(25):16267-72 (2002).

F. Döring, J. Walter, J. Will, M. Föcking, M. Boll, S. Amasheh, W. Clauss, and H. Daniel

Delta-aminolevulinic acid transport by intestinal and renal peptide transportersand its physiological and clinical implications.

Journal of Clinical Investigation 101(12): $2761-7$ (1998). 


\section{Publications in progress}

J.A. English, P. Dicker, M. Föcking, M.J. Dunn, and D.R.Cotter

Evidence for cytoskeletal abnormalities in white matter from subjects with schizophrenia and bipolar disorder.

PROTEOMGCS, in press

M. Föcking, L. Korhonen, D. Schmiegelt, D. Lindholm, and T. Trapp

Chronic glucocorticoid exposure of clonal hippocampal neurons potentiates necrosis but protects against apoptosis.

in preparation

M. Föcking, F. Erdö, S. Trapp, G. Kögler, C.P. Bührle, J. Blunk, P. Janus, P. Wester, H. Lübbert, P. Wernet, and T. Trapp

A role for $\mathrm{RhoB}$ in neuronal apoptosis.

in preparation

M. Föcking, Y. Xia, B. Fleischmann, and T. Trapp

Transient expression of GTPase RhoB in neural differentiation of murine embryonic stem cells.

in preparation

M. Föcking, L. Oláh, W. Schwindt, S. Wecker, M. Hoehn, and T. Trapp

Spatio-temporal relationship between the Apparent Diffusion Coefficient (ADC) and predictors of cellular damage after transient cerebral ischemia in rodents.

submitted

M. Föcking, M. Besselmann, and T. Trapp

Proteomics revealed caspase 3-mediated cleavage of PKC theta in experimental stroke and neuronal apoptosis.

in preparation

F. Köhler, M. Föcking, F. Holsboer, and T. Trapp

Ligand induced structural diversity of the human glucocorticoid receptor.

in preparation

\section{Book Chapter}

M. Föcking, K. Pennington, J. English, M.J. Dunn, and D.R. Cotter

Proteomics providing insights into major psychiatric disorders

in: Clinical Proteomics- From Diagnosis to Therapy,

Editors: J.E. Van Eyk and M.J. Dunn

Wiley-VCH, November 2007 


\section{Curriculum Vitae}

Melanie Föcking was born on June the $6^{\text {th }} 1969$ and grew up in Bocholt (North RhineWestphalia, Germany). After her graduation at the Mariengymnasium Bocholt; she started a professional training as a chef at the Restaurants Mövenpick, Düsseldorf, Germany which she finished in 1992 and continued to work there for a couple of month. At the same year she started her Nutritional Sciences studies at the Justus-Liebig-University in Gießen, Germany, where she did her Masters thesis entitled "Production of chimeric PepT1/2transporters and analysis of their function" at the Institute for Nutritional Sciences, Faculty for Biochemistry of Human Nutrition. After her graduation, she worked as a PhD student on the project partly described in this thesis at the Max-Planck-Institute for Neurological Research in Cologne, Germany. For her research project she had the opportunity to participate in a EURON (European Graduate School of Neuroscience) exchange program, with an awarded Marie Curie fellowship, to perform research at the Department of Psychiatry and Neuropsychology, Division Neuroscience, University of Maastricht, The Netherlands. Since spring 2004 she is a Research Fellow at the Royal College of Surgeons in Ireland, Department of Psychiatry, Dublin, Ireland.

Melanie Föcking werd geboren op 6 juni 1969 en groeide op in Bocholt, Duitsland. Na het behalen van haar eindexamen aan het Mariengymnasium in Bocholt; begon zij een opleiding als kokkin in de Restaurants Mövenpick, Düsseldorf, Duitsland dat zij afslot in 1992 om daarna nog enkele maanden er te werken. In hetzelfde jaar begon zij met de studie van Voedingswetenschappen aan de Justus-Liebig-Universiteit in Gießen, Duitsland, waar zij haar Masters thesis genoemde "Production of chimeric PepT1/2-transporters and analysis of their function" aan het Instituut voor Voedingswetenschappen, Faculteit voor Biochemie van Humaan Voeding deed. Naar het exam was zij werkzaam als assistent in opleiding (AIO) aan het Max-Planck-Instituut voor Neurologisch Onderzoek in Keulen, Duitsland. In deze periode werd een gedeelte van het onderzoek verricht dat beschreven staat in dit proefschrift. Met behulp van een toegekende Marie Curie beurs binnen EURON (European Graduate School of Neuroscience) kreeg zij de gelegenheid om voor haar onderzoeksprojekt op werkbezoek te gaan bij het onderzoeksinstituut Hersenen en Gedrag, divisie, Neurodegeneratie aan de Universiteit te Maastricht, Nederland. Sinds begin 2004 werkt ze als onderzoeker aan het Royal College of Surgeons in Ireland, Department of Psychiatry, in Dublin, Ierland. 


\section{Acknowledgements/Dankwoord}

Last but not least I would like to thank everybody who participated making this thesis possible and the work a success:

I would like to sincerely thank Dr. Thorsten Trapp and Professor David Cotter for leaving me the theme and their support and encouragement, their patience and constant willingness for discussion they accorded me during the preparation of this work.

I would like to thank Professor Hossmann and Cotter for the provision of a position and workspace at the Max-Planck Institute for Neurological Research.

I would also like to thank Professor Harry Steinbusch for taking over the position as promotor of my thesis at the University Maastricht.

I want to thank all my colleagues for the great teamwork and the creation of a working atmosphere that helped so much to make this work a success. In particular I would like to thank Irmgard Hölker, Diane Schmiegelt, Patrick Janus und André Janz, Sonja Althausen, Cordula Strecker, Änne Priblitzki, Mila Jagodnik, Markus Hartung, Mario Schelhaas and Christian Bührle, not to forget Günter Mies, Jane English, Lance Hudson, Rachel Howley, Magdalena Hryniewiecka, Aine Behan, Mary Clarke, Catriona O'Grady, Kyla Pennington, Ciara McManus, Kasper Pedersen, Caitriona Scaife; for the great atmosphere, great team play, technical help and constant helpfulness in the lab, the great social meeting on a private base; I would like to thank Bertram Huth and Ilka Mühlhöver for their fast photo work and their help with preparation of figures, Andreas Grasse und Peter Spiegelberg for finding solutions to one or the other computer problem and last but not least Ursula Beckmann for her constant encouragement. Furthermore I would like to say thank you to Hellen Steinbusch, Nicole Senden, Gunter Kenis, Jos Prickaerts, Anouk Roemen, Marjann Markerink, Wilma van Staveren and all the people in the b-sectie for a fabulous time in Maastricht.

Mein ganz besonderer Dank gilt meinen Eltern, die mir dies alles ermöglicht haben, deren Rückhalt ich immer hatte und habe und auf die ich mich immer verlassen kann.

Ein Dank ganz besonderer Art gilt Peter Knief, dessen Liebe, Verständnis und Geduld mir eine unentbehrliche Unterstützung waren sowie unseren beiden Kindern Jobst und Pauline. 